\title{
CONTROL LAW DESIGN AND VALIDATION FOR A HELICOPTER IN-FLIGHT SIMULATOR
}

\author{
A Thesis \\ presented to
}

The Faculty of California Polytechnic State University,

San Luis Obispo

\author{
In Partial Fulfillment \\ of the Requirements for the Degree \\ Master of Science in Aerospace Engineering
}

By:

Brian T. Fujizawa

February 2010 
(C) 2010

Brian T. Fujizawa

All Rights Reserved 


\section{Committee Membership}

Title:

Author:

Date Submitted:

Committee Chair:

Committee Member:

\author{
Dr. Eric A. Mehiel \\ Assistant Professor \\ Aerospace Engineering \\ California Polytechnic State University, San Luis Obispo
}

Committee Member: Dr. Jordi Puig-Suari

Professor

Aerospace Engineering

California Polytechnic State University, San Luis Obispo

Committee Member: 


\title{
Abstract
}

\author{
Control Law Design and Validation for a Helicopter In-Flight Simulator \\ Brian T. Fujizawa
}

In-flight simulation allows one aircraft to simulate the dynamic response of another aircraft. A control system designed to give RASCAL, a JUH-60A Black Hawk helicopter based at Moffett Field, CA, in-flight simulation capabilities has been designed, optimized and validated in this research. A classical explicit model following control system with a frequency dependent feedback controller was used. The frequency dependent controller allows model following of the attitude in the short term and the velocity in the long term. Controller gains were optimized using a high order, linearized model of UH-60 dynamics. Non-linear simulations of the control laws were performed, first on a desktop computer based simulation, then in the RASCAL development facility, a hardware-in-the-loop simulator. Comparing quantitative results of the non-linear simulations with the results of the optimization using the linearized model ensured that the control system designed with the linearized model was valid in non-linear environments. Finally, a piloted evaluation in the hardware-in-the-loop simulator was performed to obtain qualitative information on the behavior of the control laws. 


\section{Acknowledgments}

First I would like to offer my sincere gratitude to Dr. Mark Tischler for your guidance, support, and encouragement throughout this project. Many thanks also to Christy Ivler for your insight and all the invaluable assistance you provided. Without the two of you, this project would not have been possible.

Thank you to Ernesto Moralez for the countless hours you spent assisting me with the DF. Thank you to Hossein Mansur for all your help, especially with GenHel. Thank you also to LTC Steve Braddom for your assistance in flying the control laws in the DF and for providing valuable feedback.

Thank you to Dr. Jeff Lusardi, Chris Blanken, Kenny Cheung, Keith Rothman, Tom Berger, Eric Tobias, Luigi Cicolani, Dexter Hermstad, Weiliang Dai, and Rey Passion of the AFDD Flight controls group. Thank you to Jay Fletcher, Tom Kaisersatt, and Kevin Kalinowski of the RASCAL group for all your help with RASCAL and in the DF. Thank you also to Terry Turpin and Munroe Dearing for you assistance flying the control system.

Many thanks to Dr. Dan Biezad for being my thesis adviser and thank you Dr. Eric Mehiel for stepping in to fill that role after Dr. Biezad's retirement. Also, thank you to Dr. Jordi Puig-Suari for being on my defense committee.

Finally, I would like to thank my family. Without your support these past 24 years I would not be where I am today. 


\section{Contents}

$\begin{array}{ll}\text { List of Figures } & \text { ix }\end{array}$

List of Tables $\quad$ xi

Nomenclature $\quad$ xii

1 Introduction $\quad 1$

1.1 In-Flight Simulation . . . . . . . . . . . . . . . . . . . 1

1.2 History of In-Flight Simulation . . . . . . . . . . . . . . . . . 2

1.3 Helicopter In-Flight Simulators . . . . . . . . . . . . . . . . . 2

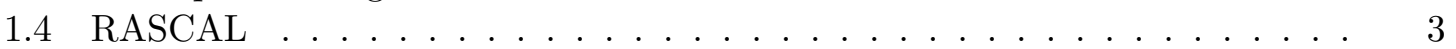

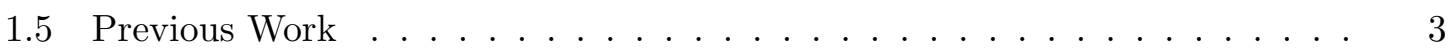

1.6 Purpose and Organization of Thesis . . . . . . . . . . . . 4

2 Software Tools 5

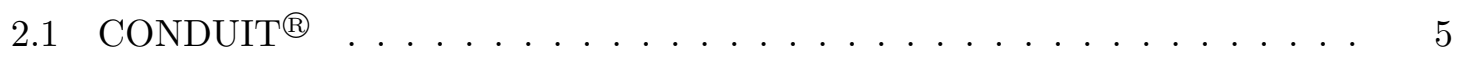

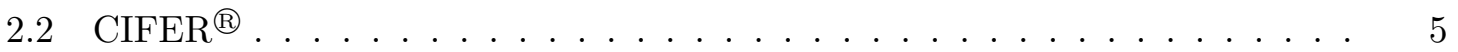

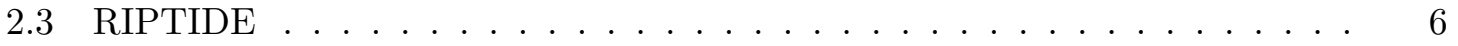

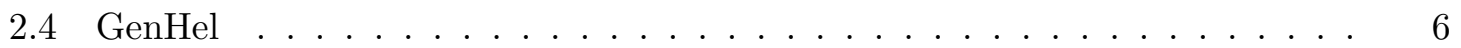

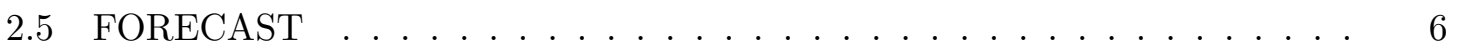

3 Control Law Design $\quad 7$

3.1 Explicit Model Following Control System . . . . . . . . . . . . . . . 8

3.1 .1 Command Model . . . . . . . . . . . . . . . . . 8

3.1 .2 Host Aircraft . . . . . . . . . . . . . . . . . . . . . 10

3.1.3 Inverse Plant Model . . . . . . . . . . . . . . . . . . . . . . . . 10

3.1.4 Equivalent Time Delay . . . . . . . . . . . . . . . . . . . . 13

3.1.5 Feedback Controller . . . . . . . . . . . . . . . . . . . 13

3.2 Additional Design Considerations . . . . . . . . . . . . . . . . 16

3.2 .1 Integral Gains . . . . . . . . . . . . . . . . . . . 16

3.2 .2 Actuator Activity . . . . . . . . . . . . . . . . . . 17

3.2.3 Longitudinal Model Following . . . . . . . . . . . . . . . . 17

3.2 .4 Feedback to Inverse . . . . . . . . . . . . . . . . . . . 18 
4 Control Law Optimization $\quad 20$

4.1 Optimization via CONDUIT ${ }^{\circledR} \ldots \ldots \ldots \ldots \ldots \ldots \ldots \ldots$

4.2 Specifications . . . . . . . . . . . . . . . . . 21

$4.2 .1 \quad$ Hard Constraints . . . . . . . . . . . . . . . . . . . . 21

4.2 .2 Soft Constraints . . . . . . . . . . . . . . . . . . 22

4.2 .3 Summed Objectives . . . . . . . . . . . . . . . 24

4.3 Optimization Strategy . . . . . . . . . . . . . . . . . . 24

4.4 Design Margin Optimization . . . . . . . . . . . . . . 26

4.5 Optimized Solution . . . . . . . . . . . . . . . . . 28

5 Linear Analysis $\quad 32$

5.1 Frequency Domain . . . . . . . . . . . . . . . . . . . 32

5.2 Time Domain . . . . . . . . . . . . . . . . . . . . 38

5.3 Predicted Limits of Performance . . . . . . . . . . . . . . . . . . 45

5.3.1 Limitation of Hover Gains . . . . . . . . . . . . . . . . . . . 45

5.3.2 Dynamic Response Limitation . . . . . . . . . . . . . . . 45

6 Desktop Simulation and Validation 48

6.1 Control System Modifications . . . . . . . . . . . . . . . . . . 48

6.1.1 Math Model Inputs . . . . . . . . . . . . . . . . . . . . . 48

6.1 .2 Trim Angles and Initial Heading . . . . . . . . . . . . . . . . . . 48

6.1.3 RIPTIDE/GenHel Interface . . . . . . . . . . . . . . . . . . 49

6.1 .4 Frequency Sweeps . . . . . . . . . . . . . . . . . . . . . . 49

6.1 .5 Inverse Plant Model . . . . . . . . . . . . . . . . . . 50

6.2 Simulation Results . . . . . . . . . . . . . . . . . . 52

6.2 .1 Frequency Domain . . . . . . . . . . . . . . . . 52

6.2 .2 Time Domain Analysis . . . . . . . . . . . . . 56

7 Hardware-in-the-Loop Simulation $\quad 62$

7.1 RASCAL Development Facility . . . . . . . . . . . . . . . . . . . 62

7.2 Control System Modifications . . . . . . . . . . . . . . . . . 62

7.2 .1 Discrete Time . . . . . . . . . . . . . . . . . . . . . . 62

7.2 .2 GenHel Interface . . . . . . . . . . . . . . . . . . . . 63

7.2 .3 Frequency Sweeps . . . . . . . . . . . . . . . . . . . . 64

7.2 .4 Control Stick Deadbands . . . . . . . . . . . . . . . 65

7.2.5 Trim, Initial Heading, and Servo Commands at System Engage . . . 65

7.2 .6 Inverse Plant Model . . . . . . . . . . . . . . . . 65

7.3 Simulation Results . . . . . . . . . . . . . . . . . . 65

7.3.1 Frequency Domain Results . . . . . . . . . . . . . . 65

7.3 .2 Piloted Evaluation . . . . . . . . . . . . . . . . 71

$\begin{array}{lll}8 & \text { Conclusions } & \mathbf{7 7}\end{array}$

8.1 Summary of Findings f . . . . . . . . . . . . . . . . 77

8.2 Future Work . . . . . . . . . . . . . . . . . . 78

$\begin{array}{lr}\text { Bibliography } & 80\end{array}$ 
A ADS-33 Mission Task Elements

B Optimized Controller Gains 


\section{List of Figures}

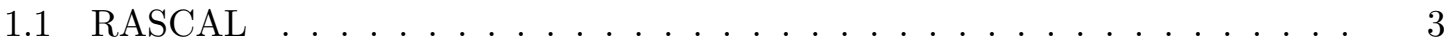

3.1 Explicit model following control system . . . . . . . . . . . . . . 7

3.2 Lateral axis canonical transfer function command model . . . . . . . . . . . 9

3.3 First and second order fit of roll rate . . . . . . . . . . . . . . . . . 12

3.4 Equivalent time delay . . . . . . . . . . . . . . . . . . . . . . . . 13

3.5 Lateral axis frequency dependent feedback controller . . . . . . . . . . . 15

3.6 Effect of frequency dependent controller on model following . . . . . . . . 16

3.7 Butterworth filter on u-axis feedback . . . . . . . . . . . . . . . 18

3.8 In-flight simulation control laws . . . . . . . . . . . . . . . . . . . . . . . 19

4.1 Stability margin specification . . . . . . . . . . . . . . . . 21

4.2 Model following specification with $50 \%$ design margin $\ldots \ldots \ldots$. . . . 26

4.3 Design margin optimization trade-off plots . . . . . . . . . . . . . 27

4.4 CONDUIT ${ }^{\circledR}$ HQ Window 1 of $3 \ldots \ldots \ldots \ldots . \ldots \ldots$

4.5 CONDUIT $^{\circledR}$ HQ Window 2 of $3 \ldots \ldots \ldots \ldots \ldots$

4.6 CONDUIT $^{\circledR}$ HQ Window 3 of $3 \ldots \ldots \ldots \ldots \ldots$. . . . . . . . . 31

5.1 Disturbance loop . . . . . . . . . . . . . . . . . . . . . . . . 33

$5.2 v$ disturbance response magnitude $\ldots \ldots \ldots \ldots \ldots \ldots$

$5.3 p$ model following error $\ldots \ldots \ldots \ldots \ldots \ldots \ldots$

$5.4 v$ model following error . . . . . . . . . . . . . . . . . . 36

$5.5 q$ model following error . . . . . . . . . . . . . . . . . 36

$5.6 u$ model following error f . . . . . . . . . . . . . . . . . 37

$5.7 w$ model following error $\ldots \ldots \ldots \ldots \ldots \ldots$

$5.8 r$ model following error $\ldots \ldots \ldots \ldots \ldots \ldots$

5.9 Doublet input . . . . . . . . . . . . . . . . . . . . . 39

5.10 Lateral axis doublet response . . . . . . . . . . . . . . . . . . . 41

5.11 Longitudinal axis doublet response . . . . . . . . . . . . . . . . 42

5.12 Collective axis doublet response . . . . . . . . . . . . . . . . 43

5.13 Pedal axis doublet response . . . . . . . . . . . . . . . . . 44

5.14 Model following cost for different airspeeds . . . . . . . . . . . . . . . 45

5.15 Pulse input . . . . . . . . . . . . . . . . . 46

5.16 Actuator rate vs. command model natural frequency for limiting case . . . 47 
6.1 Roll rate bare airframe response from FORECAST (linear) and GenHel (non-

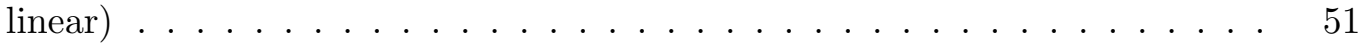

6.2 Roll rate response with FORECAST (linear) and GenHel (non-linear) inverses 51

$6.3 p$ model following error . . . . . . . . . . . . . . . . . . 54

$6.4 v$ model following error . . . . . . . . . . . . . . . . . 54

$6.5 q$ model following error . . . . . . . . . . . . . . . . . . . 55

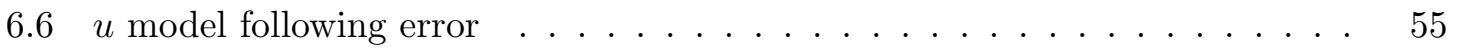

$6.7 w$ model following error $\ldots \ldots \ldots \ldots \ldots$

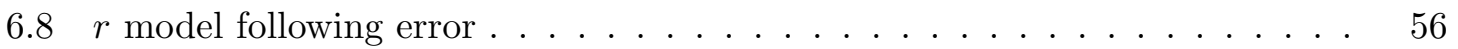

6.9 Lateral axis doublet response . . . . . . . . . . . . . . . . . . . . . . . . . . . . . . . . . . . . . 58

6.10 Longitudinal axis doublet response . . . . . . . . . . . . . . . 59

6.11 Collective axis doublet response . . . . . . . . . . . . . . . 60

6.12 Pedal axis doublet response . . . . . . . . . . . . . . . . 61

7.1 Frequency sweep input architecture . . . . . . . . . . . . . . . . . 64

$7.2 p$ inverse plant transfer function fit . . . . . . . . . . . . 66

$7.3 p$ model following error . . . . . . . . . . . . . . . . . . 68

$7.4 v$ model following error . . . . . . . . . . . . . . . . . . . . . 69

$7.5 q$ model following error . . . . . . . . . . . . . . . . . . . . 69

$7.6 u$ model following error . . . . . . . . . . . . . . . . 70

$7.7 w$ model following error $\ldots \ldots \ldots \ldots \ldots$

$7.8 r$ model following error $\ldots \ldots \ldots \ldots \ldots \ldots \ldots \ldots$

7.9 Hover MTE data . . . . . . . . . . . . . . . . . . . . . 74

7.10 Hovering turn MTE data . . . . . . . . . . . . . . . 75

7.11 Lateral reposition MTE data . . . . . . . . . . . . . . . 76 


\section{List of Tables}

3.1 Control axes and associated model following state . . . . . . . . . . 8

3.2 Linearized aircraft dynamic model states . . . . . . . . . . . . . . . . . . 10

5.1 Model following costs . . . . . . . . . . . . . . . . . . . . . 32

5.2 Broken loop stability margins and crossover frequencies . . . . . . . . . 33

5.3 Disturbance rejection bandwidth . . . . . . . . . . . . . . . . 34

5.4 Time domain model following costs . . . . . . . . . . . . . . . . . . . . . . . . . . . . .

5.5 Roll and pitch natural frequencies of selected aircraft . . . . . . . . . . 47

6.1 Sweep Parameters . . . . . . . . . . . . . . . . . . . 50

6.2 Sweep scaling gains . . . . . . . . . . . . . . . . . . . 50

6.3 Model following costs . . . . . . . . . . . . . . . . . . 52

6.4 Broken loop stability margins and crossover frequencies . . . . . . . . 53

6.5 Disturbance rejection bandwidth . . . . . . . . . . . . 53

6.6 Time domain model following costs . . . . . . . . . . . . . . . 57

7.1 Control Law and Math Model Units . . . . . . . . . . . . . . . . . . 64

7.2 Model following costs . . . . . . . . . . . . . . . . . . . . 66

7.3 Broken loop stability margins and crossover frequencies . . . . . . . . . 67

7.4 Disturbance rejection bandwidth . . . . . . . . . . . . . 67

7.5 DF piloted simulation RMS costs . . . . . . . . . . . . . 73

B.1 Optimized Controller Gains . . . . . . . . . . . . . . . . . . . 90 


\section{Nomenclature}

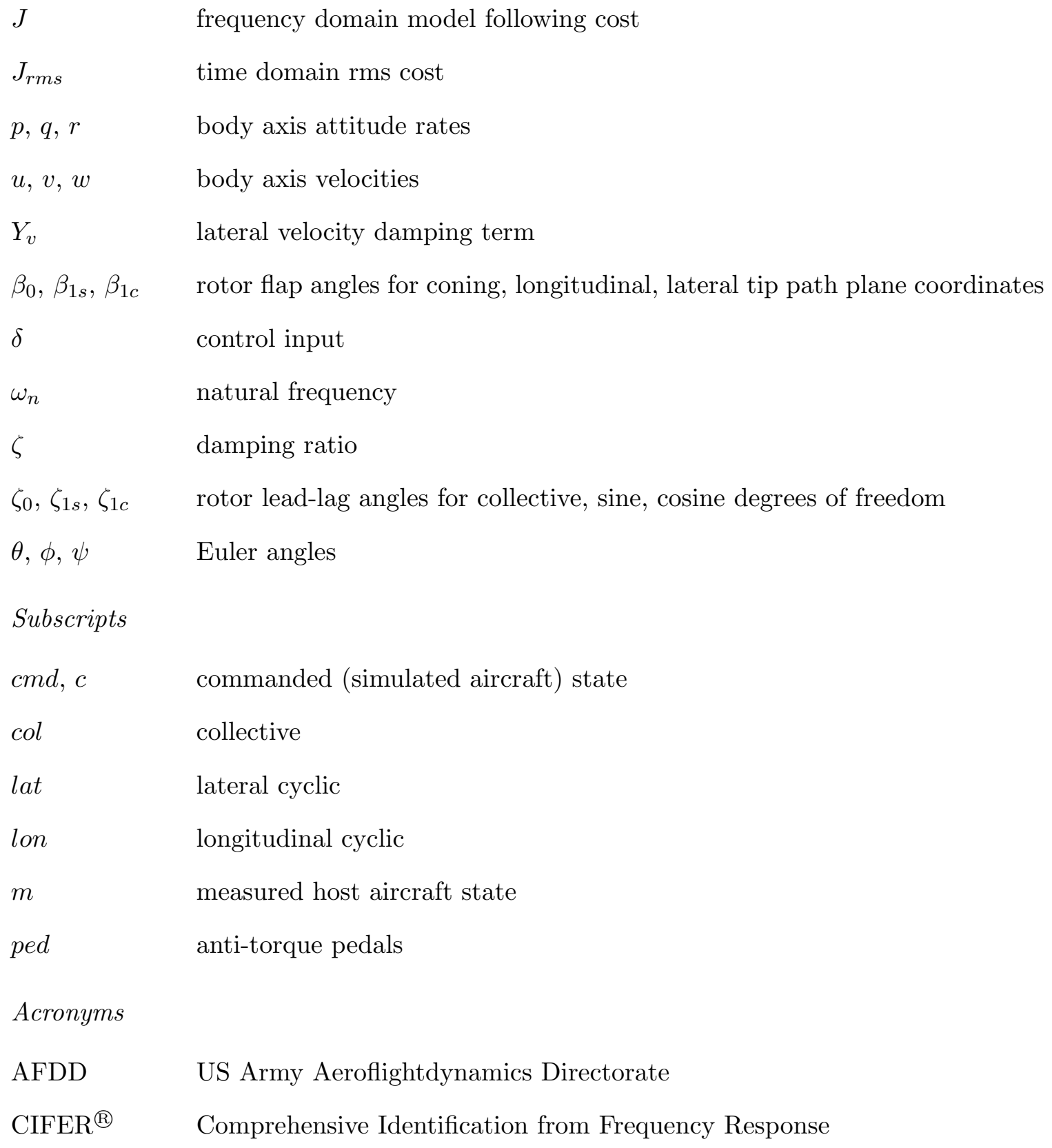


CONDUIT ${ }^{\circledR} \quad$ Control Designer's Unified Interface

DF RASCAL development facility

DLR Deutsches Zentrum für Luft- und Raumfahrt (German Aerospace Center)

FORECAST Full Order Rotorcraft Code and Simulation Tool

GenHel General Helicopter Flight Dynamics Simulation

NRC National Research Council of Canada

RASCAL Rotorcraft Aircrew Systems Concepts Airborne Laboratory

RIPTIDE Real-time Interactive Prototype Technology Integration/Development Facility 


\section{Chapter 1}

\section{Introduction}

\section{$1.1 \quad$ In-Flight Simulation}

An in-flight simulator is an aircraft and flight control system which have been modified to reproduce the dynamic response of an aircraft one wishes to simulate. In-flight simulators provide the ability to test aircraft under development early in the design process to ensure the handling qualities are acceptable as the S-76 SHADOW did for the RAH-66 Comanche program [1]. They can be used to test flight control system improvements as the UH-60 RASCAL helicopter did for the UH-60M upgrade program [2]. They also allow simulation of uncommon flight conditions which might otherwise be difficult to simulate such as landing the space shuttle [3]. Additionally, in-flight simulators can be used for handling qualities research, as a Bell 205 was used to develop the ADS-33 shipboard landing requirements [4].

Currently, ground based simulators are used to perform much of this research, however, they have some shortcomings. First, the visual cues in a ground based simulator are synthetic while those of an in-flight simulator are real. Also, the motion cues of an in flight simulator are real, though limited by the dynamic response and operating limitations of the host aircraft. The motion cues of ground based simulators are limited by the actuators and washout due to the finite range of motion. While ground based simulators are safe and reliable, the added realism of in-flight simulation can be of great benefit to flight control research and handling qualities research. 


\subsection{History of In-Flight Simulation}

In-flight simulation is a subset of variable stability research. Variable stability aircraft allow the handling qualities of the aircraft to be changed in flight. In-flight simulation takes this further by requiring that the modified handling qualities track those of another aircraft. Fixed-wing variable stability research began after World War II and was used extensively to improve the handling qualities of aircraft. Extensive fixed-wing in-flight simulation research has been performed at Cornell Aeronautical Laboratory (later Calspan, Veridian, and General Dynamics) [5] and at NASA Dryden Flight Research Center [6].

Helicopter variable stability and in-flight simulation research has historically lagged behind fixed-wing research. One of the first variable stability helicopters was a modified Bell 47 developed by the National Research Council of Canada (NRC) in the 1960s [7]. The first variable stability helicopter in the US, a modified US Navy CH-46A which had variable stability in the pitch and roll axes, was not developed until 1972 [8].

\subsection{Helicopter In-Flight Simulators}

The first generation of helicopter in-flight simulators were developed in Canada, Germany, and the US. By 1971, the NRC used a modified Bell 205 as a dedicated in-flight simulator [7]. The German Aerospace Center (DLR) began modifying a Bo-105 in 1982 and had it flying as an in-flight simulator by the mid-1980s [9]. In the US, a joint NASA/US Army group developed an in-flight simulator on a modified CH-47B in the 1980s [10]. All of these first generation in-flight simulator suffered from limitations: the Bell 205 had a teetering rotor, the Bo-105 was restricted to operate above $50 \mathrm{ft}$ in hover and $100 \mathrm{ft}$ in forward flight, and the $\mathrm{CH}-47 \mathrm{~B}$ had high inertia meaning it could not easily simulate smaller and more agile aircraft [11].

Beginning in the late 1980s, work began on the second generation in-flight simulators. The NRC developed the Advanced Systems Research Aircraft, a modified Bell 412; the DLR developed the Active Control Technology/Flying Helicopter Simulator, a modified 
EC135; and Japan's National Aerospace Laboratory (now part of Japan Aerospace Exploration Agency) developed the MuPAL- $\epsilon$, a modified Mitsubishi MH2000A. The US does not currently have in-flight simulation capabilities.

\subsection{RASCAL}

The Rotorcraft Aircrew Systems Concepts Airborne Laboratory (RASCAL), shown in Figure 1.1, is a highly modified, variable stability JUH-60A Black Hawk helicopter based at Ames Research Center, Moffett Field. Some of the modifications include a programmable, full-authority, fly-by-wire control system for the evaluation pilot, research and precision navigation instrumentation, and a system operator/researcher station. Currently, RASCAL is used to research new cockpit hardware and to investigate rotorcraft handling qualities [11].

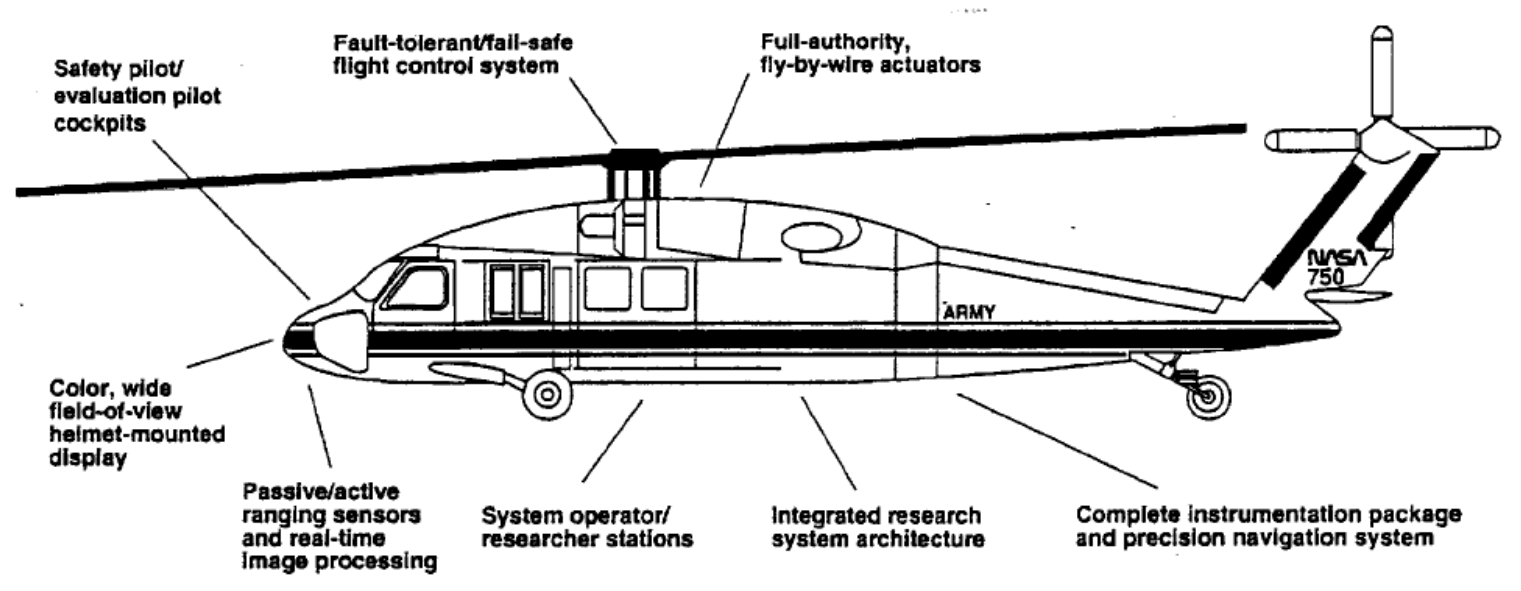

Figure 1.1: RASCAL

\subsection{Previous Work}

Previous work [12] performed preliminary design for in-flight simulation control laws for use on RASCAL, selecting the explicit model following control system architecture. In this preliminary design work, two different inverse plant models were compared and a frequency 
dependent feedback controller was developed. Additionally, piloted simulations were performed with a linear aircraft model.

\subsection{Purpose and Organization of Thesis}

The purpose of this thesis was to build on the previous work to design and validate control laws which provide RASCAL with in-flight simulation capabilities. This consisted of first selecting the control law architecture, developing a feedback controller, and developing a high-fidelity linear analysis model of RASCAL including the bare airframe dynamics, mixer matrices and actuator models, computational delays, and sensor and filter models. The control system was optimized using requirements from several performance standards and custom specifications. The optimized system was then tested, first in a non-linear simulation environment, then in a hardware-in-the-loop simulator. Frequency response identification using frequency sweep data from both simulations was used to ensure that the system designed around a linear model would work in non-linear environments. Finally, pilots flew the control laws in the hardware-in-the-loop simulator for a qualitative evaluation of the control laws.

This thesis is arranged in several chapters. Chapter 2 gives a brief discussion of the software tools used throughout the research. Chapter 3 details the structure of the control system and Chapter 4 discusses the optimization process including the specifications used to constrain the problem. Chapter 5 presents the quantitative metrics used for validation and presents predicted limits of performance for a RASCAL based in-flight simulator. Chapter 6 describes the preliminary desktop computer non-linear simulation while Chapter 7 describes the hardware-in-the-loop simulation. Finally, Chapter 8 presents conclusions and suggestions for future research. 


\section{Chapter 2}

\section{Software Tools}

This chapter gives a brief overview of the unique software tools used throughout this research. These tools were needed for control law optimization, real-time simulation, frequency response identification, and validation.

\subsection{CONDUIT $^{\circledR}$}

The Control Designer's Unified Interface (CONDUIT $\left.{ }^{\circledR}\right)$, developed by the US Army Aeroflightdynamics Directorate (AFDD), is a tool that allows rapid design, analysis and optimization of control laws for fixed or rotary-wing aircraft [13]. CONDUIT ${ }^{\circledR}$ uses specifications based on ADS-33 [14], MIL-STD-1797 [15], and MIL-DTL-9490 [16] or custom specifications to define the desired performance of the system. CONDUIT ${ }^{\circledR}$ tunes the design parameters within the system in order to meet all the specifications with minimum over-design, e.g. over-driving the actuators.

\subsection{CIFER $^{\circledR}$}

Comprehensive Identification from Frequency Response $\left(\right.$ CIFER $\left.^{\circledR}\right)$ developed by AFDD is an integrated facility for frequency response based system identification [17]. CIFER ${ }^{\circledR}$ consists of six core modules, three of which were used for this research: FRESPID, COMPOSITE, and NAVFIT. FRESPID was used to identify frequency responses from time 
history data and COMPOSITE was used to improve the identified frequency responses. NAVFIT was used to identify a low order transfer functions fit of frequency responses.

\section{$2.3 \quad$ RIPTIDE}

Real-time Interactive Prototype Technology Integration/Development Environment (RIPTIDE) is a workstation-based simulation environment that allows real-time, visual, fullflight-envelope, pilot-in-the-loop simulation [18]. RIPTIDE allows Simulink ${ }^{\circledR}$ block diagrams to be quickly converted into executable code and implemented in the simulation environment. Additionally, RIPTIDE can interface with non-linear helicopter math models such as GenHel.

\subsection{GenHel}

The General Helicopter Flight Dynamics Simulation (GenHel) is a total force, non-linear, large angle, single main-rotor, helicopter model developed by Sikorsky that is applicable over the entire flight envelope [19]. Included in the model are the six rigid body degrees of freedom, main-rotor rigid-blade flapping and lagging, non-linear lag damping, and hub rotational degrees of freedom.

\subsection{FORECAST}

Full Order Rotorcraft Evaluation Code and Simulation Tool (FORECAST) is used to generate a high-order, linear, time invariant mathematical model of a UH-60 helicopter [20]. The mathematical model used in FORECAST is based on that developed for GenHel and the equations of motion are formulated as a set of non-linear first order ordinary differential equations. Using finite difference approximations, the equations of motion can be linearized and a high order model can be extracted. 


\section{Chapter 3}

\section{Control Law Design}

This research uses the classical explicit model following control law architecture shown in Figure 3.1 which has previously been used on the NASA/US Army CH-47B in-flight simulator [10] and on several of Germany's in-flight simulators [9, 21, 22]. This architecture consists of the command model, the inverse plant, the host aircraft, the feedback controller and equivalent time delay.

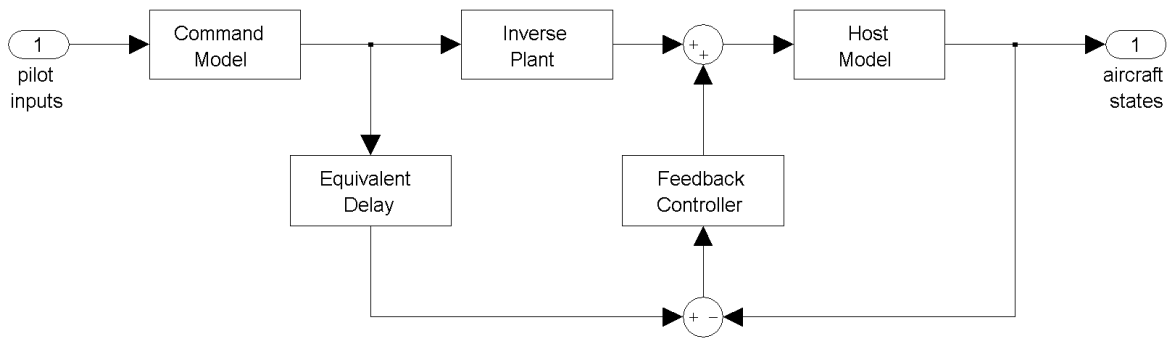

Figure 3.1: Explicit model following control system

In model following control, each control axis is associated with a state to be followed, e.g. the lateral cyclic is used to follow the roll rate of the simulated aircraft. All the states related to a control axis may be kinematically related such that perfect following of one state will result in perfect following of the other, or they may be dynamically related, in which perfect following of one does not guarantee perfect following of the other. An example of kinematically related states are roll rate and roll attitude which are related by $p=\dot{\phi}$ for small angles. An example of dynamically related states are roll attitude and lateral velocity 
since the dynamics that relate $\phi$ and $v$ are approximated by:

$$
\dot{v} \cong Y_{v} v+g \phi
$$

where $Y_{v}$ is the lateral velocity damping term. Therefore, $\phi$ and $v$ can be followed simultaneously only if $Y_{v}$ is the same for the command model and the host aircraft. However, it is possible to follow dynamically related states over different frequency ranges using a frequency dependent feedback controller (see Section 3.1.5). Table 3.1 shows the model following states and frequency range of interest for each control axis.

Table 3.1: Control axes and associated model following state

\begin{tabular}{ccc}
\hline Control Axis & State & Freq. Range of Interest \\
\hline \multirow{2}{*}{ Lateral cyclic } & $p$ & $1-10 \mathrm{rad} / \mathrm{s}$ \\
& $v$ & $0.1-1 \mathrm{rad} / \mathrm{s}$ \\
Longitudinal cyclic & $q$ & $1-10 \mathrm{rad} / \mathrm{s}$ \\
Collective & $u$ & $0.1-1 \mathrm{rad} / \mathrm{s}$ \\
Pedals & $w$ & $0.1-2 \mathrm{rad} / \mathrm{s}$ \\
\hline
\end{tabular}

The following sections discuss the elements of the classical explicit model following control system as well as other features included in the control system. The final Simulink ${ }^{\circledR}$ block diagram is shown in Figure 3.8 at the end of this chapter.

\subsection{Explicit Model Following Control System}

\subsubsection{Command Model}

The command model is a mathematical representation of the simulated aircraft dynamics. This model can be in either state-space or transfer function form and can represent the bare airframe dynamics or the end-to-end response of an aircraft and its control system.

This research focuses on a simple, decoupled, transfer function model which is known to have good handling qualities. The transfer functions representing the attitude responses for the lateral and longitudinal axes are second order while those for the vertical and direc- 
tional axes are first order. The transfer functions are implemented in Simulink ${ }^{\circledR}$ in canonical form which provides the rate and acceleration signals without the need for a differentiator. Figure 3.2 shows the block diagram of the lateral axis command model which models the dynamics of Equations 3.2-3.5:

$$
\begin{gathered}
\frac{\phi}{\delta_{l a t}}=\frac{\omega_{n}^{2}}{s^{2}+2 \zeta \omega_{n} s+\omega_{n}^{2}} \\
p \approx \dot{\phi} \\
\frac{v}{\phi} \approx \frac{\dot{v}}{p} \approx \frac{g}{s-Y_{v}} \\
\dot{p} \approx L_{\beta_{1 s}} \beta_{1 s}
\end{gathered}
$$

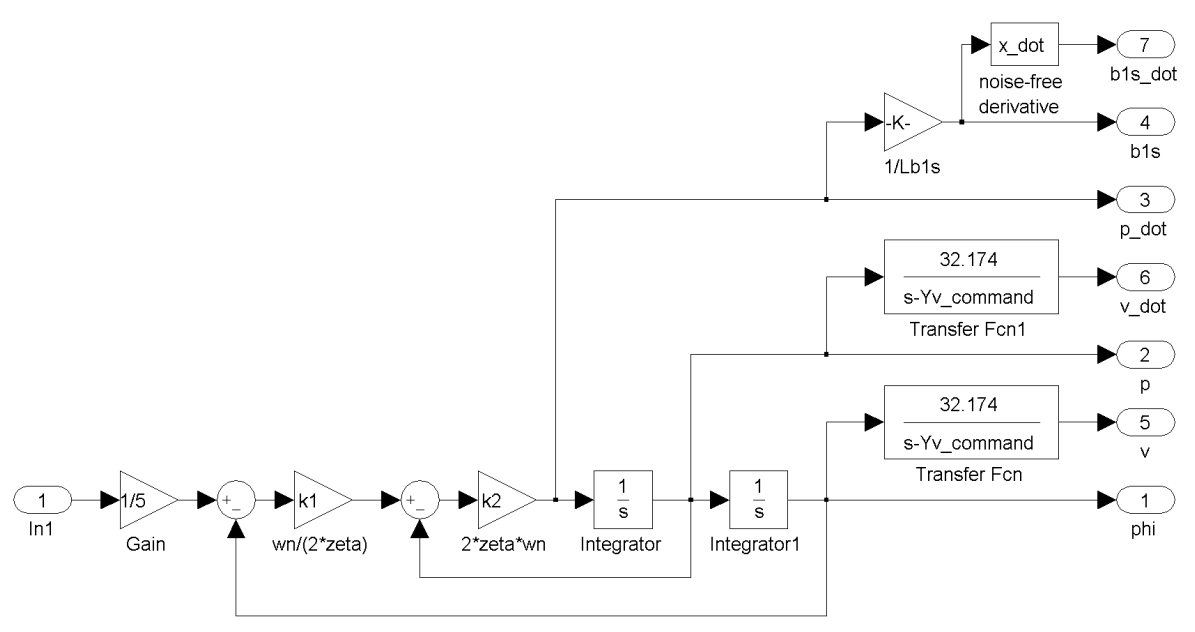

Figure 3.2: Lateral axis canonical transfer function command model

Equation 3.2 represents the second order attitude dynamics of the simulated roll response to a lateral cyclic input used in the command model. Equation 3.3 is the small angle approximation. Equation 3.4 approximates the body-axis velocity and acceleration. Equation 3.5 is used to approximate the rotor flapping angle from a known roll acceleration and a differentiator is needed to obtain the rotor flapping angular rate. The rotor flap states 
are included as a replacement for $\ddot{p}$ for use in the inverse (Section 3.1.3) because rotor states can be measured while $\ddot{p}$ is rarely measured.

\subsubsection{Host Aircraft}

The host aircraft is the aircraft that the pilot will actually be flying which, for this research, is RASCAL (a UH-60). During design and optimization, the host aircraft was represented by a high-order, linearized, mathematical model.

The aircraft dynamics in this research for optimization and linear analysis are modeled by a 39-state, physics based, fully coupled, state-space FORECAST model linearized about the hover condition, the states of which are shown in Table 3.2. In addition to the aircraft dynamics, the host model includes the actuator dynamics of two sets of actuators, the sensor and filter dynamics, and the computational delays.

Table 3.2: Linearized aircraft dynamic model states

\begin{tabular}{ll}
\hline Body states & $u, v, w, p, q, r, \phi, \theta, \psi$ \\
Rotor flap states & $\dot{\beta}_{0}, \dot{\beta}_{1 s}, \dot{\beta}_{1 c}, \beta_{0}, \beta_{1 s}, \beta_{1 c}$ \\
Rotor lag states & $\dot{\zeta}_{0}, \dot{\zeta}_{1 s}, \dot{\zeta}_{1 c}, \zeta_{0}, \zeta_{1 s}, \zeta_{1 c}$ \\
Rotor torsion states & $\phi_{d y n}, \dot{\phi}_{d y n}$ \\
Aerodynamic inflow states & $\lambda, \lambda_{1 s}, \lambda_{1 c}, \lambda_{t}, \nu_{x}, \nu_{y}$ \\
Engine states & $\Psi, \Omega, N_{G}, W_{f}$ \\
Aerodynamic phase lag states & \\
\hline
\end{tabular}

${ }^{a}$ there are six aerodynamic phase lag states

For the simulation portions of this research, the host is modeled by the non-linear GenHel model. The same actuator, sensor, and filter models used for the optimization are used for the desktop simulation. For the hardware-in-the-loop simulation, the actuators and sensor/filter dynamics are modeled by the flight control computer.

\subsubsection{Inverse Plant Model}

The inverse plant model is included to "cancel" the host aircraft dynamics by predicting the appropriate commands to force the host aircraft to respond with the simulated aircraft 
dynamics. A diagonalized inverse, which uses a decoupling matrix to diagonalize the plant, was used in this research.

To determine the decoupling matrix, the aircraft dynamics model was first reduced to a six degree-of-freedom model. The appropriate rows of the B-matrix, those corresponding to $w, p, q$, and $r$ are collected into a $4 \times 4$ matrix. The decoupling matrix is the matrix that removes the off-axis terms from this reduced B-matrix as shown in Equation 3.6. This equation can easily be solved for the decoupling matrix using matrix algebra. This decoupling matrix is placed directly before the host aircraft so as to remove control coupling due to the B-matrix.

$$
\left[\begin{array}{cccc}
Z_{\delta_{l a t}} & Z_{\delta_{l o n}} & Z_{\delta_{c o l}} & Z_{\delta_{p e d}} \\
L_{\delta_{l a t}} & L_{\delta_{l o n}} & L_{\delta_{c o l}} & L_{\delta_{p e d}} \\
M_{\delta_{l a t}} & M_{\delta_{l o n}} & M_{\delta_{c o l}} & M_{\delta_{p e d}} \\
N_{\delta_{l a t}} & N_{\delta_{l o n}} & N_{\delta_{c o l}} & N_{\delta_{p e d}}
\end{array}\right]\left[\begin{array}{c}
\text { Decoupling } \\
\text { Matrix }
\end{array}\right]=\left[\begin{array}{cccc}
0 & 0 & Z_{\delta_{c o l}} & 0 \\
L_{\delta_{l a t}} & 0 & 0 & 0 \\
0 & M_{\delta_{l o n}} & 0 & 0 \\
0 & 0 & 0 & N_{\delta_{p e d}}
\end{array}\right]
$$

For a diagonalized inverse, only the on-axis bare airframe responses of the diagonalized host model (decoupler + host) are needed and each axis has a separate inverse transfer function. The NAVFIT program in CIFER ${ }^{\circledR}$ is used to fit low order transfer functions to these diagonalized bare airframe responses. First order transfer function fits are easy to implement and are sufficient for the vertical and directional axes. However, first order fits for pitch and roll are only accurate at low frequencies as the pitch and roll response are effectively second order. This is illustrated in Figure 3.3 which compares first and second order fits with the lateral axis bare airframe. Also notice in Figure 3.3 that even the second order fit is only good between 1-10 rad/s which indicates that only these mid-frequency dynamics will be accurately inverted. 

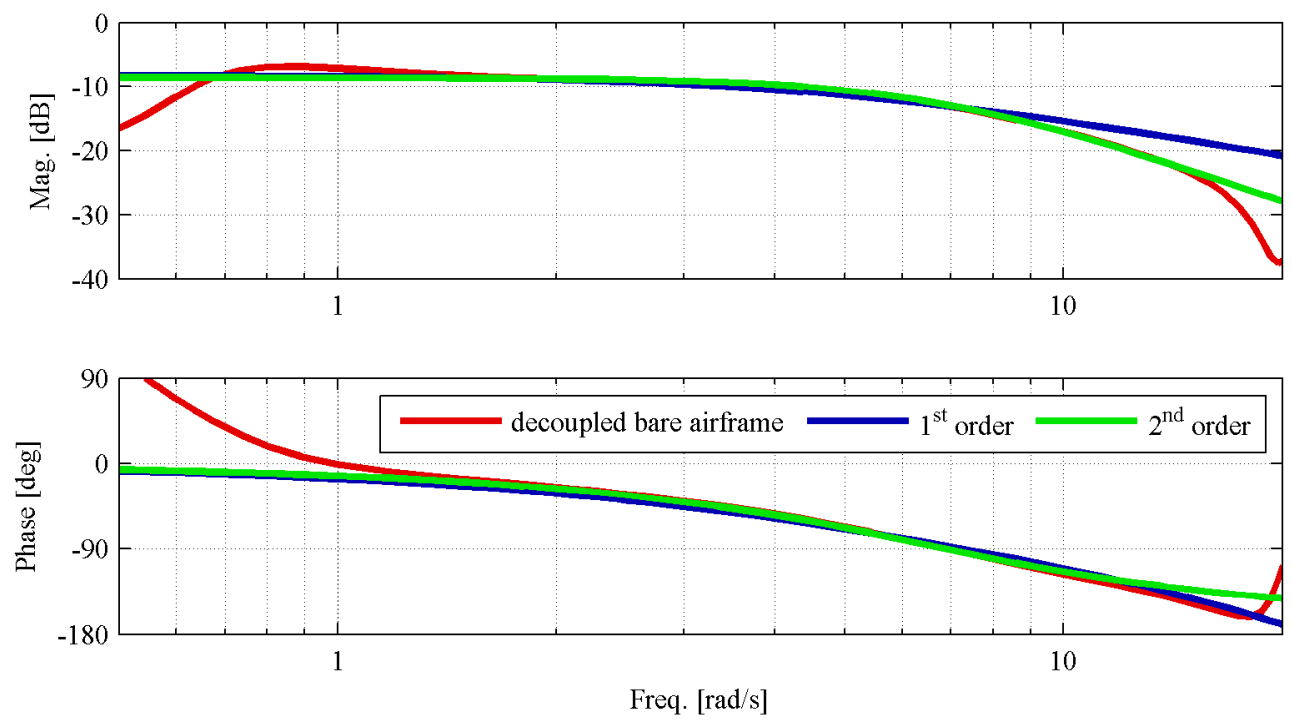

Figure 3.3: First and second order fit of roll rate

The second order fit for the lateral axis takes the form:

$$
\frac{p}{\delta_{l a t}}=\frac{K}{s^{2}+d_{1} s+d_{2}}
$$

which is inverted and rearranged and transformed into the time domain to give:

$$
\delta_{l a t}=\frac{1}{K}\left(\ddot{p}+d_{1} \dot{p}+d_{2} p\right)
$$

Equation 3.8 shows that the predicted $\delta_{\text {lat }}$ is a function of $p, \dot{p}$, and $\ddot{p}$ from the command model however, the command model does not provide $\ddot{p}$. Instead the rotor flapping rate is used to approximate $\ddot{p}$ with the following relation:

$$
\ddot{p} \approx L_{\beta_{1 s}} \dot{\beta}_{1 s}
$$

The rotor flapping rate is used because aircraft are more likely to be equipped with rotor state measurement system than jerk sensors. 


\subsubsection{Equivalent Time Delay}

The equivalent time delay is included to account for delays in the forward path such as computational delays, sampling delays, filtering delays, and aircraft delays. Additionally, it accounts for high frequency dynamics which are not modeled by the inverse and appear in the response as time delays. The time delay can be calculated by comparing the commanded state with the measured state and using frequency domain arithmetic to divide the measured response by the commanded response, e.g. $\frac{\left(p / \delta_{\text {lat }}\right)_{m}}{\left(p / \delta_{l a t}\right)_{c}}$. The resulting response represents the error between the signals and should have a magnitude of roughly $0 \mathrm{~dB}$ and show phase roll off at higher frequencies which can be fit with a time delay as shown in Figure 3.4. The fit shown in Figure 3.4 represents a time delay of $\tau=0.0894 \mathrm{~s}$.
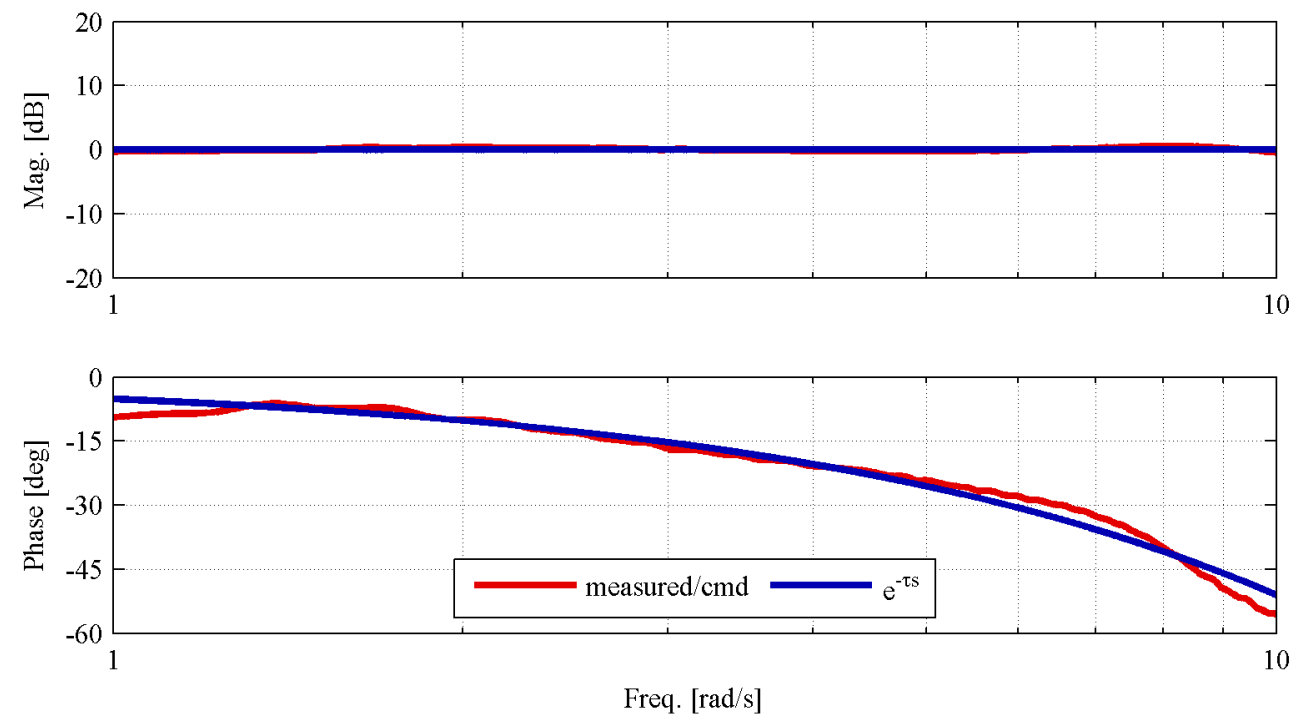

Figure 3.4: Equivalent time delay

\subsubsection{Feedback Controller}

Since the inverse plant model can only accurately cancel the short-term (mid-frequency) plant dynamics, a feedback controller is required to reduce the long-term (low-frequency) error. Similar to the diagonalized inverse plant model, each axis has a controller with proportional-integral-derivative (PID) controllers for the pitch, roll and yaw axes and a 
proportional-integral (PI) controller in the heave axis. For the PID controllers, the rate signals $(p, q$, and $r)$ are used as the derivative signals once again using the small angle approximation.

In addition to the PID and PI controllers, feedback cross-feed gains are used to improve control of the off-axis responses due to the A-matrix. The cross-feeds add a control input which is proportional to an off-axis host aircraft measurement. Cross-feeds are used to minimize the following off-axis responses: (1) pitch rate due to lateral cyclic (p feedback to longitudinal cyclic), (2) roll rate due to pedal (r feedback to lateral cyclic), and (3) pitch rate due to pedal ( $\mathrm{r}$ feedback to longitudinal cyclic). These cross-feeds work with the decoupler to remove off-axis responses.

The controller as described above can only follow $p, q, w$, and $r$ but as indicated in Table 3.1, is desirable to follow $u$ and $v$ as well. Velocity following is accomplished by closing an additional loop around the lateral and longitudinal attitude controllers with PI controllers for $u$ and $v$. The output of these velocity controllers forms an additional attitude command that is used to drive the inner attitude loop. Since the velocity controllers have low crossover frequencies, there is little high frequency attitude command from the velocity controller. At low frequencies, the attitude command from the command model will be negligible compared to the attitude command from the velocity controller. This setup allows velocities to be followed at low frequencies and attitude to be followed at mid and high frequencies. The lateral axis feedback controller is shown in Figure 3.5. 


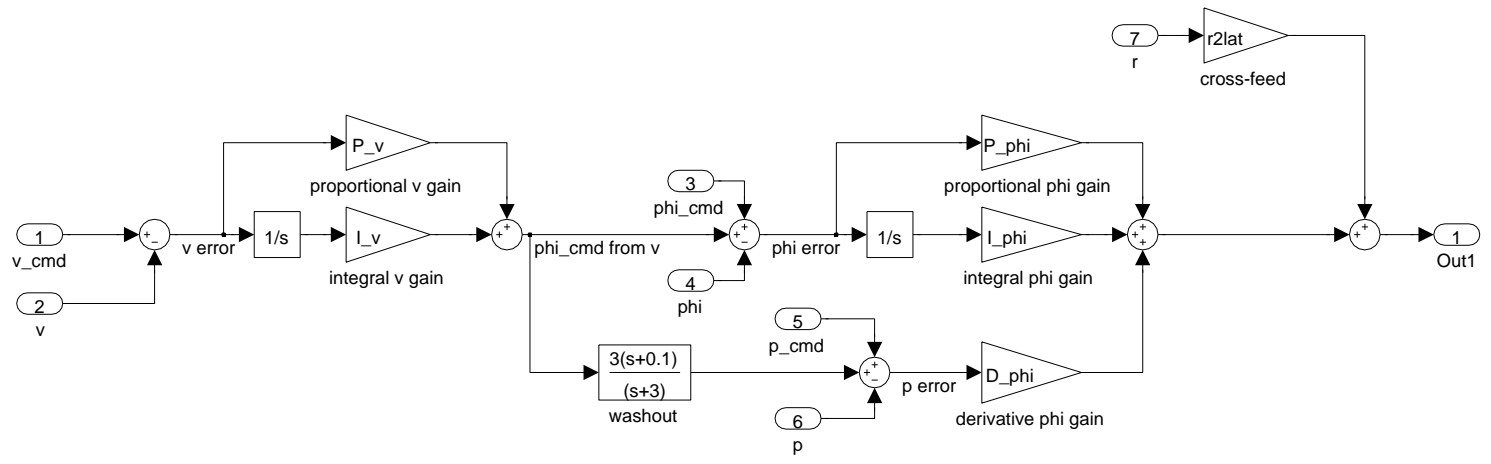

Figure 3.5: Lateral axis frequency dependent feedback controller

Also notice the washout between the velocity controller and the derivative gain of the attitude controller. This filter acts as a differentiator over the frequency range of interest of the velocity controller. This helps to keep the attitude and rate commands from the velocity controller kinematically consistent over this frequency range.

Figure 3.6 shows the effect of the frequency dependent feedback controller on the model following performance. Good model following is represented by how close the actual response ('on' or 'off') is to the commanded response ('cmd'). Each has a different frequency range where it is desirable to have good model following; for $p$ it is between 1 and $10 \mathrm{rad} / \mathrm{s}$ while for $v$ it is between 0.1 and $1 \mathrm{rad} / \mathrm{s}$. Figure $3.6 \mathrm{a}$ shows that the with the velocity controller on, there is degradation in the low frequency roll rate model following. However, recall that the frequency range of interest for attitude model following is between 1 and $10 \mathrm{rad} / \mathrm{s}$ and the velocity has little effect in this frequency range. Figure 3.6b shows that with the velocity controller on, the low frequency lateral velocity model following is improved within the frequency range of interest $(0.1-1 \mathrm{rad} / \mathrm{s})$. This is the fundamental trade-off associated with the frequency dependent feedback controller. 

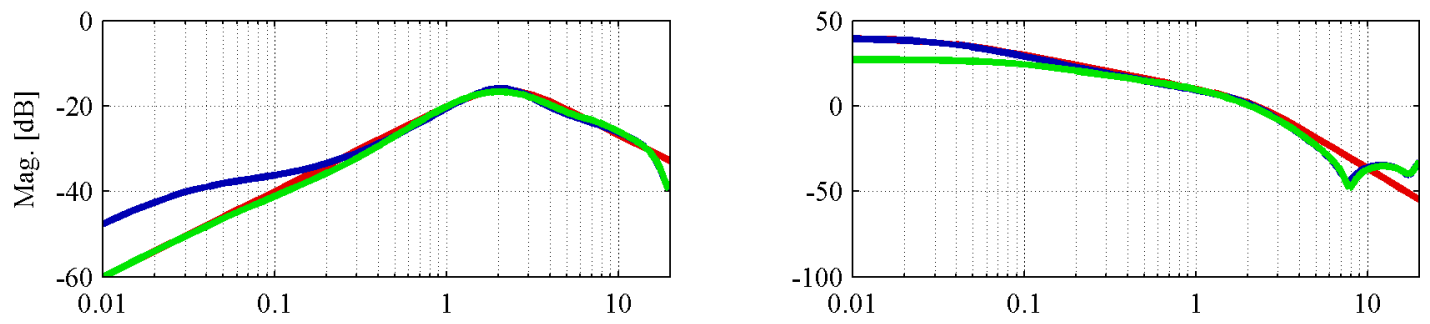

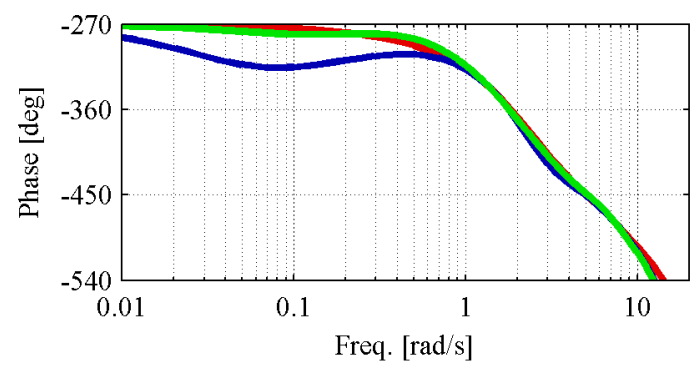

(a) $p$ model following

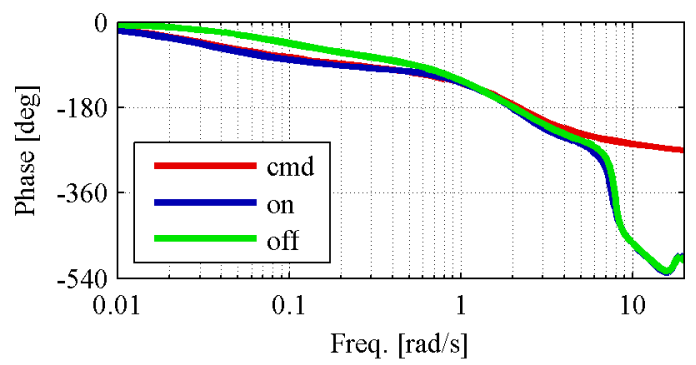

(b) $v$ model following

Figure 3.6: Effect of frequency dependent controller on model following

\subsection{Additional Design Considerations}

\subsubsection{Integral Gains}

Initial analysis found that the optimization did not adequately tune the integral gains but instead drove them to 0.0001 , the smallest value a design parameter can have in CONDUIT ${ }^{\circledR}$. This was due to the insensitivity of these gains with respect to the selected specifications (see Section 4.2). The problem arose because the specifications focus on the short term response while the integral gain affects the long term response, i.e. steady-state error. To ensure that the integral gains had reasonable values, they were constrained to the corresponding proportional gain i.e. $K_{\phi_{i}} \propto K_{\phi}$. Using a integral to proportional gain ratio of between $\frac{\omega_{c}}{10}$ and $\frac{\omega_{c}}{5}$ ensures that the integral gains are effective yet not so large as to adversely effect the phase margin. A ratio of $\frac{\omega_{c}}{8}$ follows this guideline while providing sufficient damping to meet other requirements. 


\subsubsection{Actuator Activity}

Initial analysis also found that the actuator RMS was high, exceeding the specification's level 1 value. This was due to high-frequency content in the forward path exciting the actuators. To reduce the actuator RMS, second-order Butterworth filters were placed on the output of the inverse plant. A filter cutoff frequency of $40 \mathrm{rad} / \mathrm{s}$ provided a good compromise between actuator activity and the additional time delay added by the filter.

\subsubsection{Longitudinal Model Following}

A first-order Butterworth filter was placed at the output of the velocity controller in the longitudinal axis to minimize the effect the center of rotation with respect to the center of gravity in the longitudinal velocity shown in Figure 3.7a. Since the mode is at about $2.5 \mathrm{rad} / \mathrm{s}$, it had no effect in the velocity controller but it did effect the attitude response since the output of the velocity controller provides an additional pitch attitude command to the attitude controller. By including this filter, the pitch rate model following was improved as shown in Figure 3.7b. 

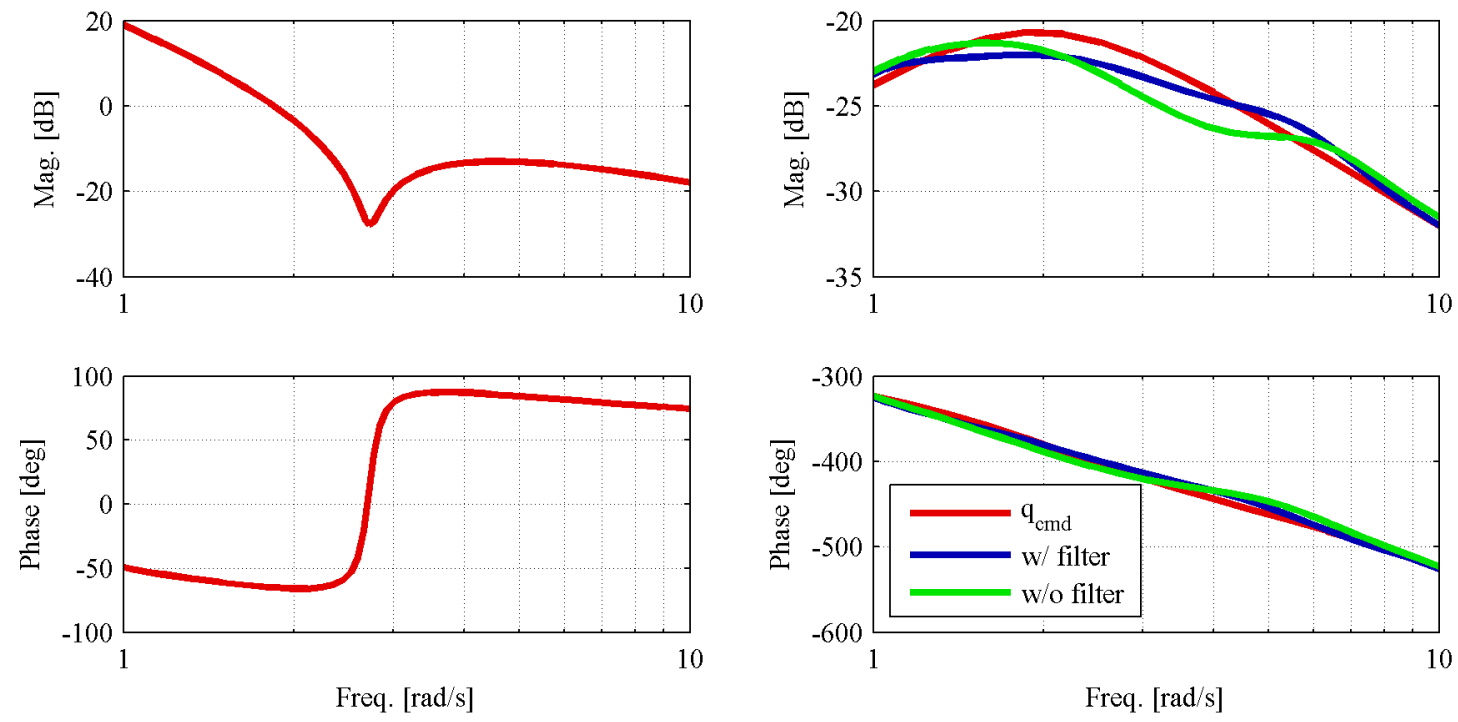

(a) $u / \delta_{l o n}$

(b) $q / \delta_{l o n}$

Figure 3.7: Butterworth filter on u-axis feedback

The cutoff frequency of the filter was set as an additional design parameter of the optimization since including the filter hand an effect on several of the specifications that were being used for the optimization (see Section 4.3).

\subsubsection{Feedback to Inverse}

Recall that the velocity controllers output an attitude command to the attitude controller in addition to the command from the command model. To ensure kinematic consistency, this attitude command from velocity is put through a lead filter which approximates a derivative to give the angular rate for the attitude controller. This same angular rate command from velocity is sent back to the inverse plant model to keep the commanded angular rates consistent in the inverse and the feedback controller. 


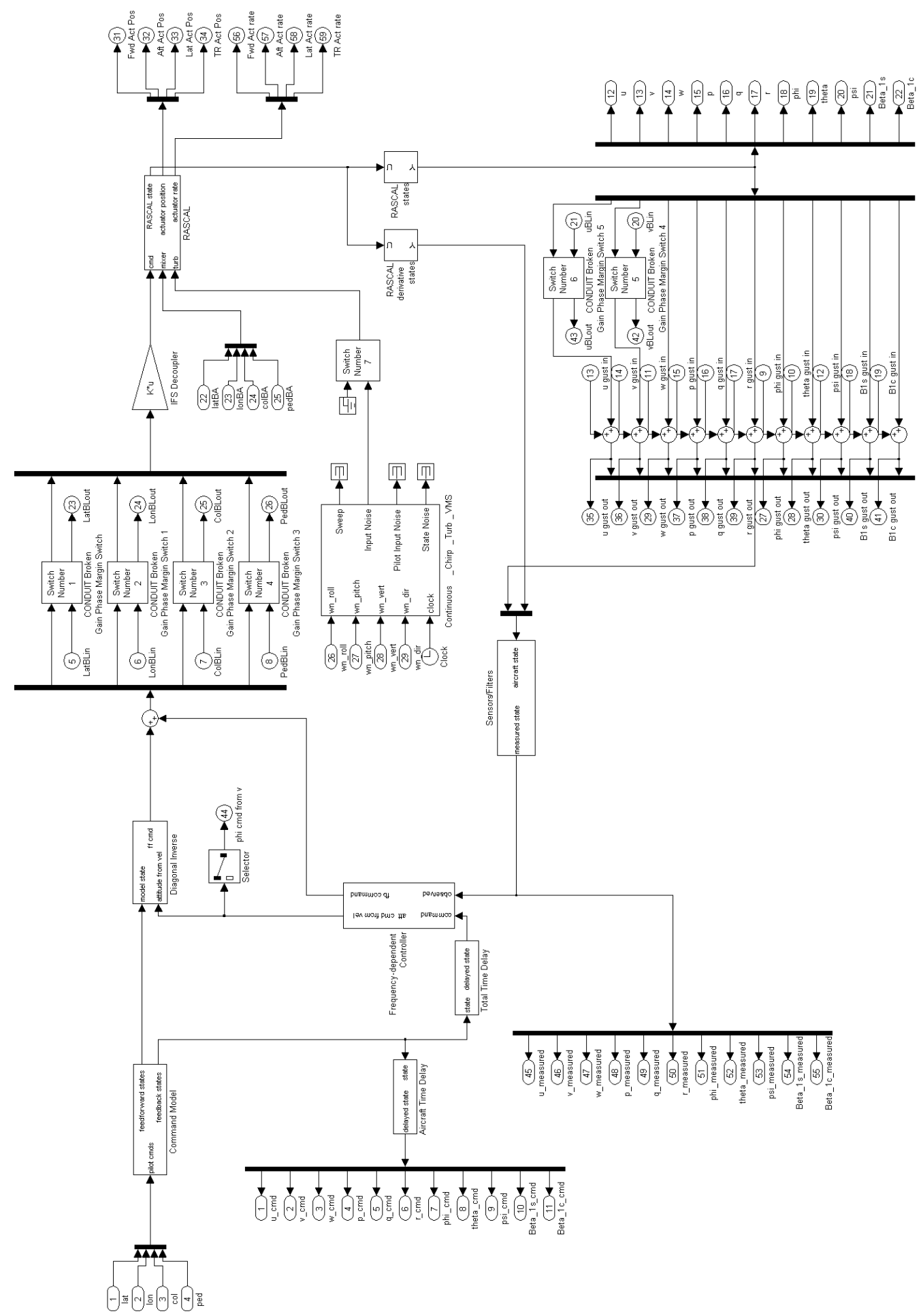

Figure 3.8: In-flight simulation control laws 


\section{Chapter 4}

\section{Control Law Optimization}

\subsection{Optimization via CONDUIT $^{\circledR}$}

The model following control system described previously was optimized using CONDUIT $^{\circledR}$.

The control system architecture was defined in Simulink ${ }^{\circledR}$ with design parameters that were to be tuned by the optimization. Specifications were selected to define the performance requirements of the system. These specifications are divided into three regions which correspond to the Cooper-Harper [23] handling qualities rating scale: level 1 - satisfactory without improvement, level 2 - deficiencies warrant improvement, and level 3 - deficiencies require improvement. These specifications can be one of three types: hard constraints, soft constraints, or objectives. Hard constraints generally define the stability requirements of the system, the soft constraints define the performance requirements, and the objectives define the cost of feedback. During the optimization process, there are three phases. In the first phase, the design parameters are tuned to such that all hard constraints are in level 1. In the second phase, the design parameters are tuned so that all specifications are in level 1. In the third phase, the design parameters are tuned to drive objective specifications as deep into the level 1 region as possible without violating any of the other constraints. This reduces over-design and over-driving the actuators. 


\subsection{Specifications}

Specifications define the required performance of the control system and serve as constraints during the optimization process. Specifications come from a variety of sources including: ADS-33E-PRF [14], military rotorcraft handling qualities; MIL-DTL-9490E [16], general flight control characteristics; MIL-STD-1797A [15], fixed-wing handling qualities; or custom specifications. Each specification has three regions based on the Cooper-Harper [23] rating scale (i.e. levels 1, 2, and 3) and predict the pilot rating.

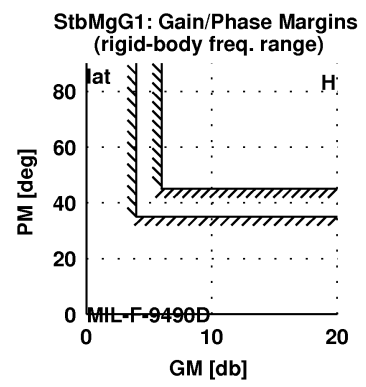

Figure 4.1: Stability margin specification

Figure 4.1 is the graphical representation of the stability margins specification used by CONDUIT $^{\circledR}$. The specification has been divided into three regions which correspond to a Cooper-Harper pilot rating of 1,2 , or 3 . The "better" side of the boundary is the side without the hash marks, i.e. the top right section is the level 1 region.

\subsubsection{Hard Constraints}

\section{Eigenvalues}

This specification requires the eigenvalues of the closed-loop system to be in the left-half plane to ensure stability. A tolerance can be used to allow slowly divergent eigenvalues. 


\section{Stability Margins}

This specification, from MIL-9490, requires the broken loop stability margins to be at least $6 \mathrm{~dB}$ and $45^{\circ}$. To determine the broken loop response, several CONDUIT ${ }^{\circledR}$ broken loop switches were added to the block diagram (see Figure 3.8).

\subsubsection{Soft Constraints}

\section{Model Following}

An important performance requirement for in-flight simulation is model following performance. The model following specification looks at the model following cost, a weighted, least-squares average of the magnitude and phase error between the commanded and actual response which is given by the following equation from [17]:

$$
J=\frac{20}{n} \sum_{\omega_{1}}^{\omega_{n}}\left[\left(\left|T_{c m d}\right|-\left|T_{\text {host }}\right|\right)^{2}+0.01745\left(\angle T_{c m d}-\angle T_{\text {host }}\right)^{2}\right]
$$

where:

$$
\begin{aligned}
& n=\text { number of frequency points } \\
& \omega_{n}=\mathrm{n}^{\text {th }} \text { frequency point } \\
& T=\text { frequency response } \\
& |\ldots|=\text { magnitude in } \mathrm{dB} \text { at each frequency point } \\
& L \quad=\text { phase in degrees at each frequency point }
\end{aligned}
$$

A perfect simulator would have a model following cost of zero. Research has shown [17] that for model following costs less than 50, the pilot should feel only the dynamics of the simulated aircraft while a cost of less than 100 is acceptable, though host aircraft dynamics may be noticeable. 


\section{Minimum Crossover Frequency}

This specification sets a lower limit on the crossover frequency. Lower crossover frequencies reduce the actuator activity but also increase the variation of the closed loop characteristics due to uncertainty in the plant model. The minimum allowable value (level 1-2 boundary) came from recent work on the UH-60M upgrade research performed at AFDD [2].

\section{Damping Ratio}

This specification, from ADS-33, requires that the minimum damping ratio of 0.35 for the closed-loop system. This is required only for frequencies up to the piloted bandwidth.

\section{Open Loop Operating Point}

The open loop operating point specification, from [24], was included to reduce pilot-inducedoscillation (PIO) tendencies of the control system. Additionally, this specification was used to prevent rate limiting due to large disturbance inputs by looking at the actuator response to disturbance inputs.

\section{Disturbance Rejection Bandwidth}

The disturbance response is the sensitivity function of the system. The disturbance rejection bandwidth is the lowest frequency where the sensitivity function crosses $-3 \mathrm{~dB}$ and is a measure of the frequency range over which disturbances will be attenuated. Requirements for $\phi, \theta$ and $\psi$ disturbance rejection bandwidths are given in the ADS-33 Test Guide [25].

\section{Disturbance Rejection Peak}

The disturbance response may exhibit overshoot before settling to a high frequency asymptote of $0 \mathrm{~dB}$. This overshoot is undesirable as it will magnify disturbances. The magnitude of this overshoot is limited by the peak response specification. 


\subsubsection{Summed Objectives}

\section{Crossover Frequency}

As mentioned previously, high crossover frequencies increase the actuator activity which is undesirable. This specification attempts to drive the crossover frequency down to the boundary specified by the minimum crossover frequency specification.

\section{Actuator RMS}

This specification ensures that actuator usage is minimized while meeting all other specifications. Minimizing the actuator activity is useful in reducing wear on the actuators and the likelihood of actuator saturation.

\section{Actuator Rate RMS in Moderate Turbulence}

This specification was included to minimize the actuator rate RMS due to moderate turbulence. Dr. Jeff Lusardi [26] developed the Control Equivalent Turbulence Inputs model which is driven by white noise and produces turbulence inputs in the pilot stick axes.

\section{Cross-feed Peak Magnitude}

This specification was included to tune the cross-feed gains by minimizing the peak magnitude of the appropriate off-axis response in the frequency domain.

\subsection{Optimization Strategy}

For a controller with nested loops, there are two optimization strategies. The first is to optimize all loops simultaneously. The benefit of this strategy is that it uses the architecture to the fullest giving the optimal design, however, this method is computationally intensive. The second optimization strategy is to optimize each loop individually starting with the innermost and freezing the optimized gains before moving on to the next loop. The benefit of this method is that problems are easier to diagnose one loop at a time however, the 
nested optimization method is suboptimal as it may not use the architecture fully but it computationally faster.

For this research, a mixture of the two methods was used. Initially, the nested optimization method was used while the optimization process could not finish due to competing constraints. The simultaneous optimization was used once phase three optimization of all the individual loops was possible.

For the nested optimization, the innermost loop is the attitude loop which consists of the proportional-integral-derivative (PID) controllers on $\phi, \theta$, and $\psi$ and a proportionalintegral (PI) controller on $w$. For this loop, only those specifications constraining the attitude loop are used and those design parameters not a part of the attitude loop are frozen at zero.

The second loop of the nested optimization was the velocity loop which consisted of the proportional-integral controllers on $u$ and $v$ as well as the filter between the attitude and velocity controller on the longitudinal axis. The specifications used to optimize this loop were those which constrained the the velocity axes and the objective constraints. Also, the $q$ model following specification and $\theta$ disturbance specifications were left as soft constraints as without leaving them active, the filter will work to improve the velocity response at the expense of the attitude loop. All other specifications were set to check only and the attitude loop design parameters were frozen at their optimized values. Freezing the gains of the attitude loop is acceptable due to the frequency separation between the loops.

The final loop of the nested optimization consisted of the cross-feed gains. For this loop all specifications other than those needed to tune the cross-feed gains were set to check only and all design parameters other than the cross-feed gains were fixed at the optimized values.

By optimizing individual loops the effect of changes could be examined quickly, however, once major changes had been implemented, the simultaneous optimization method was used to achieve the fullest effect of the control system. For the simultaneous optimization, all specifications were active and all design parameters were optimized at the same time. 
The nested optimization results were used as the initial guess for the design parameters of the simultaneous optimization.

\subsection{Design Margin Optimization}

The specifications used during the optimization defined the minimum response characteristics necessary to achieve a level 1 Cooper-Harper rating. Better performance is expected as the response is driven further into the level 1 region. The design margin in CONDUIT ${ }^{\circledR}$ offers a simple way to force the response further into the level 1 region.

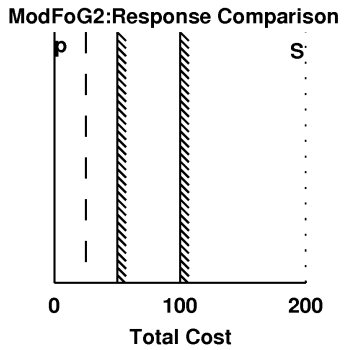

Figure 4.2: Model following specification with 50\% design margin

As shown in Figure 4.2, the design margin moves the effective level 1 boundary (represented by the dashed line) into the level 1 region. The distance into the level 1 region is based on the width of the level 2 region, i.e. a $50 \%$ design margin moves the boundary into the level 1 region by $50 \%$ of the width of the level 2 region. In CONDUIT $^{\circledR}$, the design margin optimization tool progressively changes the design margin and performs an optimization for each case.

As mentioned previously, the model following performance is an important specification for the in-flight simulation control laws. For this reason, a design margin optimization was performed with the design margin applied to the model following specifications. The following plots show the major results of the design margin optimization. 


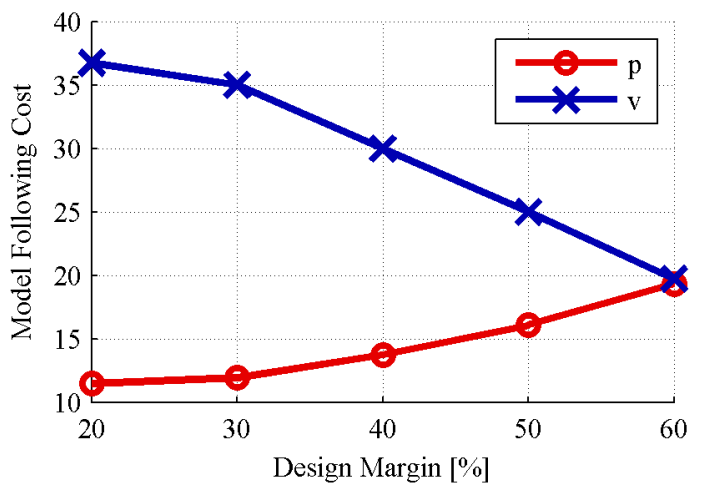

(a) Model Following Cost

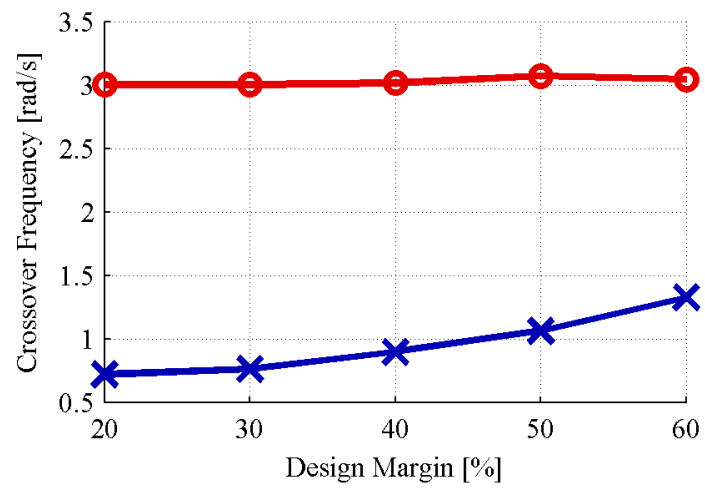

(b) Crossover Frequency

Figure 4.3: Design margin optimization trade-off plots

Figure 4.3a shows the trade-off between the roll rate and lateral velocity model following costs. This trade-off exists because helicopters cannot independently command attitude and velocity. To achieve a desired velocity, an attitude command must be given. As the lateral velocity model following cost is driven down, the roll rate model following cost increases until they are identical with a design margin of $60 \%$. Based on Figure $4.3 \mathrm{a}$ alone, the $60 \%$ case would be the best choice as it offers good model following for both states.

Figure $4.3 \mathrm{~b}$ shows the effect of the crossover frequencies of the roll rate and lateral velocity for the same design margins. This shows that while the roll rate crossover frequency remains relatively constant, the lateral velocity crossover increases with design margin reducing the frequency separation between the controllers. A frequency separation of 3 is desired between the attitude and velocity controller crossover frequencies to avoid over-driving the roll rate by the lateral velocity controller. Based on this plot, the $50 \%$ design margin case was selected as the best design because it offers improved lateral velocity model following while maintaining adequate frequency separation between the velocity and attitude controllers. 


\subsection{Optimized Solution}

As mentioned above, the controller gains that corresponded to the $50 \%$ design margin case were selected as the final design. The results presented below represent the $50 \%$ design margin case.

The following figures show the CONDUIT ${ }^{\circledR}$ handling qualities window. The handling qualities window shows the specifications used for the optimization and plots the results on each specification. The design margin is visible on the model following specifications (the first four of Figure 4.4 and two others in Figure 4.5) as the dashed vertical line. The figures show that all specifications were in the level 1 region. 

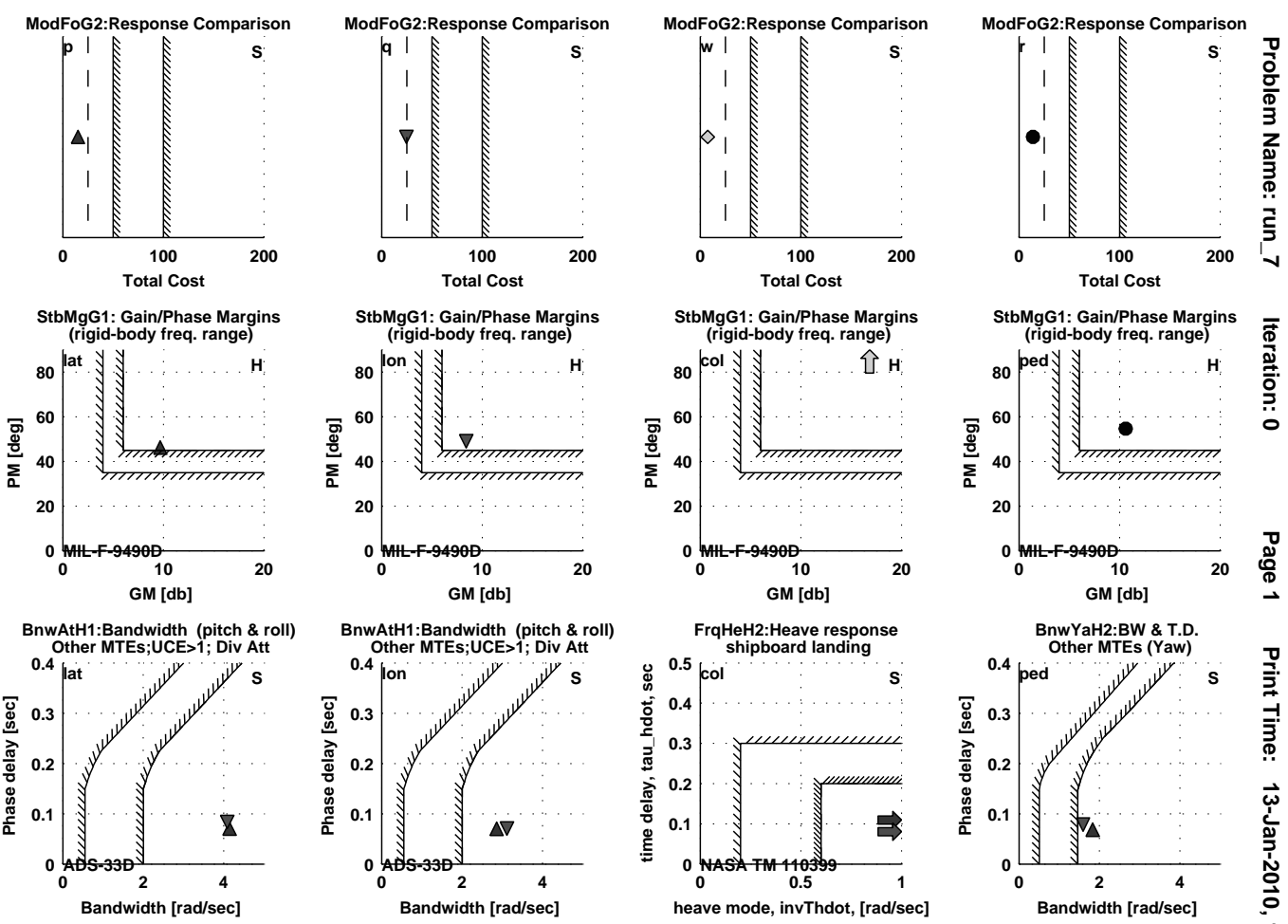

BnwAtH1:Bandwidth (pitch \& roll)

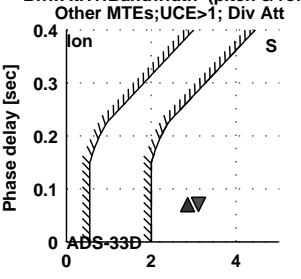

CrsMnG2:Min. Cross. Freq.

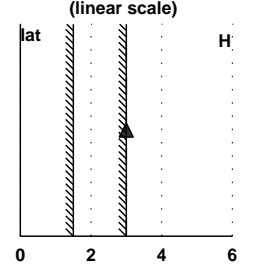

Crossover Frequency [rad/sec] CrsLnG1:Crossover Freq.
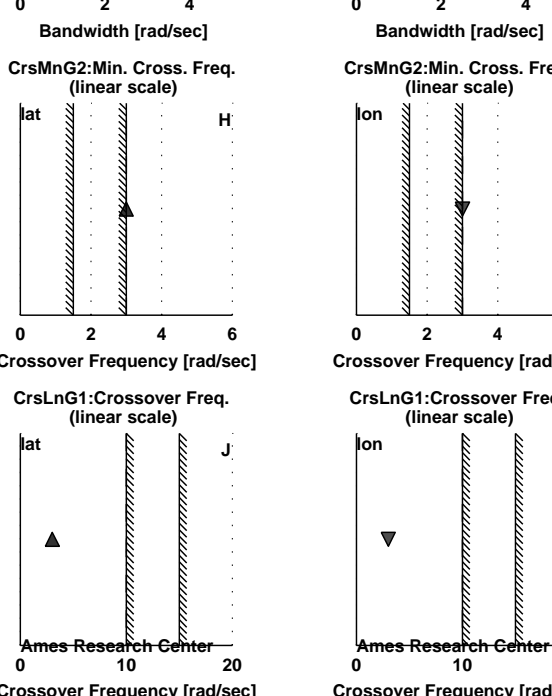

CrsMnG2:Min. Cross. Freq.
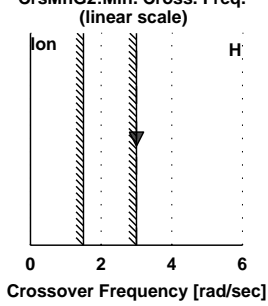

CrsLnG1:Crossover Freq
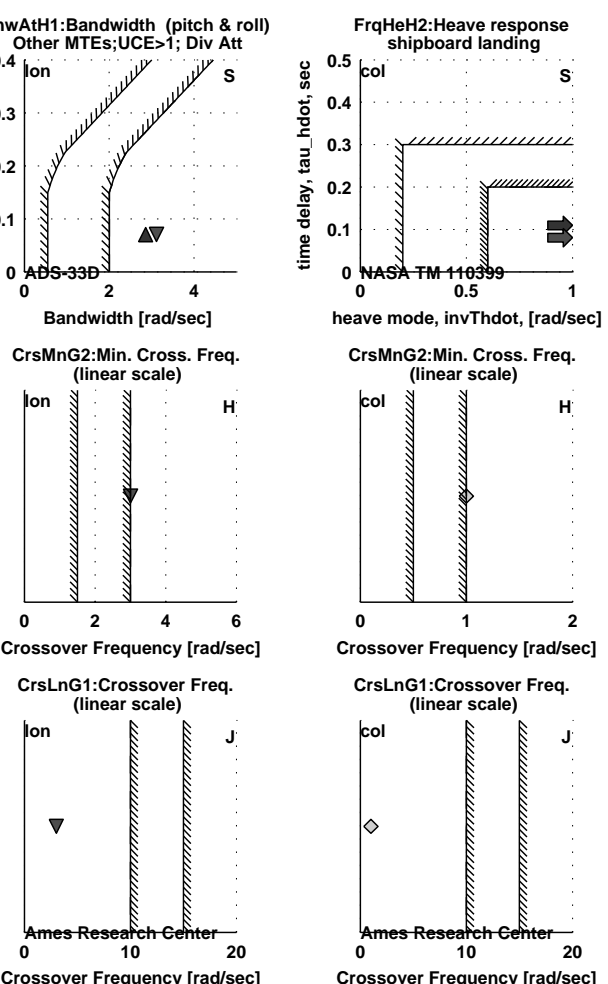

heave mode, invThdot, [rad/sec]
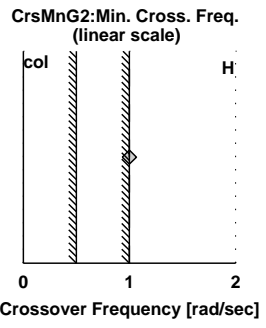

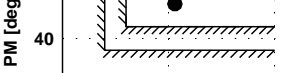

20

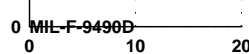

GM [db]

ญัญ
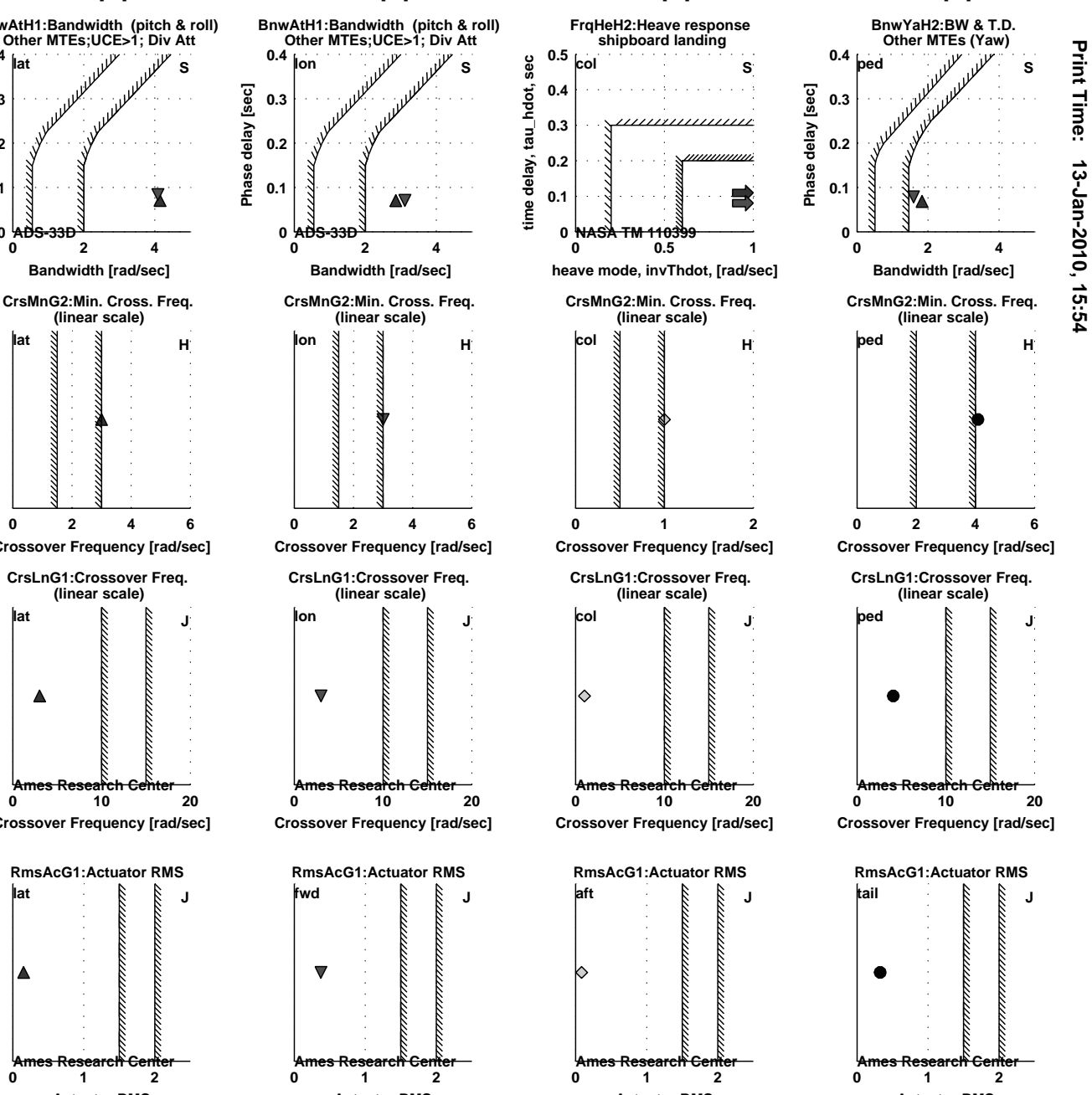

CrsLnG1:Crossover Freq
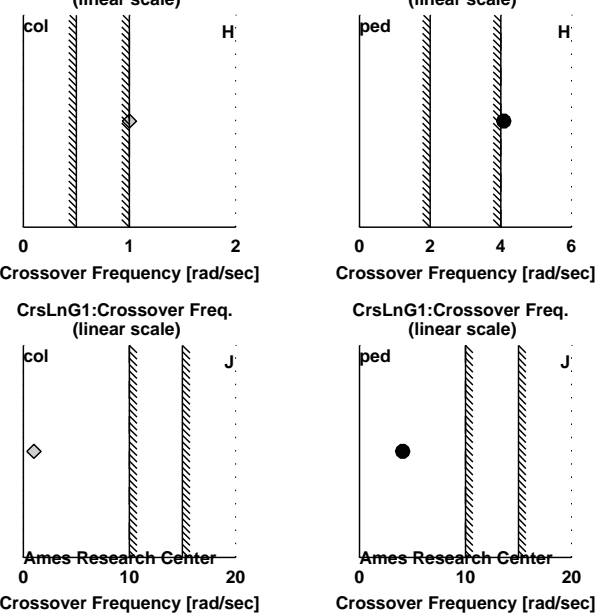

CrsLnG1:Crossover Freq.
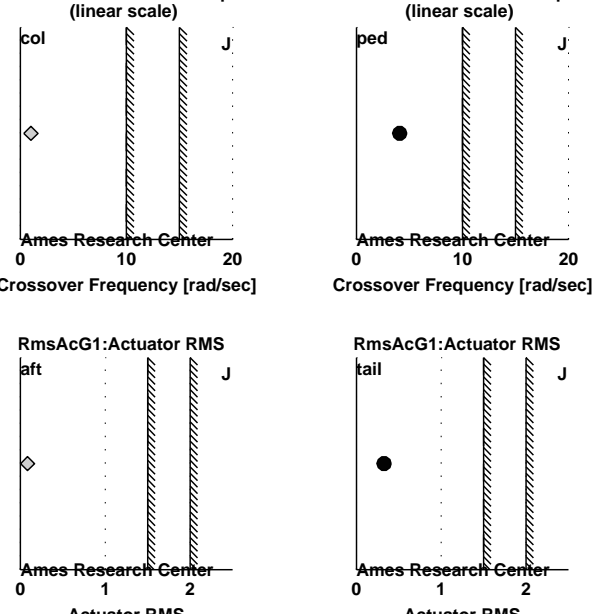

Figure 4.4: CONDUIT ${ }^{\circledR}$ HQ Window 1 of 3 

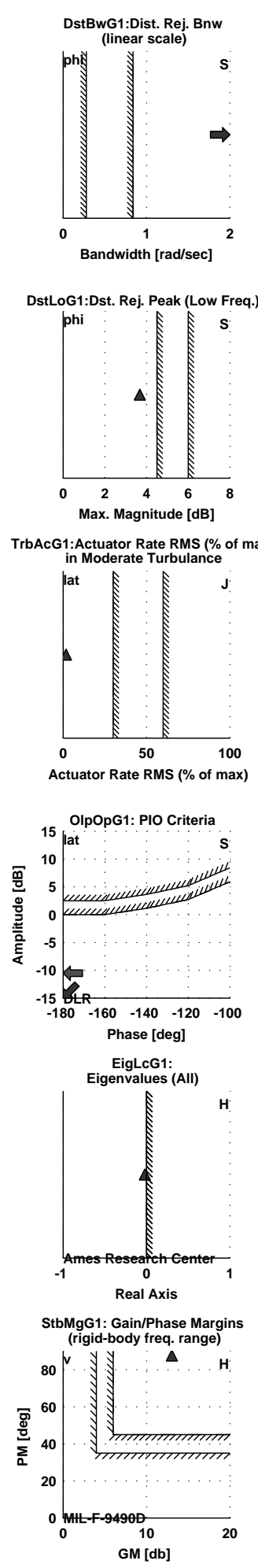

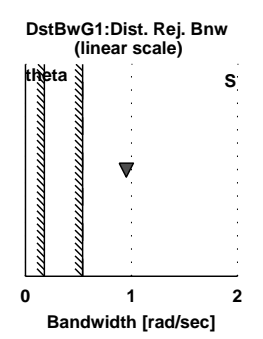

DstLoG1:Dst. Rej. Peak (Low Freq.)
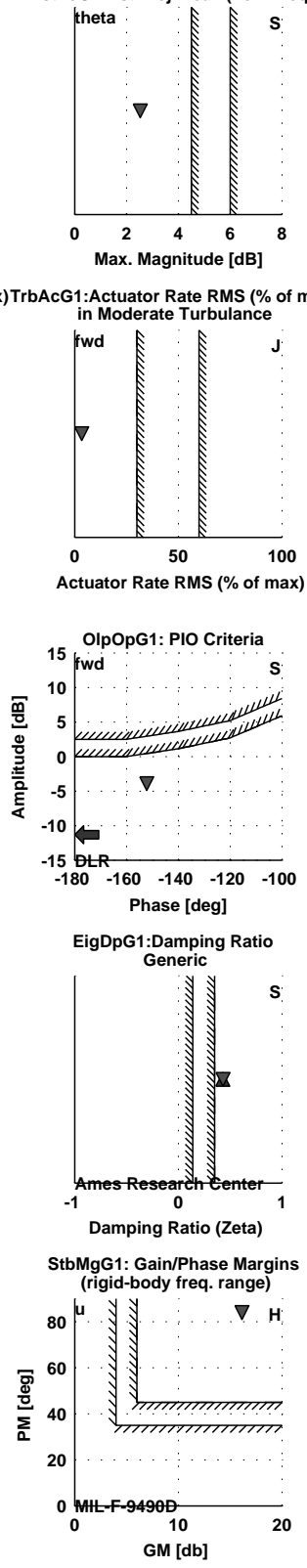
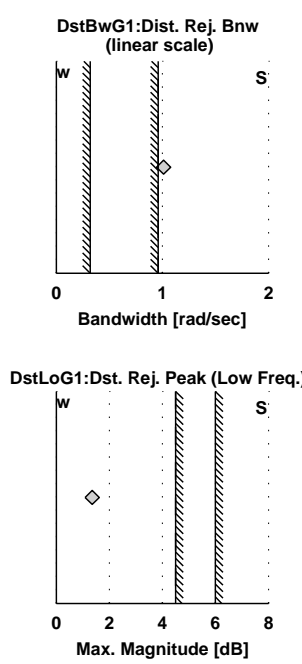

DstLoG1:Dst. Rej. Peak (Low Freq.) $\overline{\bar{\Phi}}$
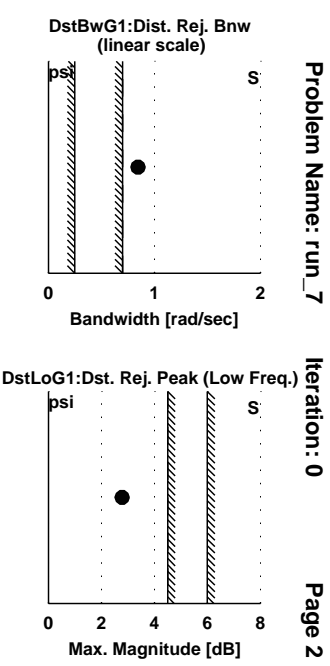

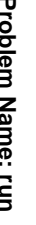

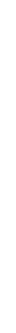

AcG1: Actuator Rate RMS (\% of max)TrbAcG1:Actuator Rate RMS (\% of max)
in Moderate Turbulance
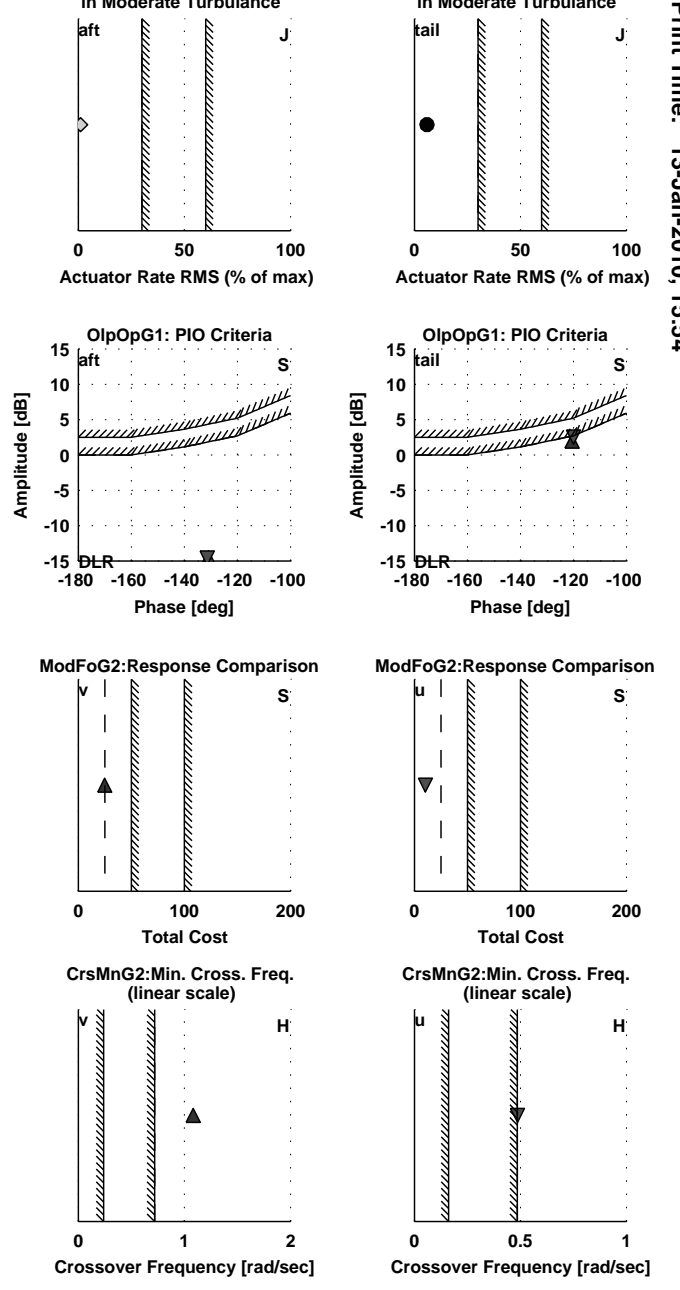

Figure 4.5: CONDUIT $^{\circledR}$ HQ Window 2 of 3 

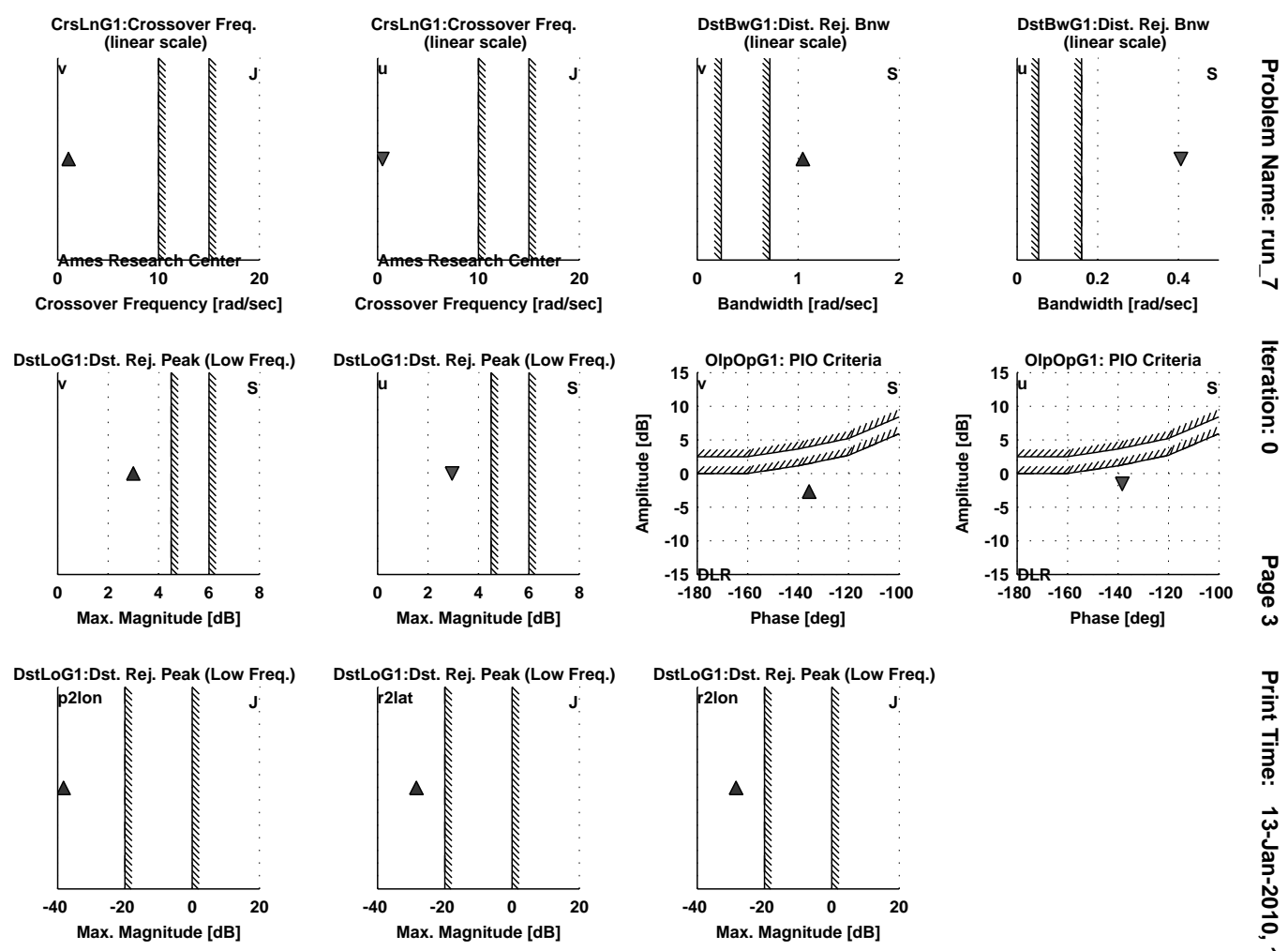

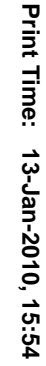

Figure 4.6: CONDUIT ${ }^{\circledR}$ HQ Window 3 of 3 


\section{Chapter 5}

\section{Linear Analysis}

From the optimized solution, several quantitative metrics were obtained to validate the performance of the control laws later in the non-linear desktop simulations and hardwarein-the-loop simulations. This chapter presents these parameters along with predicted limits of performance of a RASCAL based in-flight simulator.

\subsection{Frequency Domain}

Table 5.1 shows the frequency domain model following cost calculated using Equation 4.1. Recall that costs less than 50 are good and notice that all costs in Table 5.1 are below 25, due to the $50 \%$ design margin, indicating that the optimized design has excellent model following performance.

Table 5.1: Model following costs

\begin{tabular}{ccc}
\hline State & $\begin{array}{c}\text { Frequency } \\
\text { Range } \\
{[\mathrm{rad} / \mathrm{s}]}\end{array}$ & Cost $[\mathrm{J}]$ \\
\hline$p$ & $1-10$ & 15.1 \\
$q$ & $1-10$ & 24.6 \\
$r$ & $1-10$ & 19.9 \\
$u$ & $0.1-1$ & 10.4 \\
$v$ & $0.1-1$ & 25.0 \\
$w$ & $0.1-2$ & 7.5 \\
\hline
\end{tabular}


Table 5.2 shows the broken loop stability margins, crossover, and $\omega_{180}$ frequency for each axis. The standard margins of $6 \mathrm{~dB}$ and $45^{\circ}$ were used in the optimization. All stability margins meet this minimum value. Additionally, the crossover frequencies are all at the minimum value allowed by the minimum crossover frequency specifications.

Table 5.2: Broken loop stability margins and crossover frequencies

\begin{tabular}{clcr}
\hline \multirow{2}{*}{ Roll } & GM & $9.7 \mathrm{~dB}$ at & $9.09 \mathrm{rad} / \mathrm{s}$ \\
& PM & $46.2^{\circ}$ at & $3.00 \mathrm{rad} / \mathrm{s}$ \\
\hline \multirow{2}{*}{ Pitch } & GM & $8.4 \mathrm{~dB}$ at & $6.97 \mathrm{rad} / \mathrm{s}$ \\
& PM & $49.0^{\circ}$ at & $3.00 \mathrm{rad} / \mathrm{s}$ \\
\hline \multirow{2}{*}{ Yaw } & GM & $10.6 \mathrm{~dB}$ at & $13.12 \mathrm{rad} / \mathrm{s}$ \\
& PM & $54.6^{\circ}$ at & $4.09 \mathrm{rad} / \mathrm{s}$ \\
\hline \multirow{2}{*}{ Lon. Vel. } & GM & $16.1 \mathrm{~dB}$ at & $1.83 \mathrm{rad} / \mathrm{s}$ \\
& PM & $83.9^{\circ}$ at & $0.49 \mathrm{rad} / \mathrm{s}$ \\
\hline \multirow{2}{*}{ Lat. Vel. } & GM & $13.0 \mathrm{~dB}$ at & $4.08 \mathrm{rad} / \mathrm{s}$ \\
& PM & $87.7^{\circ}$ at & $1.08 \mathrm{rad} / \mathrm{s}$ \\
\hline \multirow{2}{*}{ Heave } & GM & $16.8 \mathrm{~dB}$ at & $13.31 \mathrm{rad} / \mathrm{s}$ \\
& PM & $91.1^{\circ}$ at & $1.00 \mathrm{rad} / \mathrm{s}$ \\
\hline
\end{tabular}

The disturbance response represents the system's susceptibility to disturbances such as turbulence. Figure 5.1 shows the input and output which are used to identify the disturbance response; Figure 5.2 shows the $v / v_{\text {dist }}$ disturbance response. The disturbance rejection bandwidth is the lowest frequency at which the disturbance response crosses $-3 \mathrm{~dB}$ of magnitude. Disturbances at frequencies below the bandwidth are quickly attenuated.

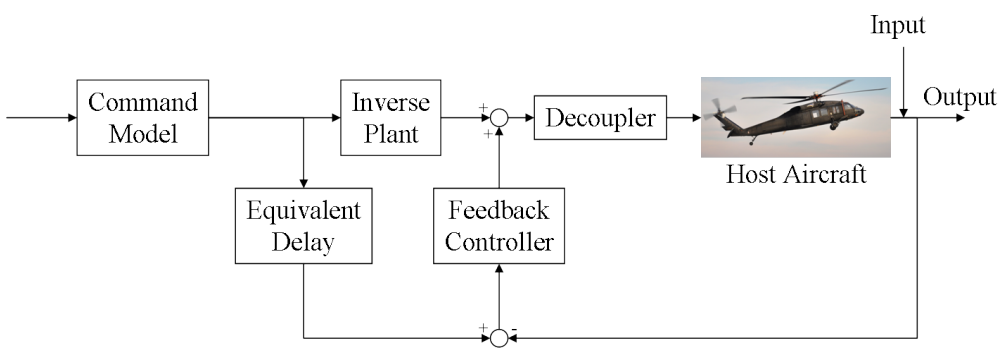

Figure 5.1: Disturbance loop 


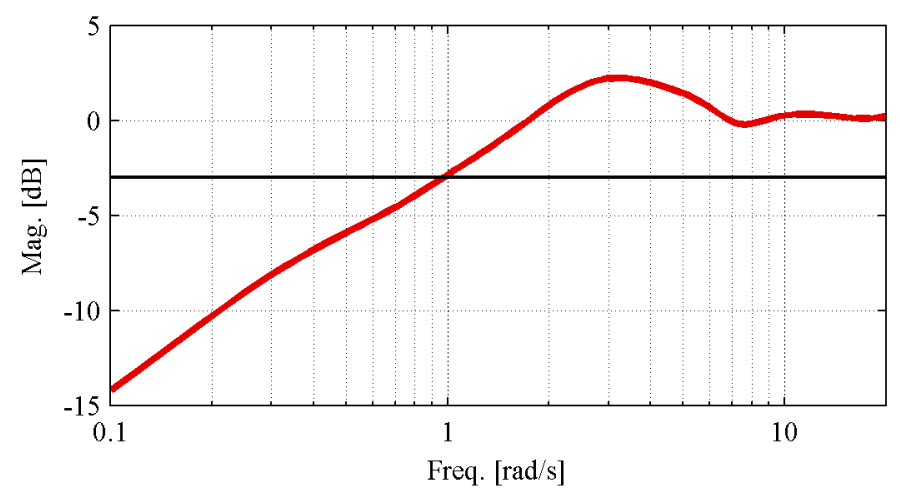

Figure 5.2: $v$ disturbance response magnitude

Table 5.3 shows the disturbance rejection bandwidth for each axis. The results for $\phi, \theta$, and $\psi$ meet the requirements of ADS-33. No requirements exist for $u, v$, or $w$.

Table 5.3: Disturbance rejection bandwidth $[\mathrm{rad} / \mathrm{s}]$

\begin{tabular}{cc}
\hline State & Bandwidth \\
\hline$\phi$ & 2.14 \\
$\theta$ & 0.95 \\
$\psi$ & 0.85 \\
$u$ & 0.41 \\
$v$ & 1.05 \\
$w$ & 1.01 \\
\hline
\end{tabular}

Figures 5.3-5.8 plot the model following error for the six model following states. The model following error is determined by normalizing the aircraft response by the command model response with perfect model following (zero error) indicated by $0 \mathrm{~dB}$ and $0^{\circ}$. Figure 5.3, Figure 5.5, and Figure 5.8 include the bounds of maximum unnoticed additional dynamics which are used here to indicate acceptable model following.

These bounds were originally developed to indicate the point where additional dynamics would cause a noticeable difference in the handling qualities [27]. More recent research [28] determined that these bounds are conservative in predicting a decrease in handling qualities as larger excursions were possible without the pilot noticing the additional dynamics. However, this research also indicated that their use for simulation validation was 
still appropriate. These boundaries were originally developed for pitch rate but are used here for the roll and yaw rates as well because the piloted bandwidth, which are near the narrowest point of the boundaries, are similar to that of pitch rate for these axes. The bounds are not shown on Figure 5.4, Figure 5.6, and Figure 5.7 because the bandwidth for these states are lower than that of roll and so the narrow points in the bounds are not in the correct place. Instead, a line indicating perfect model following is plotted as a reference.

As the data from Table 5.1 indicates, the results shown in Figures 5.3-5.8 show good model following performance over the frequency ranges of interest. As expected, the midfrequency velocity model following of $u$ and $v$ (Figure 5.6 and Figure 5.4) is degraded due to the effect of the frequency dependent controller. The low-frequency model following of $p$ and $q$, Figure 5.3 and Figure 5.5 is also degraded, however, it stays within the boundaries indicating the pilot should not notice the host aircraft dynamics.
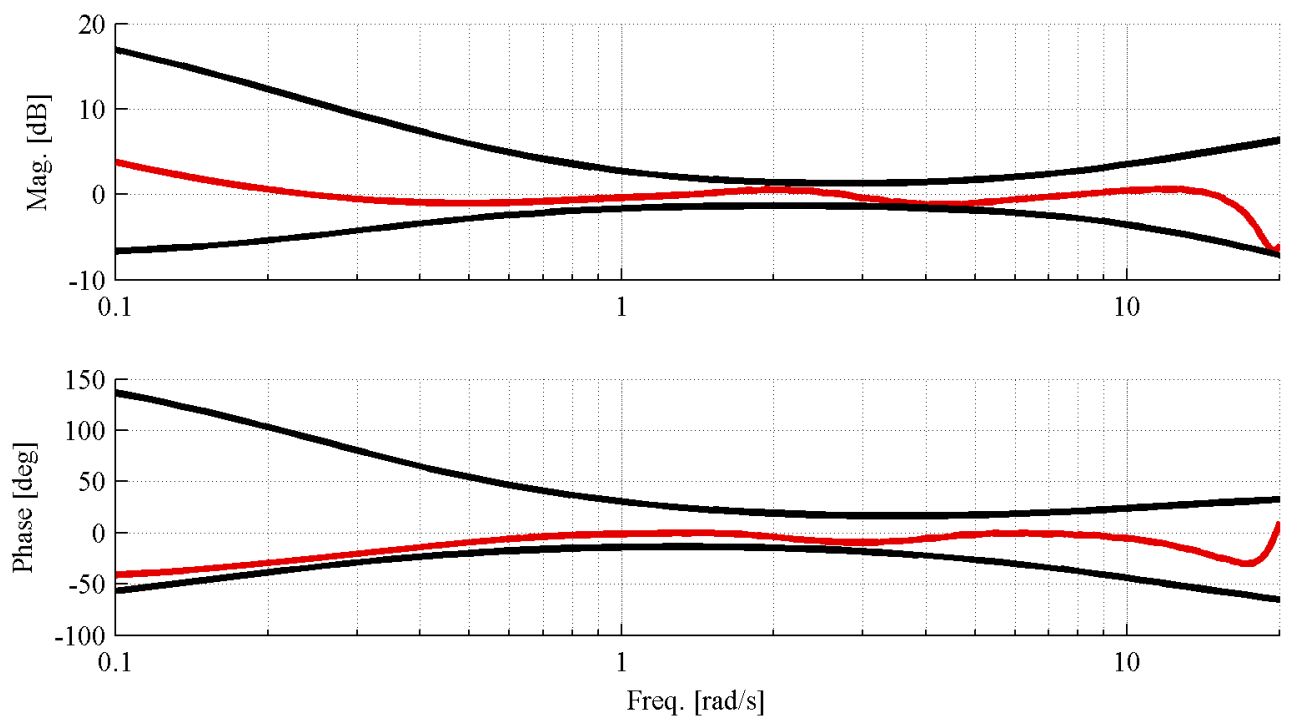

Figure 5.3: $p$ model following error 

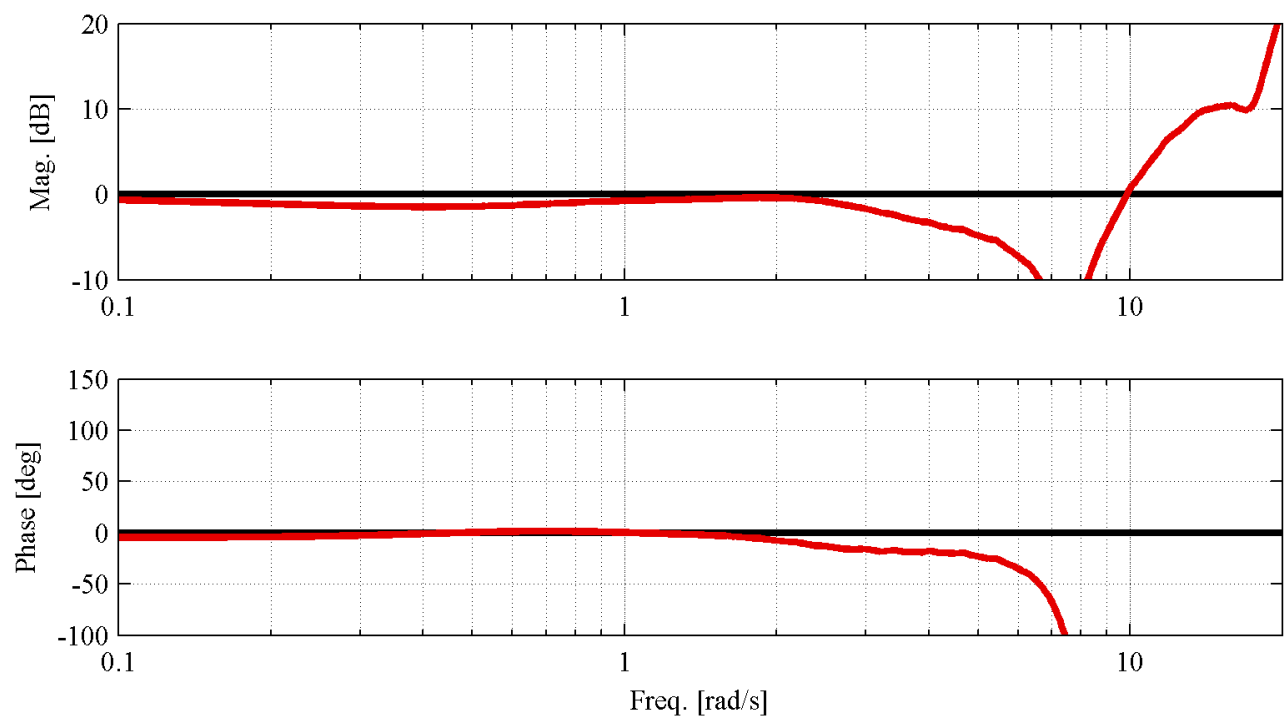

Figure 5.4: $v$ model following error
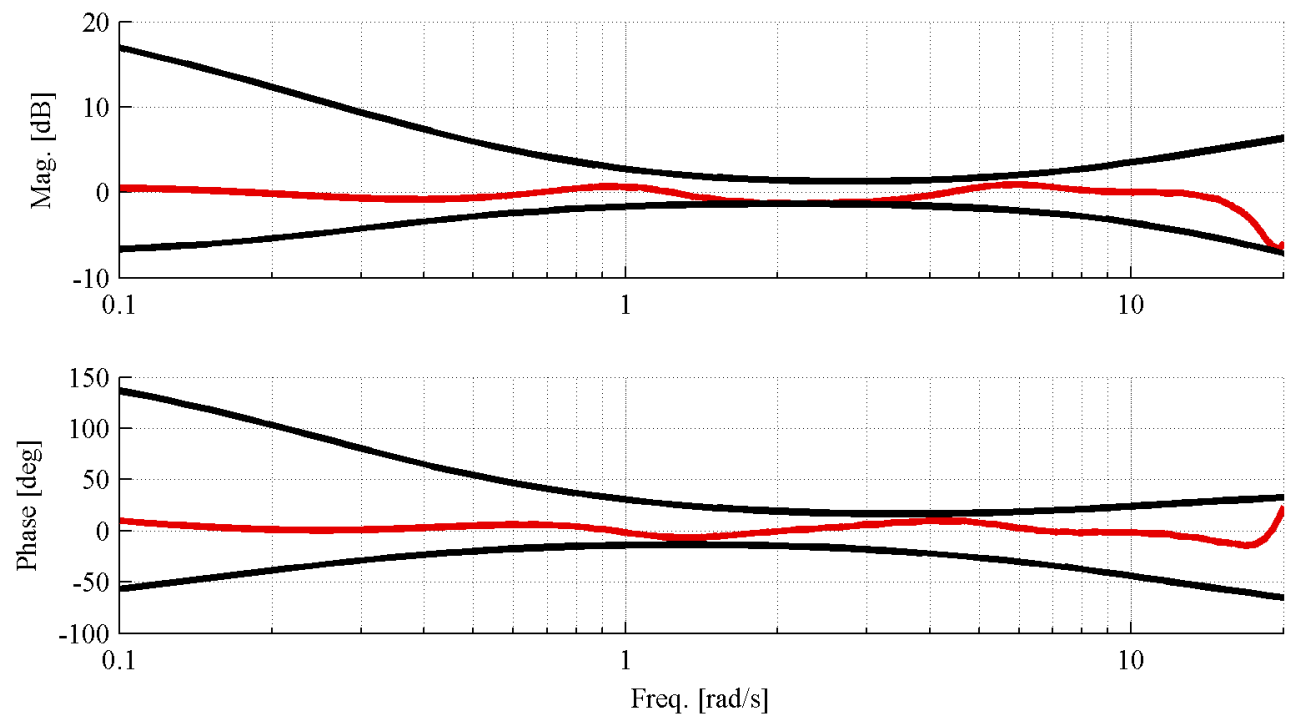

Figure 5.5: $q$ model following error 

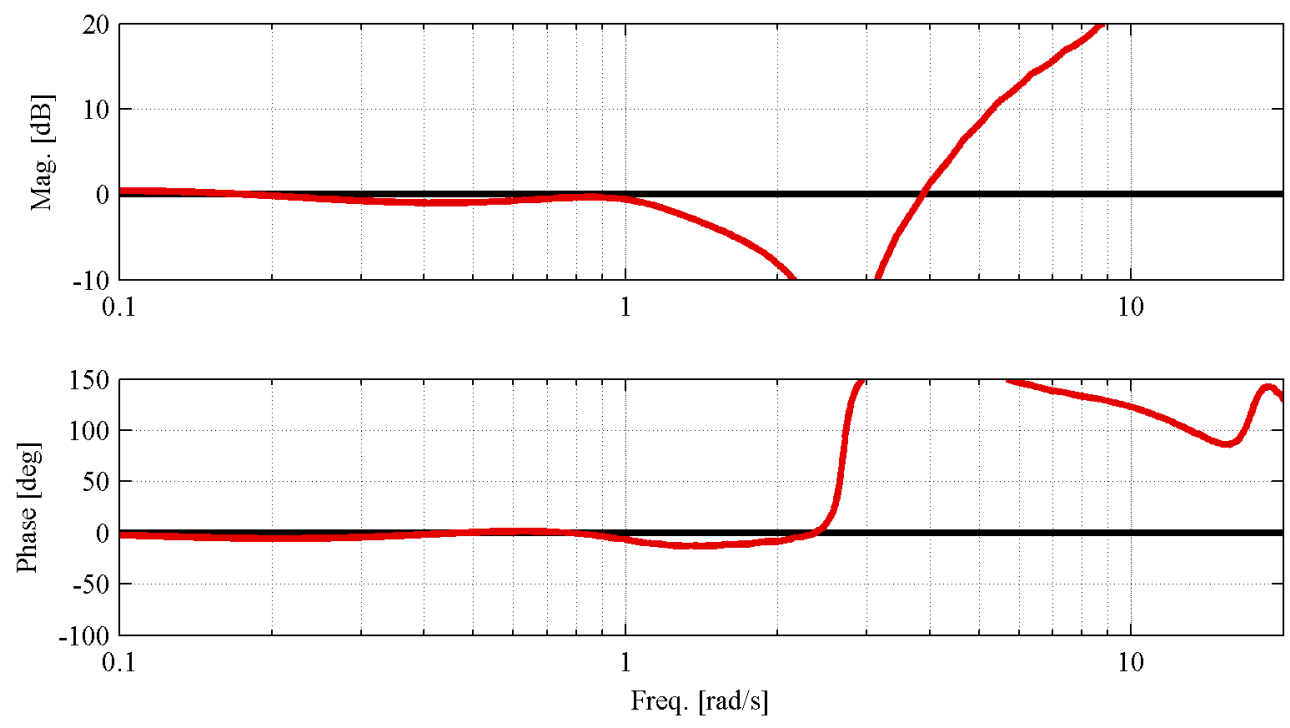

Figure 5.6: $u$ model following error
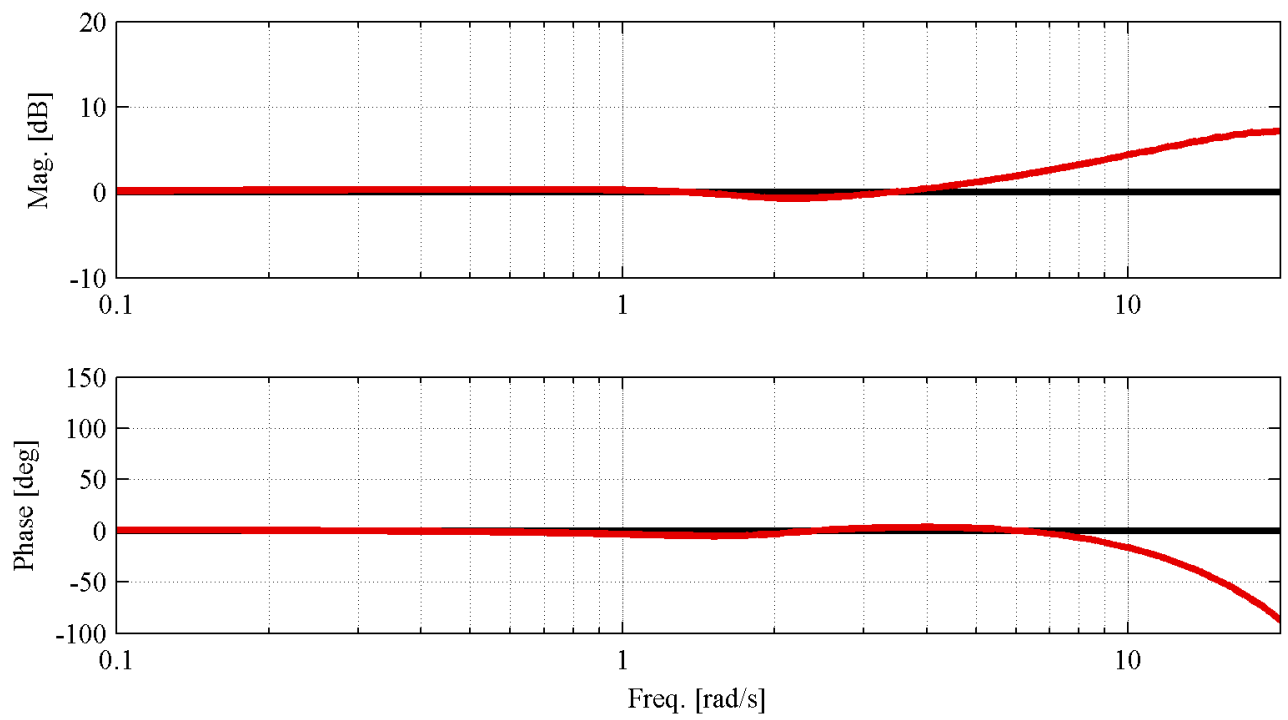

Figure 5.7: $w$ model following error 

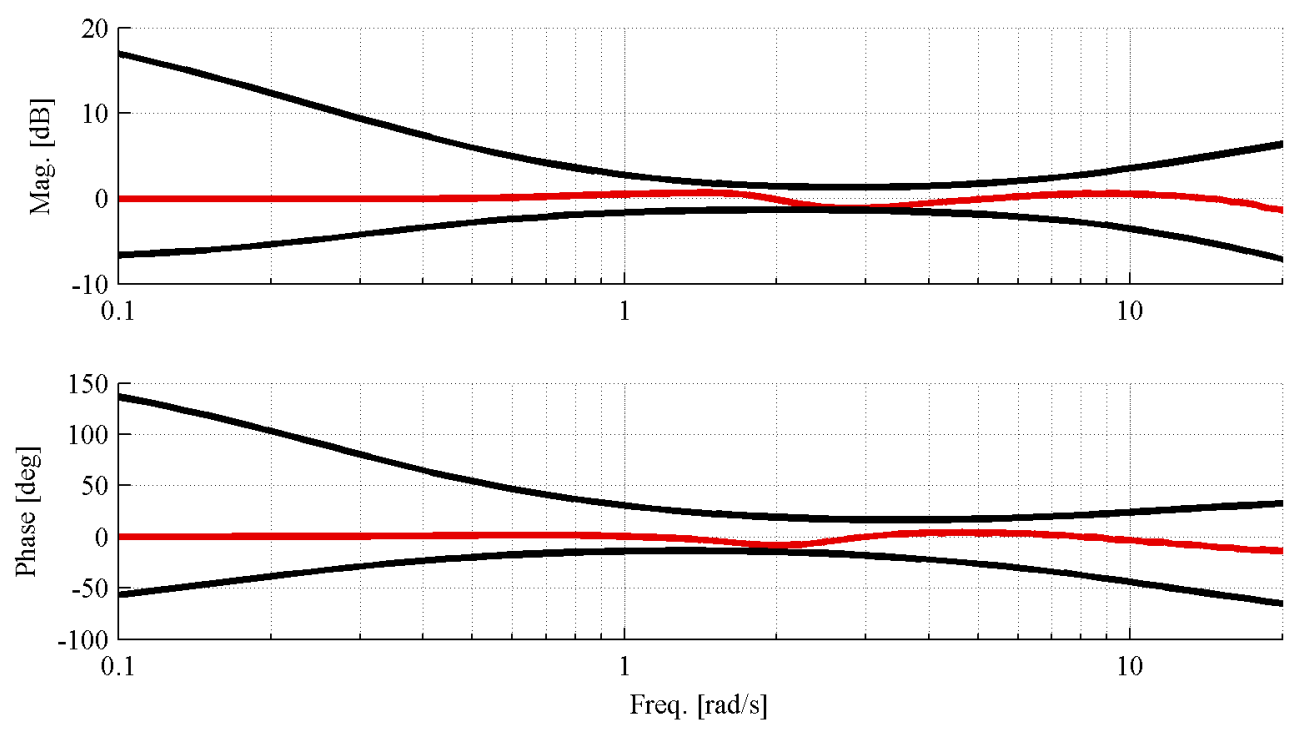

Figure 5.8: $r$ model following error

\subsection{Time Domain}

Table 5.4 shows the rms fit error, $J_{r m s}$, which is a measure of the overall time domain accuracy of the system. The rms cost includes the on-axis and off-axis error unlike the frequency domain model following cost which just includes the on-axis error. The rms cost is given by the following equation from [17]:

$$
J_{r m s}=\sqrt{\frac{1}{n_{0} n_{t}} \sum_{i=1}^{n_{t}}\left[\left(\mathbf{y}_{\text {data }}-\mathbf{y}\right)^{T} \mathbf{W}\left(\mathbf{y}_{\text {data }}-\mathbf{y}\right)\right]}
$$

where:

$$
\begin{aligned}
& \mathbf{y}_{\text {data }}=\text { actual response } \\
& \mathbf{y}=\text { predicted response } \\
& n_{t}=\text { number of time history points in record } \\
& n_{0}=\text { number of signals in record } \\
& \mathbf{W}=n_{0} \times n_{0} \text { weighting matrix }
\end{aligned}
$$


If the following weighting is used, rms costs less than 1 are excellent and rms costs less than 2 are acceptable. Notice that all values in Table 5.4 are less than 1 indicating excellent time domain model following.

$$
1 \operatorname{deg}=1 \mathrm{deg} / \mathrm{s}=1 \mathrm{ft} / \mathrm{s}=1 \mathrm{ft} / \mathrm{s}^{2}
$$

Table 5.4: Time domain model following costs

\begin{tabular}{ll}
\hline Axis & $J_{r m s}$ \\
\hline lateral & 0.23 \\
longitudinal & 0.39 \\
collective & 0.70 \\
pedal & 0.48 \\
\hline
\end{tabular}

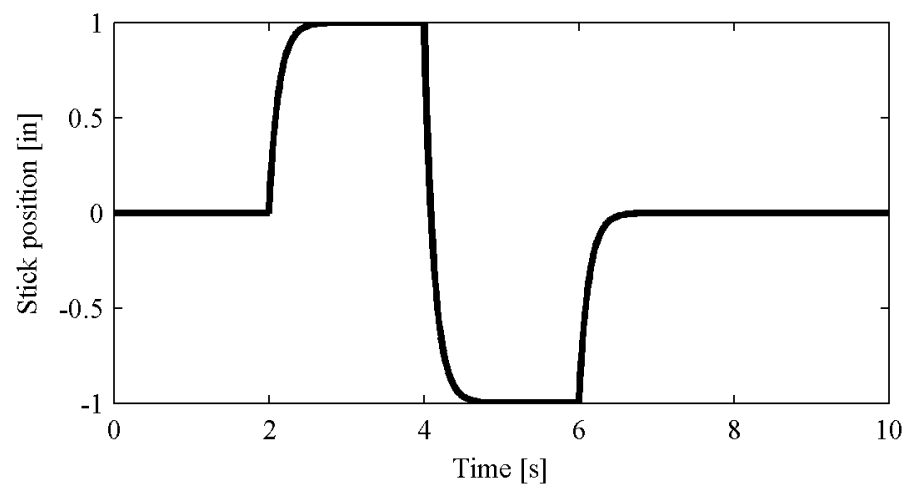

Figure 5.9: Doublet input

Figures 5.10-5.13 plot the time domain response of the aircraft to piloted doublet (Figure 5.9) inputs in each control axis scaled to give a roughly $10 \mathrm{deg} / \mathrm{s}$ response in $p, q$, and $r$ and a $10 \mathrm{ft} / \mathrm{s}$ response in $w$. For each axis, the commanded and measured responses of $u$, $v, w, p, q, r, \phi, \theta$, and $\psi$ are overlaid. As the results of Table 5.4 indicate, the overall time domain model following is good. The response to a lateral axis doublet, Figure 5.10, shows excellent on-axis model following and insignificant off-axis responses. For a longitudinal doublet, Figure 5.11, the $q$ and $\theta$ model following is good while the $u$ response shows some 
error. Also, the $p$ response shows off-axis activity, especially at $2 \mathrm{~s}, 4 \mathrm{~s}$, and $6 \mathrm{~s}$, when the input is at the highest frequency which a cross-feed gain was unable to reduce.

The collective doublet response, shown in Figure 5.12, shows excellent on-axis following but significant off-axis activity in $r$ and $p$. As with the $\frac{p}{\delta_{l o n}}$ response, cross-feed gains were unable to reduce the off-axis response. Finally, for the pedal doublet shown in Figure 5.13, there is good on-axis model following and the cross-feed gains have reduced the $p$ and $q$ responses. 

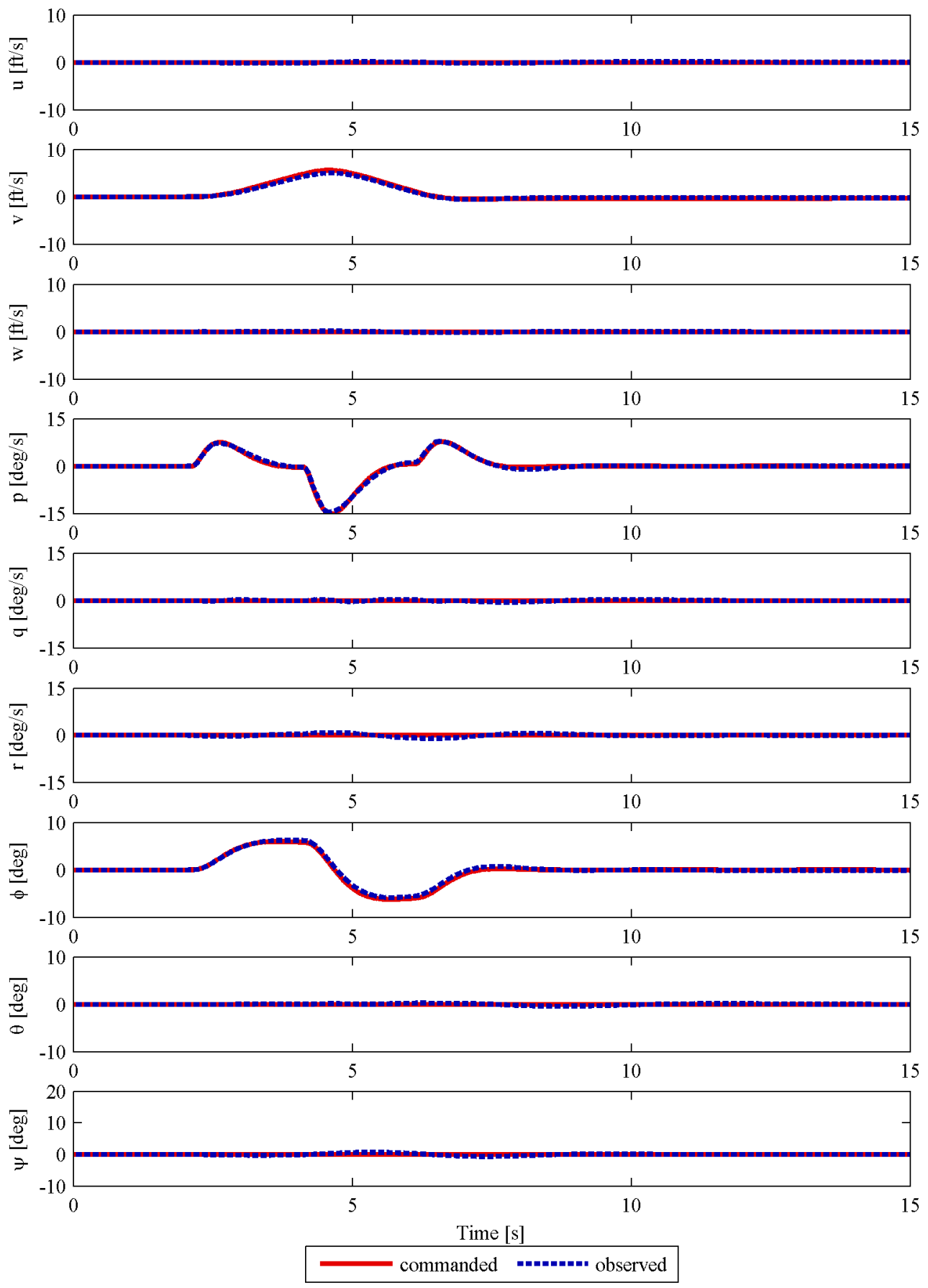

Figure 5.10: Lateral axis doublet response 

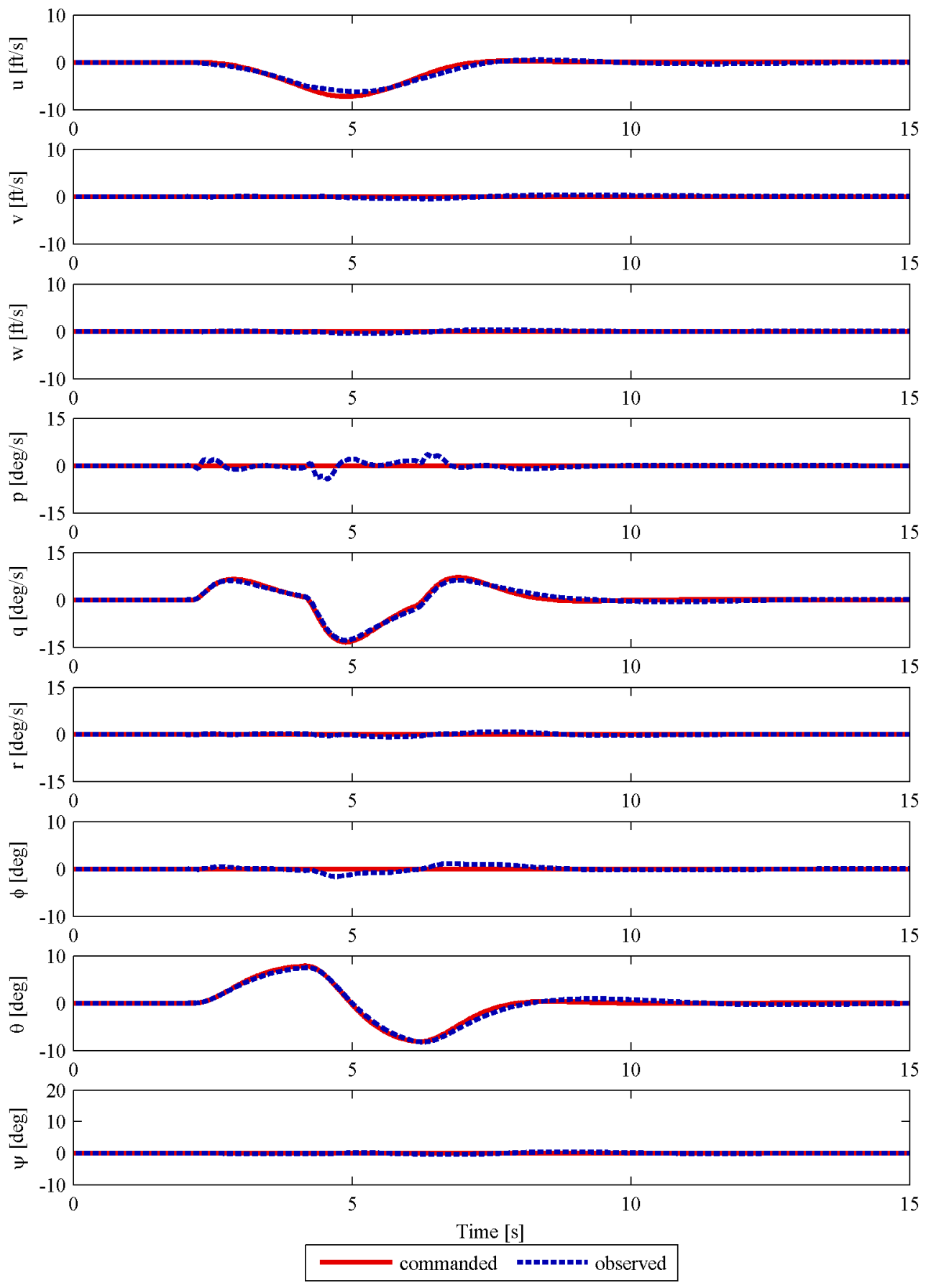

Figure 5.11: Longitudinal axis doublet response 

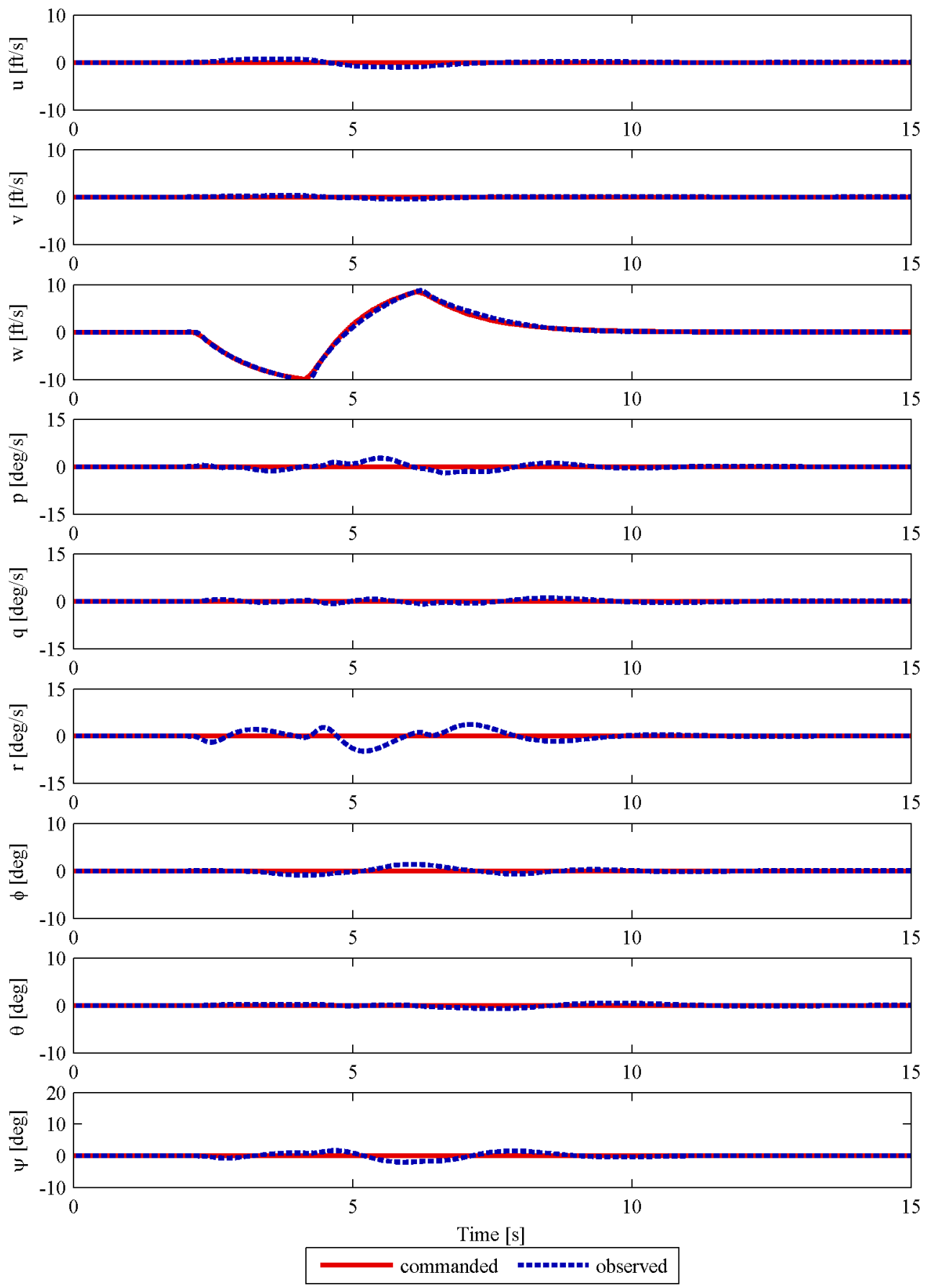

Figure 5.12: Collective axis doublet response 

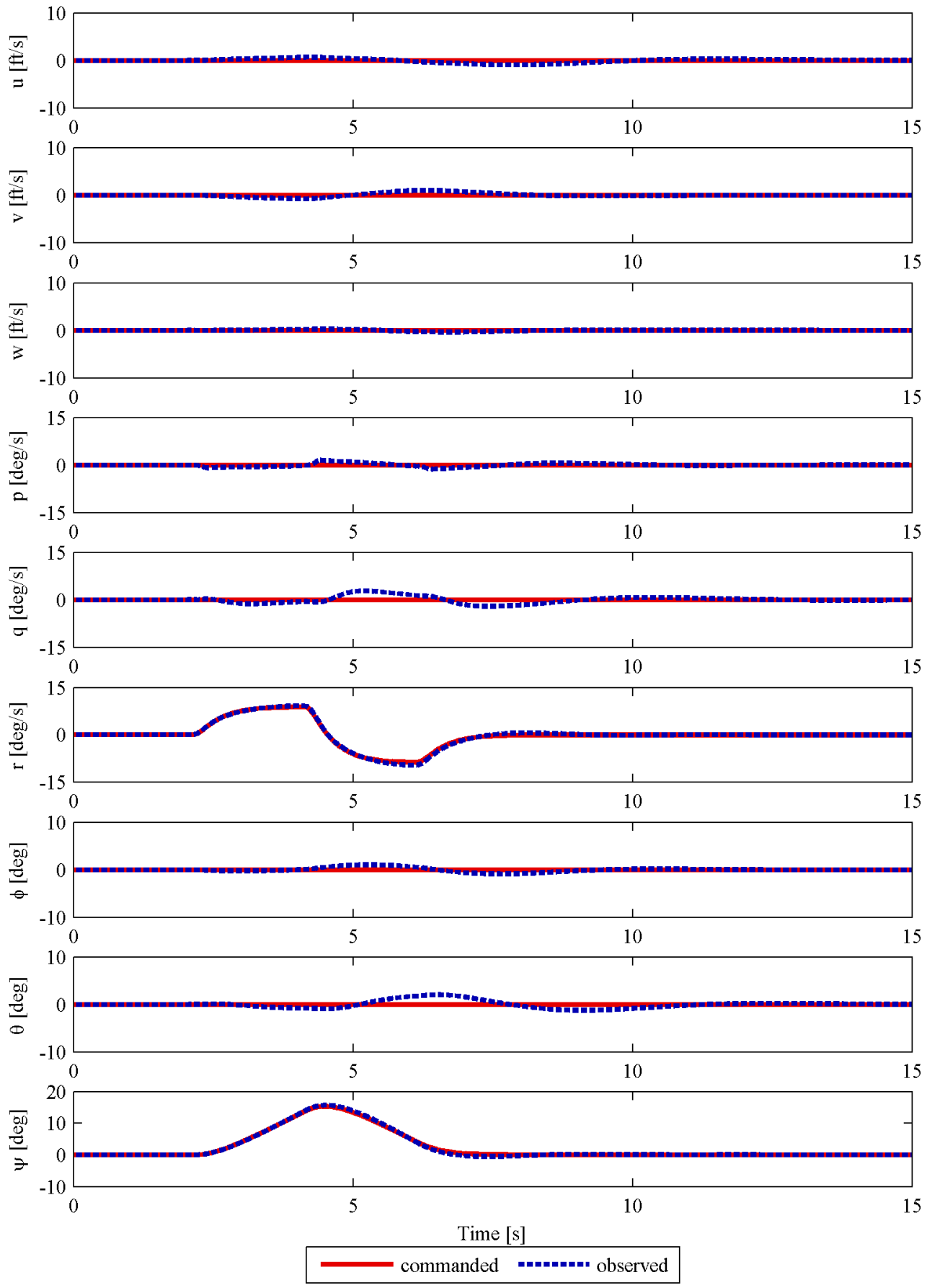

Figure 5.13: Pedal axis doublet response 


\subsection{Predicted Limits of Performance}

\subsubsection{Limitation of Hover Gains}

During the optimization, an aircraft dynamics model linearized about hover was used to determine the controller gains. To check the airspeed range over which the hover gains are useful, six additional models were obtained which were linearized about airspeeds from 10 to 60 knots. Each model was placed into the control system in CONDUIT ${ }^{\circledR}$ and the model following costs at each airspeed were calculated. The results are shown below in Figure 5.14 which shows that the hover gains give acceptable model following to about 25 knots.

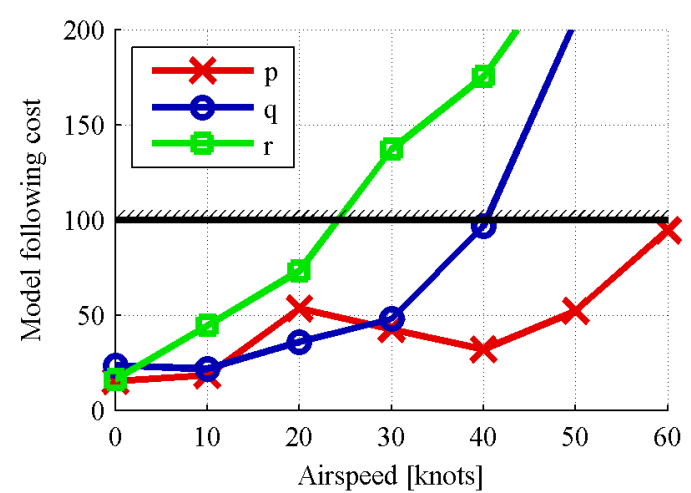

(a) Attitudes

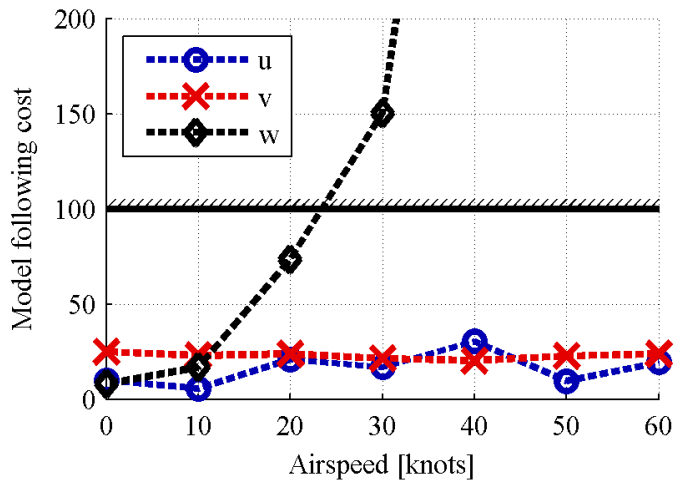

(b) Velocities

Figure 5.14: Model following cost for different airspeeds

\subsubsection{Dynamic Response Limitation}

A major limiting factor of in-flight simulators can be the dynamic response of the host aircraft. Generally, simulating a more agile aircraft on a less agile host aircraft will result in rate or position limiting the actuators. When actuator limiting occurs, there is a decrease in model following performance as the host aircraft is slower to respond than the simulated aircraft. On RASCAL, rate and position saturation is prevented by safety monitors which disengage the research control laws when saturation occurs. This system prevents degraded 
model following performance of highly agile aircraft however, limited testing of agile aircraft could be performed for less demanding maneuvers.

To determine the limit of simulated aircraft agility on a RASCAL based in-flight simulator, the command model natural frequencies were increased until a pulse input, shown in Figure 5.15, caused actuator rate limiting. The limiting cases are plotted in Figure 5.16. For the lateral, vertical, and directional axes, the tail rotor actuator with a rate limit of 7 in/s, saturated first. For the longitudinal axis, the forward and aft actuators with rate limits of $5 \mathrm{in} / \mathrm{s}$ were the limiting actuators.

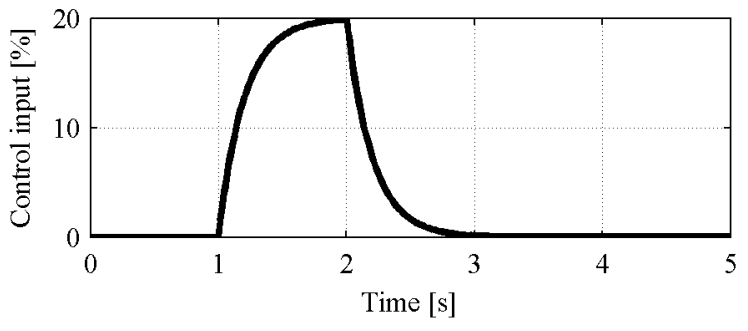

Figure 5.15: Pulse input

Table 5.5 shows the pitch and roll natural frequencies for several other aircraft. The data presented in this table comes from References $[29,30]$. The first entry, RASCAL IFS, represents the maximum values for pitch and roll as shown in Figure 5.16. These values predict that the RASCAL based in-flight simulator should be able to simulate slow, heavier aircraft such as a CH-47, a CH-53. Also, it could be used for the roll axis of an OH-58 but not the pitch axis. Based on the data provided in the table, it should also be possible to simulate an AH-64, however, as the limits were based on small inputs, the quickness of response for a simulated AH-64 may be reduced. Much smaller, more agile aircraft such as the OH-6 and BO-105 are outside of the RASCAL based in-flight simulator's range. 


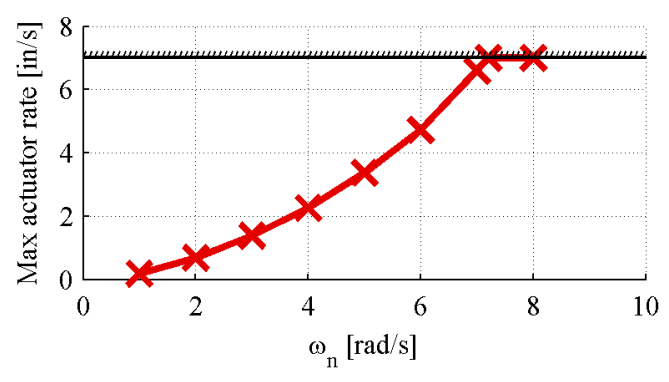

(a) Lateral axis

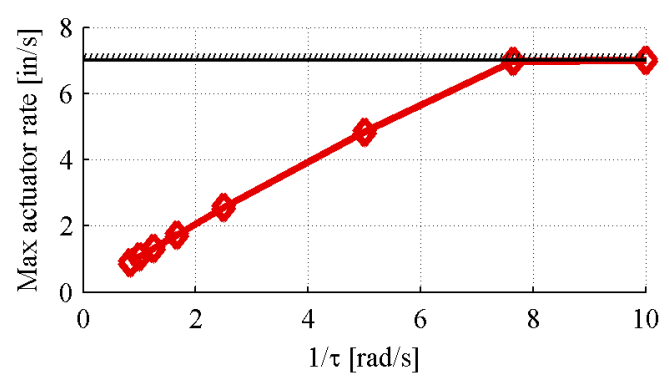

(c) Vertical axis

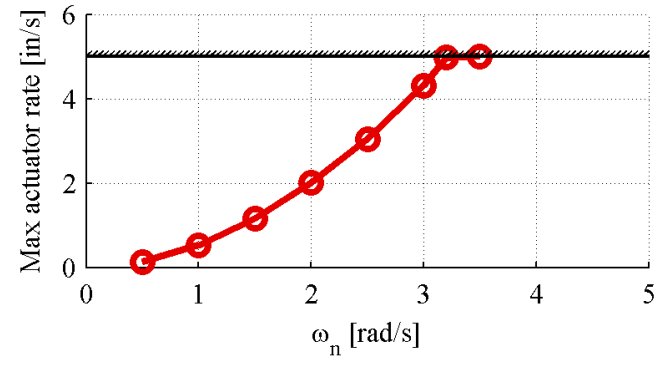

(b) Longitudinal axis

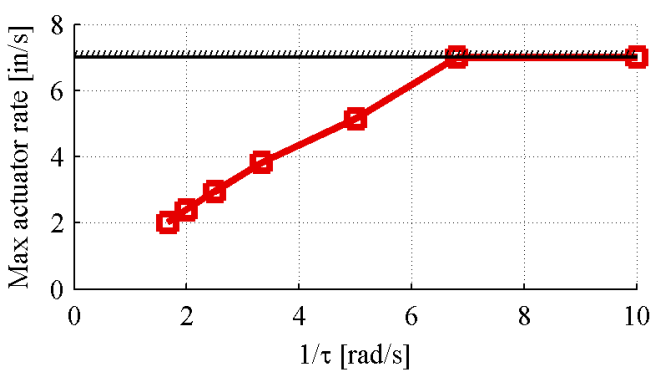

(d) Directional axis

Figure 5.16: Actuator rate vs. command model natural frequency for limiting case

Table 5.5: Roll and pitch natural frequencies of selected aircraft

\begin{tabular}{ccc}
\hline Aircraft & Roll $\omega_{n}$ & Pitch $\omega_{n}$ \\
\hline RASCAL IFS & 7.2 & 3.2 \\
CH-47B & 3.8 & 1.6 \\
CH-53D & 4.4 & 1.9 \\
AH-64 & 5.8 & 2.7 \\
OH-58D & 6.9 & 4.2 \\
OH-6A & 8.0 & 4.8 \\
BO-105 & 8.3 & 5.0 \\
\hline
\end{tabular}




\section{Chapter 6}

\section{Desktop Simulation and Validation}

After the control system design and optimization was complete, the control system was evaluated with RIPTIDE, a flight simulation and visualization tool and GenHel, a nonlinear UH-60 model. The goal of this preliminary simulation was to ensure that the control laws designed around a linearized model would work with a non-linear model.

\subsection{Control System Modifications}

The Simulink ${ }^{\circledR}$ block diagram used in CONDUIT ${ }^{\circledR}$ needed several modifications before it could be used in RIPTIDE.

\subsubsection{Math Model Inputs}

GenHel uses swashplate deflections as the control inputs unlike the FORECAST model which uses actuator positions. To get the swashplate deflections from the actuator positions an additional control mixer was placed before the output to GenHel. This new control mixer was derived and provided by M. Hossein Mansur of AFDD.

\subsubsection{Trim Angles and Initial Heading}

Unlike the linearized model, GenHel models the nonzero trim angles of a UH-60. To prevent the feedback integrators from winding up to hold trim, the $\phi$ and $\theta$ trim angles were added to the commanded $\phi$ and $\theta$ in the command model. Similarly, to account for the initial 
heading of the aircraft, the initial heading angle when the simulation starts was used as an initial condition on the $r$ integrator in the command model.

\subsubsection{RIPTIDE/GenHel Interface}

RIPTIDE arena blocks were added to the Simulink ${ }^{\circledR}$ block diagram to serve as the interface between the block diagram and GenHel. GenHel can only send data to or receive data from these blocks. All commands into the control system are passed through control arena blocks and the state information from GenHel is passed through state arena blocks.

\subsubsection{Frequency Sweeps}

Frequency sweeps were used to evaluate the control laws as they provide good frequency content over a range of frequencies. To perform a quantitative comparison between the non-linear results of GenHel and the linearized results from CONDUIT ${ }^{\circledR}$, frequency sweeps were needed at the pilot inputs for the end-to-end responses, the actuators for the broken loop responses, and the disturbance inputs for the disturbance rejection responses.

A frequency sweep generator allows the minimum and maximum frequencies, fade in and fade out times, and the sweep length to be set and automatically fed into the system when activated; Table 6.1 shows the sweep parameters used. Since the default seep amplitude is one, scaling gains are used to prevent actuator saturation, large angles, or non-hover/low speed flight; the gain values are shown in Table 6.2. For the piloted sweep, it is possible to perform the sweep manually by following cues displayed in the RIPTIDE HUD, however the data is better when an automatic sweep is used. Data is collected via Simulink ${ }^{\circledR}$ "To workspace" blocks added to the system on each signal to be recorded.

Frequency response identification was performed using CIFER ${ }^{\circledR}$ which allowed the desktop simulation results to be compared with the optimization predictions. 
Table 6.1: Sweep Parameters

(a) Piloted and Broken Loop

\begin{tabular}{ll} 
initial frequency & $0.2 \mathrm{rad} / \mathrm{s}$ \\
final frequency & $25 \mathrm{rad} / \mathrm{s}$ \\
duration & $170 \mathrm{~s}$ \\
fade in & $5 \mathrm{~s}$ \\
fade out & $28 \mathrm{~s}$ \\
\hline
\end{tabular}

(b) Disturbance Rejection

\begin{tabular}{ll}
\hline initial frequency & $0.1 \mathrm{rad} / \mathrm{s}$ \\
final frequency & $10 \mathrm{rad} / \mathrm{s}$ \\
duration & $170 \mathrm{~s}$ \\
fade in & $5 \mathrm{~s}$ \\
fade out & $5 \mathrm{~s}$ \\
\hline
\end{tabular}

Table 6.2: Sweep scaling gains

\begin{tabular}{|c|c|c|c|c|c|}
\hline \multicolumn{2}{|c|}{ End-to-end } & \multicolumn{2}{|c|}{ Broken loop } & \multicolumn{2}{|c|}{ Disturbance } \\
\hline Axis & Gain & Axis & Gain & Axis & Gain \\
\hline Lateral & $5 \%$ & Lateral & 0.5 in & $\mathrm{u}$ & $6 \mathrm{ft} / \mathrm{s}$ \\
\hline Longitudinal & $5 \%$ & Longitudinal & 0.5 in & $\mathrm{V}$ & $6 \mathrm{ft} / \mathrm{s}$ \\
\hline Collective & 0.5 in & Collective & $0.5 \mathrm{in}$ & $\mathrm{w}$ & $6 \mathrm{ft} / \mathrm{s}$ \\
\hline Pedal & $5 \%$ & Lateral & $0.25 \mathrm{in}$ & $\phi$ & $0.07 \mathrm{rad}$ \\
\hline & & & & $\theta$ & $0.07 \mathrm{rad}$ \\
\hline & & & & $\psi$ & $0.07 \mathrm{rad}$ \\
\hline
\end{tabular}

\subsubsection{Inverse Plant Model}

Initial analysis showed that the roll rate model following was degraded in the non-linear desktop simulation compared to the linear analysis. This was due to the fact that the lateral axis bare airframe responses differed significantly between the linearized (FORECAST) model and the non-linear (GenHel) model as shown in Figure 6.1. Since the inverse plant model was based on the linearized model, it did not properly invert the dynamics of the non-linear model. A new inverse was identified using frequency response identification $\left(\right.$ CIFER $\left.^{\circledR}\right)$ on the bare airframe response of the non-linear model. By using this new inverse, the roll rate model following cost improved from 201 with the FORECAST inverse to 90 with the GenHel inverse, these responses are shown in Figure 6.2. 

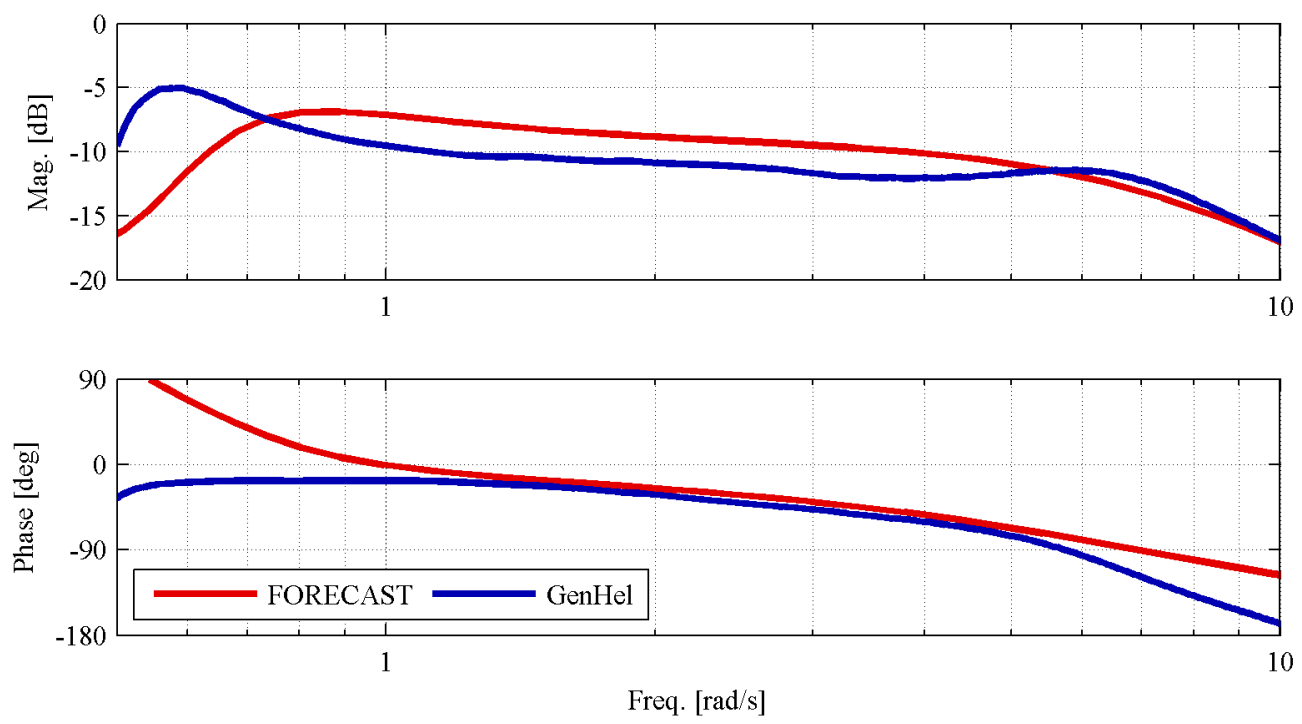

Figure 6.1: Roll rate bare airframe response from FORECAST (linear) and GenHel (nonlinear)
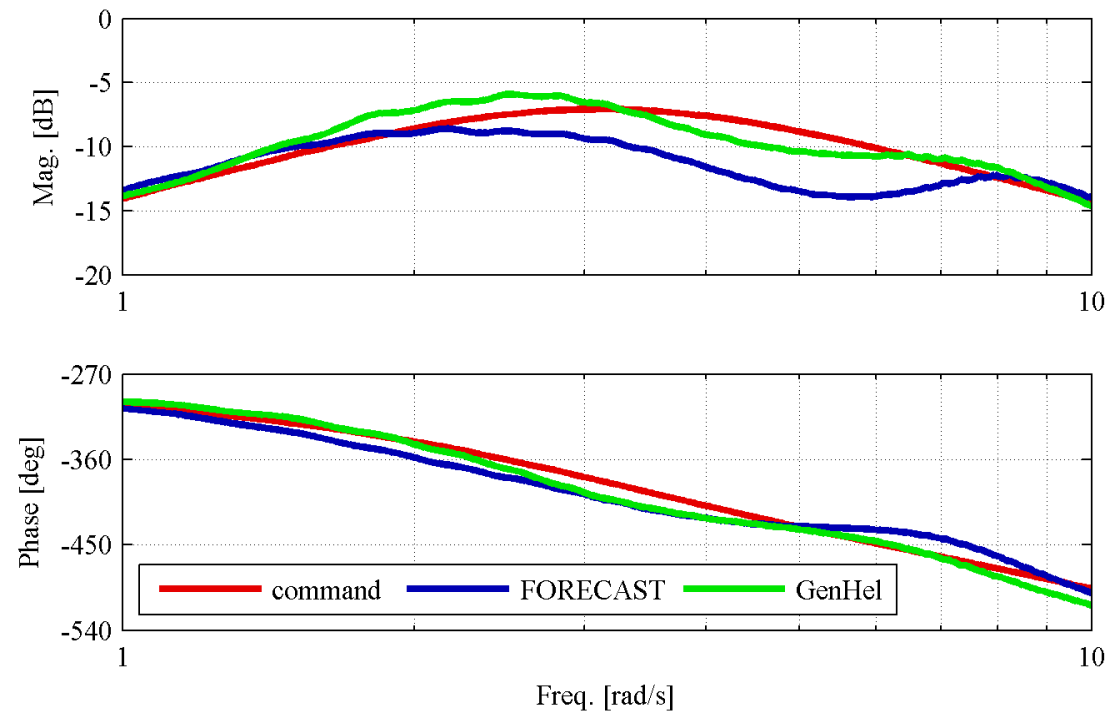

Figure 6.2: Roll rate response with FORECAST (linear) and GenHel (non-linear) inverses

Checking the other axes showed that the directional axis bare airframe responses had slight mismatches between the linear and non-linear models, however this had only a small effect on the model following cost. Instead, this difference had an effect on the gain and phase margins, and crossover and $180^{\circ}$ frequencies. 


\subsection{Simulation Results}

\subsubsection{Frequency Domain}

Table 6.3 compares the RIPTIDE frequency domain model following costs with those predicted by the CONDUIT ${ }^{\circledR}$ optimization. Recall that values less than 50 are excellent and values less than 100 are acceptable. The major cause for the difference between the CONDUIT $^{\circledR}$ (linear) and RIPTIDE (non-linear) results is due to the uncertainty of inverting and controlling a non-linear plant.

Table 6.3: Model following costs

\begin{tabular}{ccc}
\hline State & CONDUIT $^{\circledR}$ & RIPTIDE \\
\hline$p$ & 15.1 & 89.6 \\
$q$ & 24.6 & 51.7 \\
$r$ & 19.9 & 65.8 \\
$u$ & 10.4 & 9.3 \\
$v$ & 25.0 & 6.7 \\
$w$ & 7.5 & 4.7 \\
\hline
\end{tabular}

Table 6.4 compares the RIPTIDE stability margins and frequencies with those from the CONDUIT $^{\circledR}$ case. Notice that the crossover frequencies for roll and yaw differ from the CONDUIT ${ }^{\circledR}$ optimization predictions. This difference is due to the difference in bare airframe responses between the linearized FORECAST model and the non-linear GenHel model. To bring the simulation crossover frequencies closer to those of the linearized model, the controller gains would need to be adjusted. 
Table 6.4: Broken loop stability margins and crossover frequencies

\begin{tabular}{|c|c|c|c|}
\hline & & CONDUIT $^{\circledR}$ & RIPTIDE \\
\hline Roll & $\begin{array}{l}\text { GM } \\
\mathrm{PM}\end{array}$ & 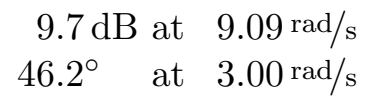 & $\begin{array}{l}10.1 \mathrm{~dB} \text { at } 9.58 \mathrm{rad} / \mathrm{s} \\
41.9^{\circ} \text { at } 2.42 \mathrm{rad} / \mathrm{s}\end{array}$ \\
\hline Pitch & $\begin{array}{l}\text { GM } \\
\mathrm{PM}\end{array}$ & $\begin{array}{ll}8.4 \mathrm{~dB} \text { at } & 6.97 \mathrm{rad} / \mathrm{s} \\
49.0^{\circ} \text { at } & 3.00 \mathrm{rad} / \mathrm{s}\end{array}$ & $\begin{array}{ll}7.8 \mathrm{~dB} \text { at } & 7.45 \mathrm{rad} / \mathrm{s} \\
54.0^{\circ} \text { at } & 2.60 \mathrm{rad} / \mathrm{s}\end{array}$ \\
\hline Yaw & $\begin{array}{l}\text { GM } \\
\text { PM }\end{array}$ & $\begin{array}{l}10.6 \mathrm{~dB} \text { at } 13.12 \mathrm{rad} / \mathrm{s} \\
54.6^{\circ} \text { at } 4.09 \mathrm{rad} / \mathrm{s}\end{array}$ & $\begin{array}{l}9.9 \mathrm{~dB} \text { at } 17.52 \mathrm{rad} / \mathrm{s} \\
53.6^{\circ} \text { at } 4.56 \mathrm{rad} / \mathrm{s}\end{array}$ \\
\hline Lon. Vel. & $\begin{array}{l}\text { GM } \\
\mathrm{PM}\end{array}$ & $\begin{array}{ll}16.1 \mathrm{~dB} \text { at } & 1.83 \mathrm{rad} / \mathrm{s} \\
83.9^{\circ} \text { at } & 0.49 \mathrm{rad} / \mathrm{s}\end{array}$ & $\begin{array}{l}15.2 \mathrm{~dB} \text { at } 1.76 \mathrm{rad} / \mathrm{s} \\
74.7^{\circ} \text { at } 0.55 \mathrm{rad} / \mathrm{s}\end{array}$ \\
\hline Lat. Vel. & $\begin{array}{l}\text { GM } \\
\mathrm{PM}\end{array}$ & $\begin{array}{l}13.0 \mathrm{~dB} \text { at } 4.08 \mathrm{rad} / \mathrm{s} \\
87.7^{\circ} \text { at } 1.08 \mathrm{rad} / \mathrm{s}\end{array}$ & $\begin{array}{l}13.4 \mathrm{~dB} \text { at } 3.66 \mathrm{rad} / \mathrm{s} \\
73.1^{\circ} \text { at } 1.20 \mathrm{rad} / \mathrm{s}\end{array}$ \\
\hline Heave & $\begin{array}{l}\text { GM } \\
\text { PM }\end{array}$ & $\begin{array}{l}16.8 \mathrm{~dB} \text { at } 13.31 \mathrm{rad} / \mathrm{s} \\
91.1^{\circ} \text { at } 1.00 \mathrm{rad} / \mathrm{s}\end{array}$ & $\begin{array}{l}15.5 \mathrm{~dB} \text { at } 12.61 \mathrm{rad} / \mathrm{s} \\
85.1^{\circ} \text { at } 0.97 \mathrm{rad} / \mathrm{s}\end{array}$ \\
\hline
\end{tabular}

Table 6.5 compares the CONDUIT ${ }^{\circledR}$ and RIPTIDE disturbance rejection bandwidths. Overall, there is little difference between the CONDUIT ${ }^{\circledR}$ predictions and the RIPTIDE values. The bandwidths for $\phi, \theta$, and $\psi$ still meet the ADS-33 requirements.

Table 6.5: Disturbance rejection bandwidth $[\mathrm{rad} / \mathrm{s}$ ]

\begin{tabular}{ccc}
\hline State & CONDUIT $^{\circledR}$ & RIPTIDE \\
\hline$\phi$ & 2.14 & 1.94 \\
$\theta$ & 0.95 & 0.93 \\
$\psi$ & 0.85 & 0.86 \\
$u$ & 0.41 & 0.41 \\
$v$ & 1.05 & 0.98 \\
$w$ & 1.01 & 0.87 \\
\hline
\end{tabular}

The following figures show the model following error of the GenHel results. The results are further away from the perfect model following of $0 \mathrm{~dB}$ and $0^{\circ}$ than the $\mathrm{CONDUIT}^{\circledR}$ figures which was expected based on the higher model following costs from RIPTIDE shown in Table 6.3. Also, notice that the $p, q$, and $r$ responses go slightly outside of the boundaries of acceptable model following. Recall that when the response leaves the boundaries, the 
pilot will notice the added dynamics which corresponds to a model following cost greater than 50 as is the case for the $p, q$, and $r$ responses.
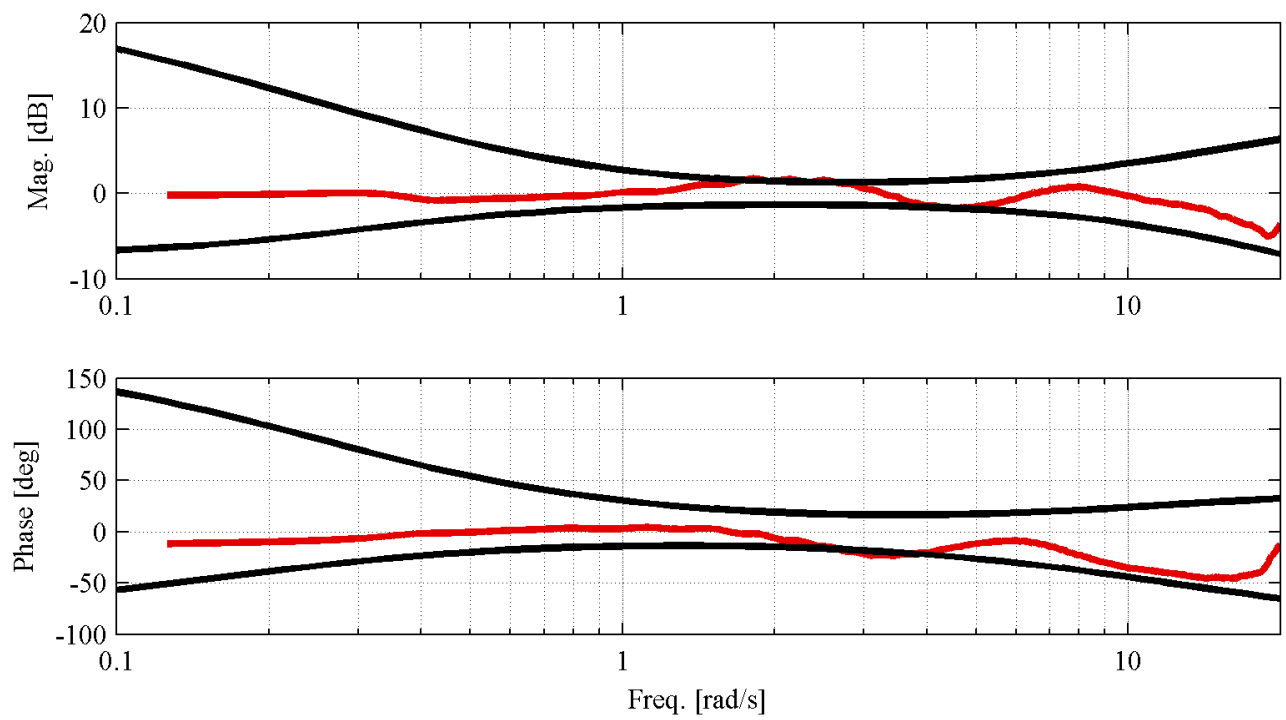

Figure 6.3: $p$ model following error
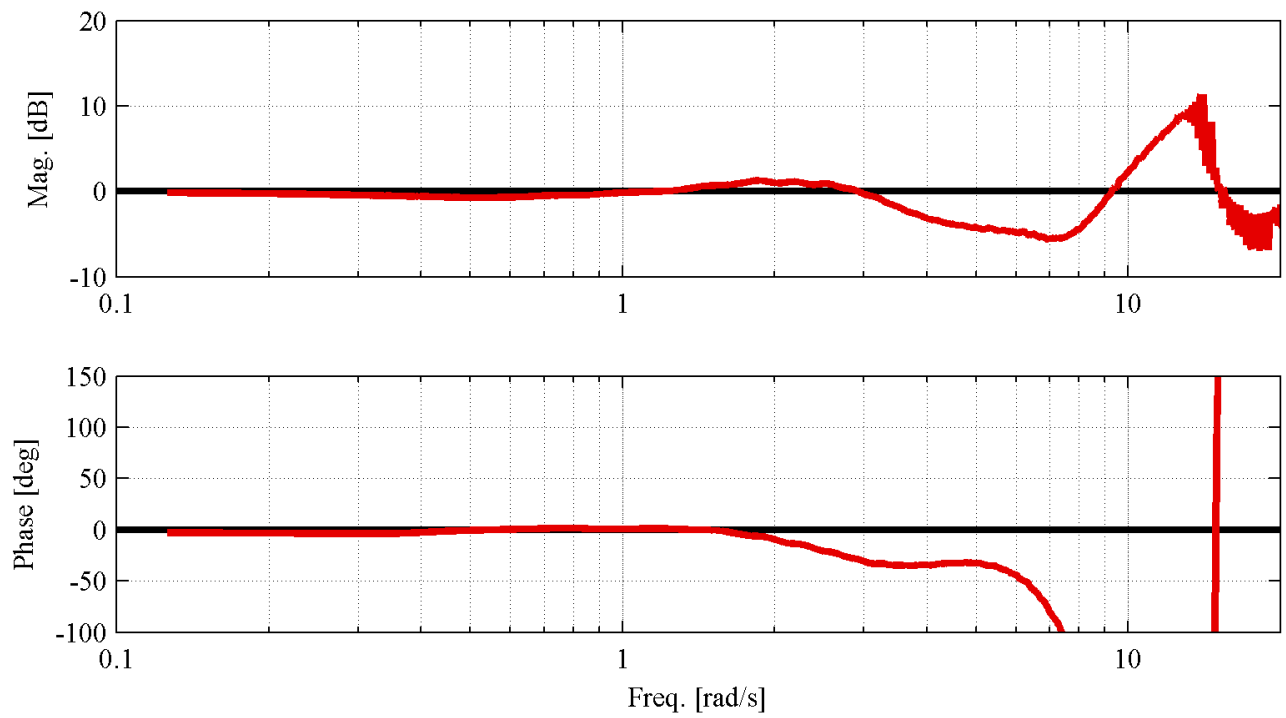

Figure 6.4: $v$ model following error 

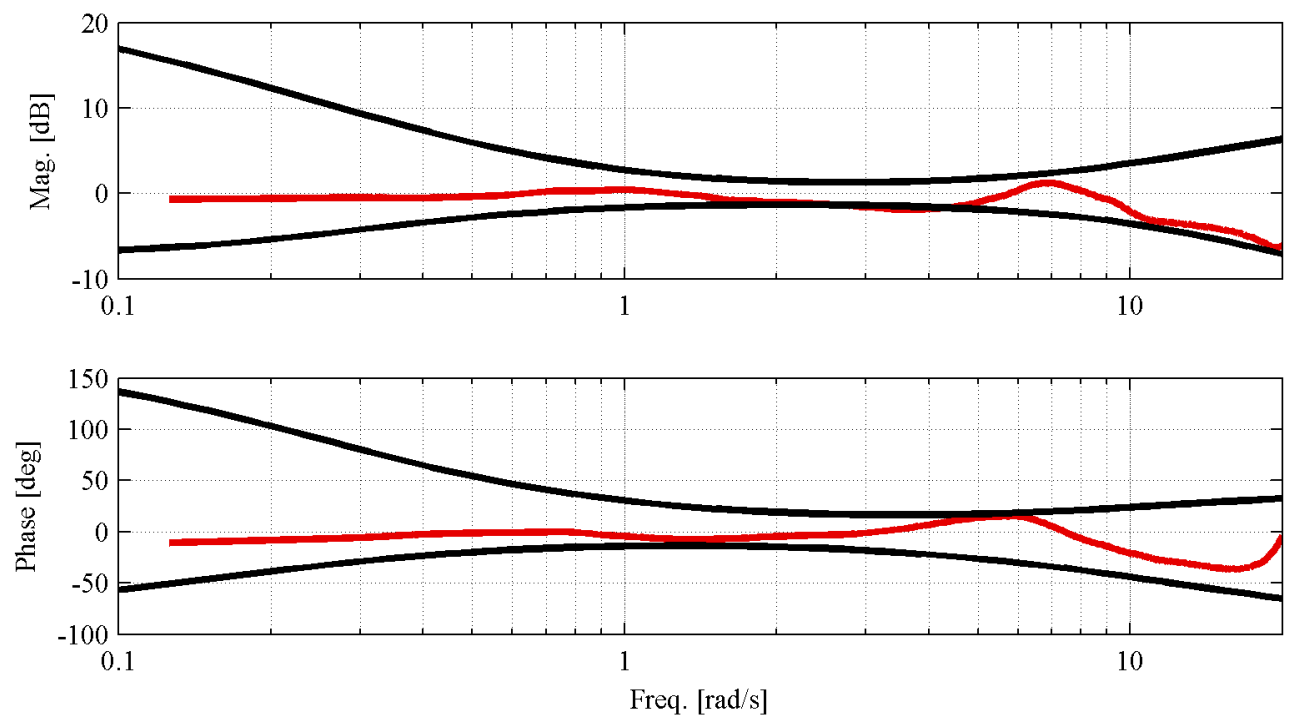

Figure 6.5: $q$ model following error
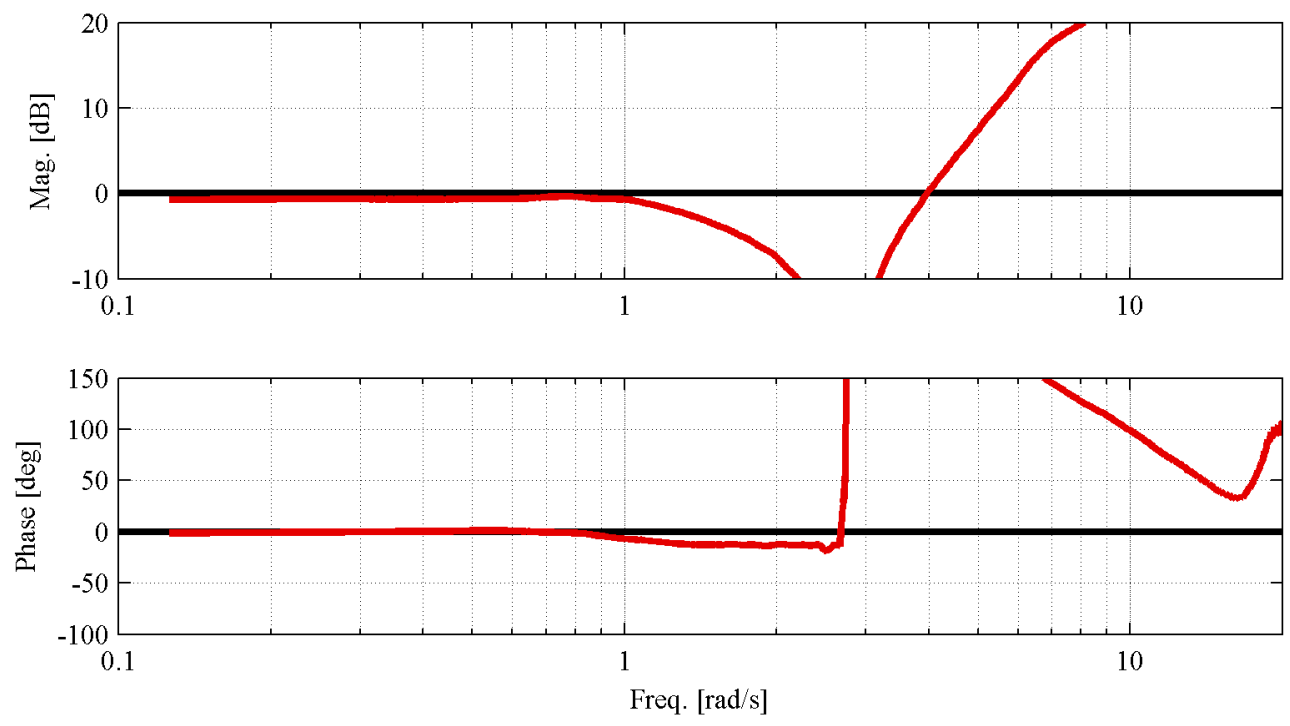

Figure 6.6: $u$ model following error 

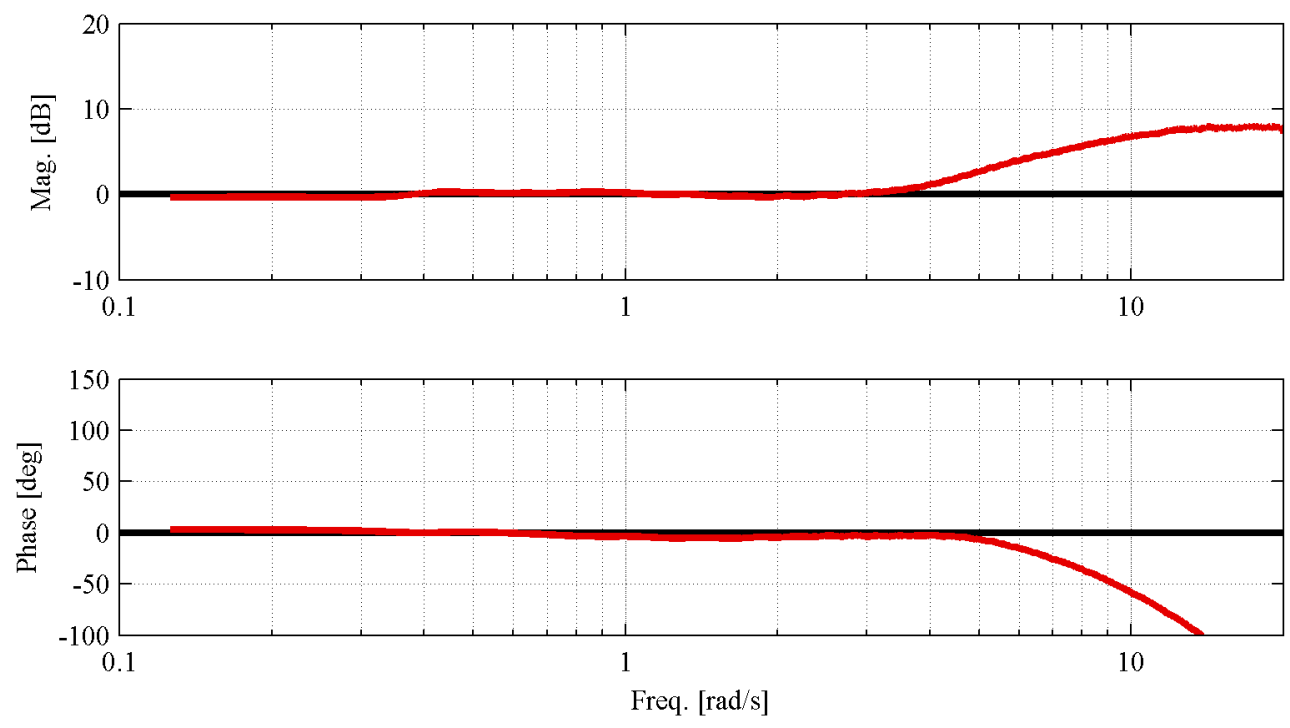

Figure 6.7: $w$ model following error
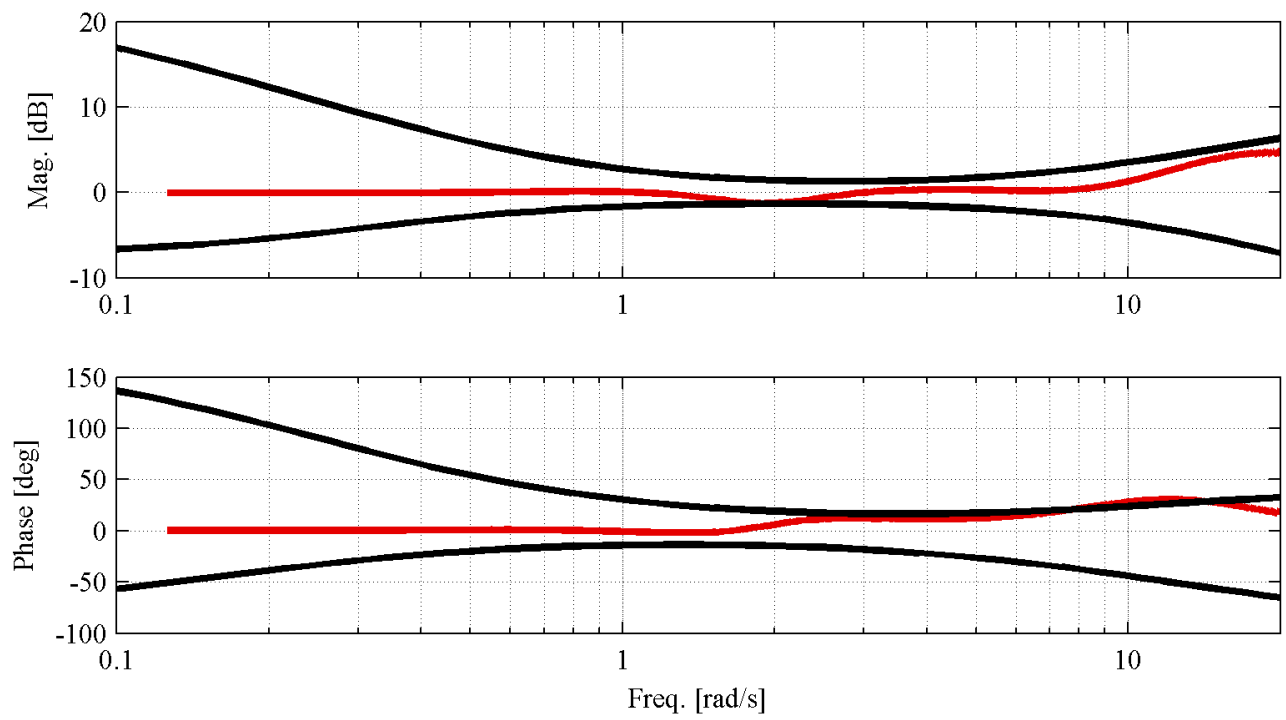

Figure 6.8: $r$ model following error

\subsubsection{Time Domain Analysis}

Table 6.6 compares the time domain RMS costs from CONDUIT ${ }^{\circledR}$ and RIPTDE. The costs for all axes have increased indicating slightly degraded on-axis following and/or more 
uncommanded off-axis responses. The collective cost is higher than the suggested value of 1 which is due to the fact that there are noticeable off-axis responses in most axes but it is still less than 2 which is acceptable.

Table 6.6: Time domain model following costs

\begin{tabular}{lll}
\hline Axis & CONDUIT & \\
& & RIPTIDE \\
\hline lateral & 0.25 & 0.34 \\
longitudinal & 0.55 & 0.88 \\
collective & 0.95 & 1.60 \\
pedal & 0.32 & 0.58 \\
\hline
\end{tabular}

The following figures plot the commanded and measured response of the system in the time domain. The same inputs used in Chapter 4 were used to generate these plots for accurate comparisons. As Table 6.6 indicates, the on-axis model following has degraded and/or the off-axis responses have increased in magnitude. Most of the large offaxis responses are those which cross-feed gains were not able to reduce in the CONDUIT ${ }^{\circledR}$ optimization. Also, the decoupler was based on the FORECAST model which has a slightly different bare airframe response from GenHel. To determine a decoupler for the GenHel model, the control matrix (B-matrix) would have to bee identified from GenHel. 

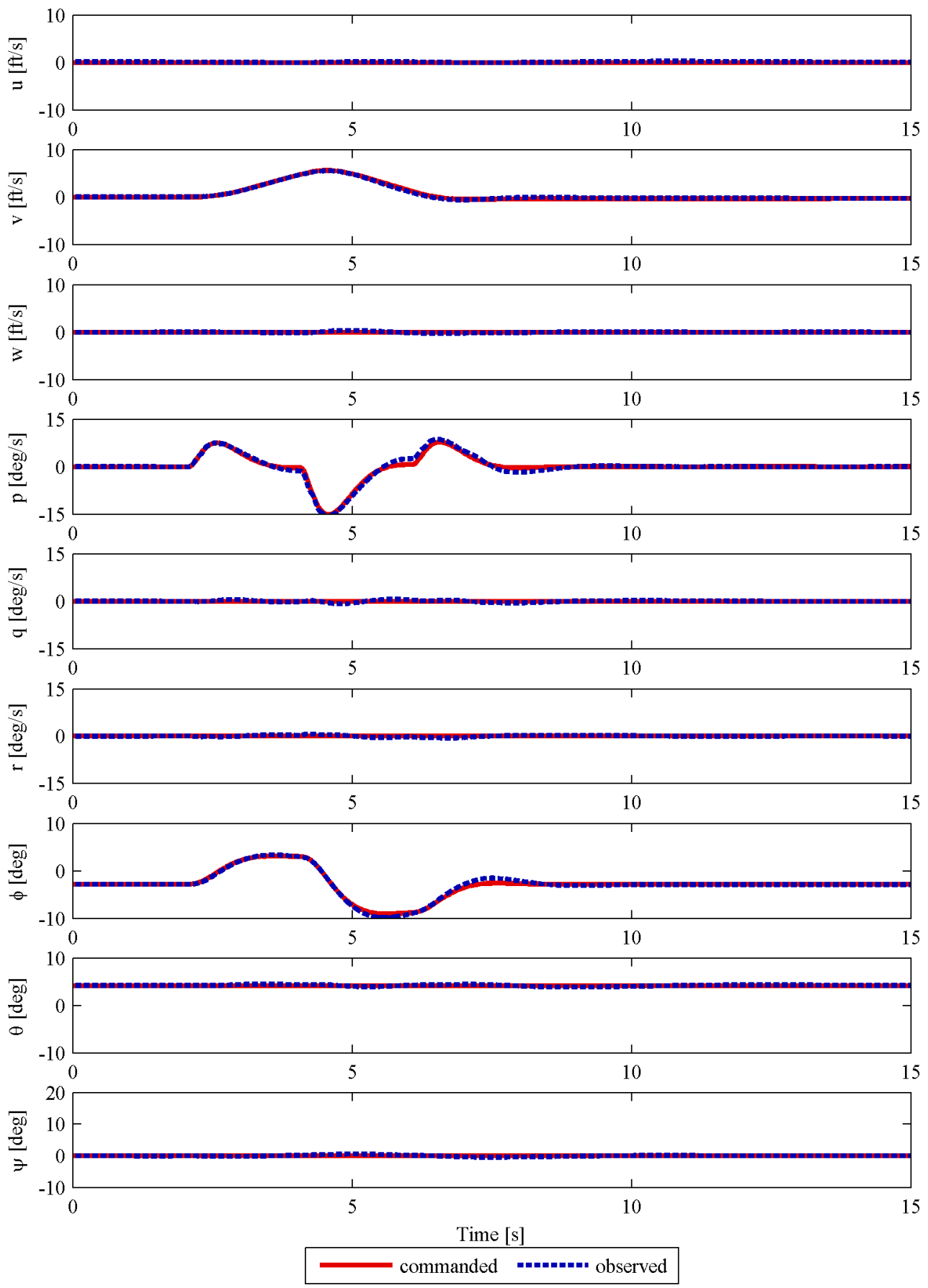

Figure 6.9: Lateral axis doublet response 

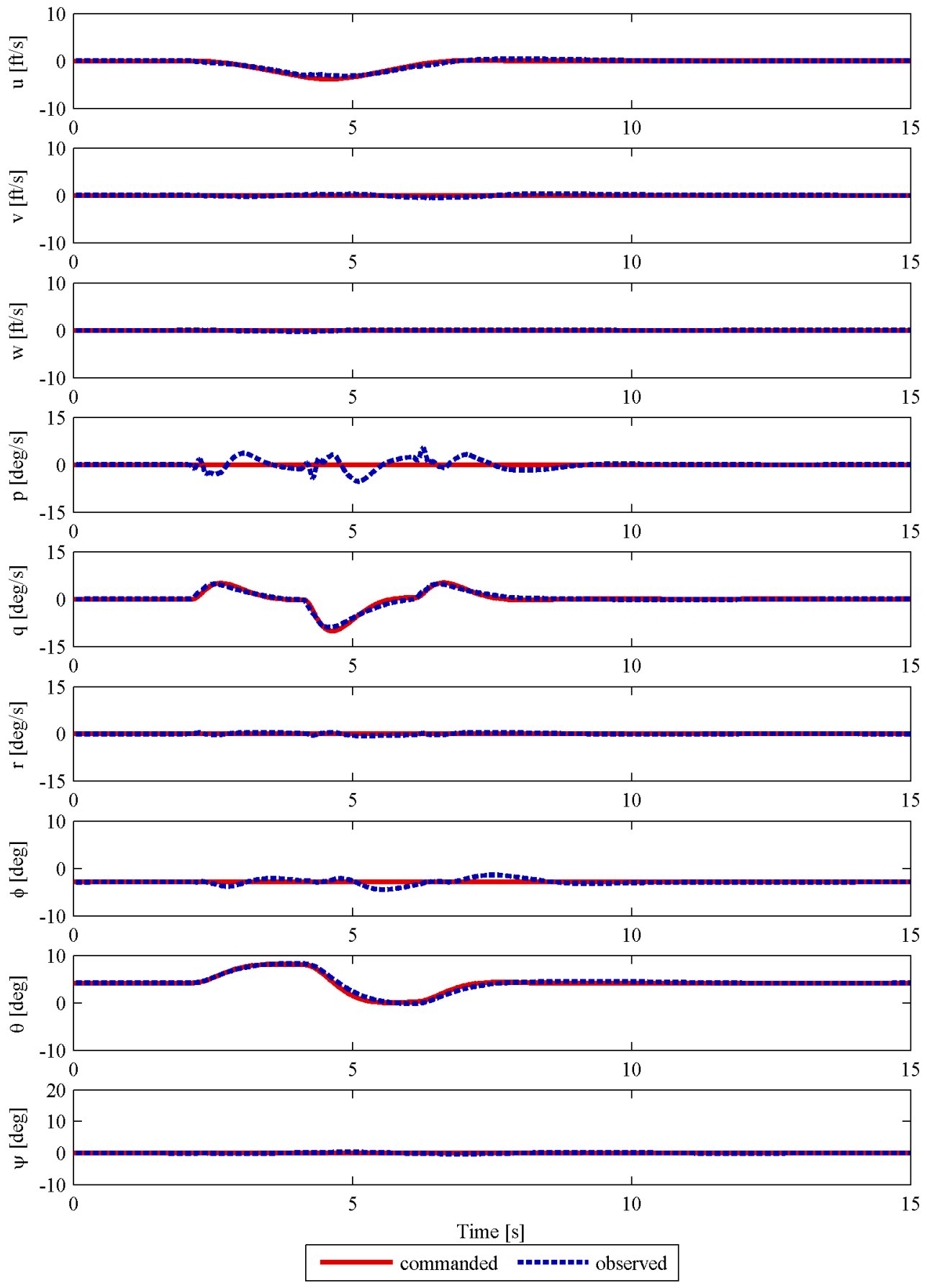

Figure 6.10: Longitudinal axis doublet response 

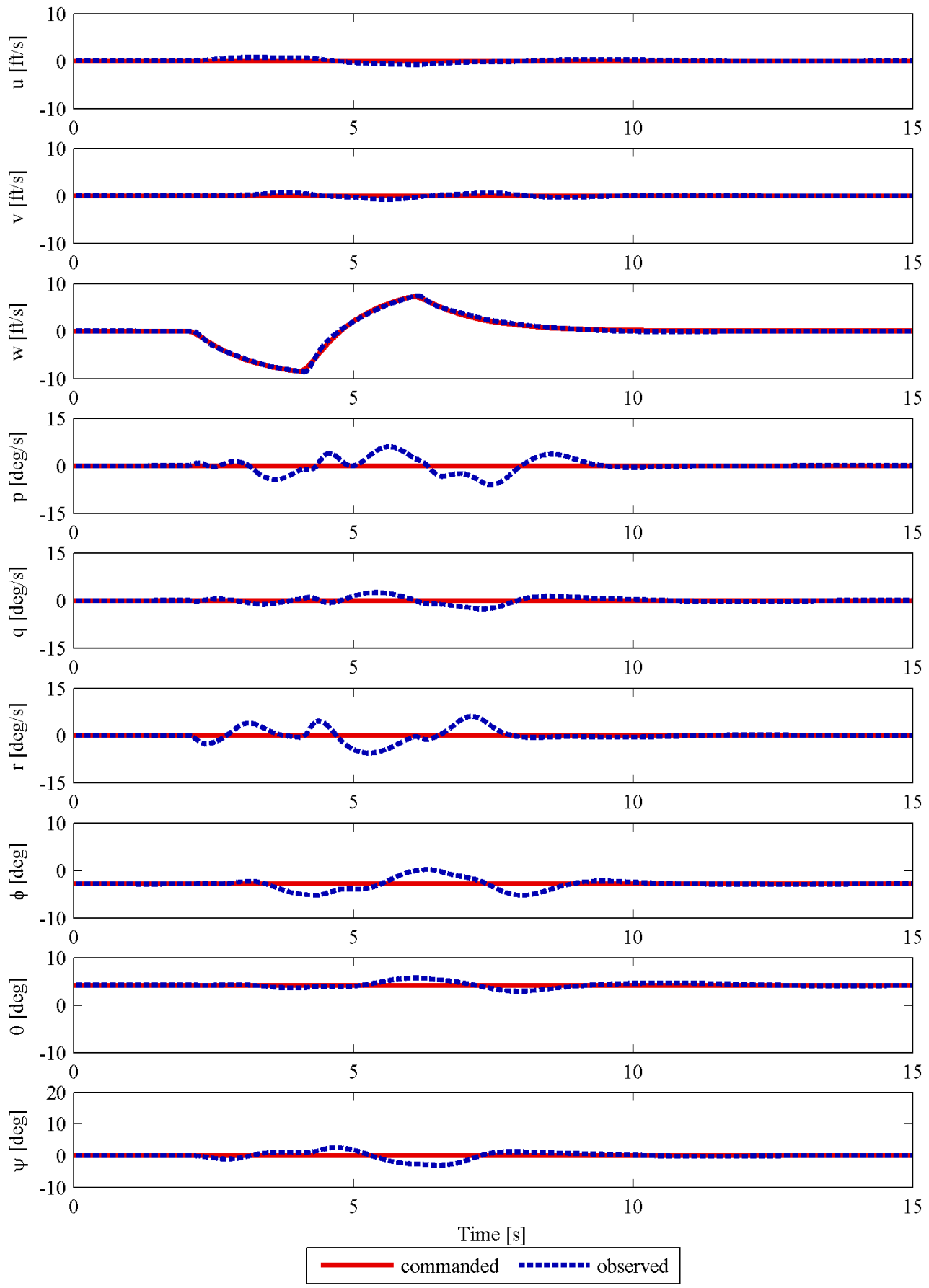

Figure 6.11: Collective axis doublet response 

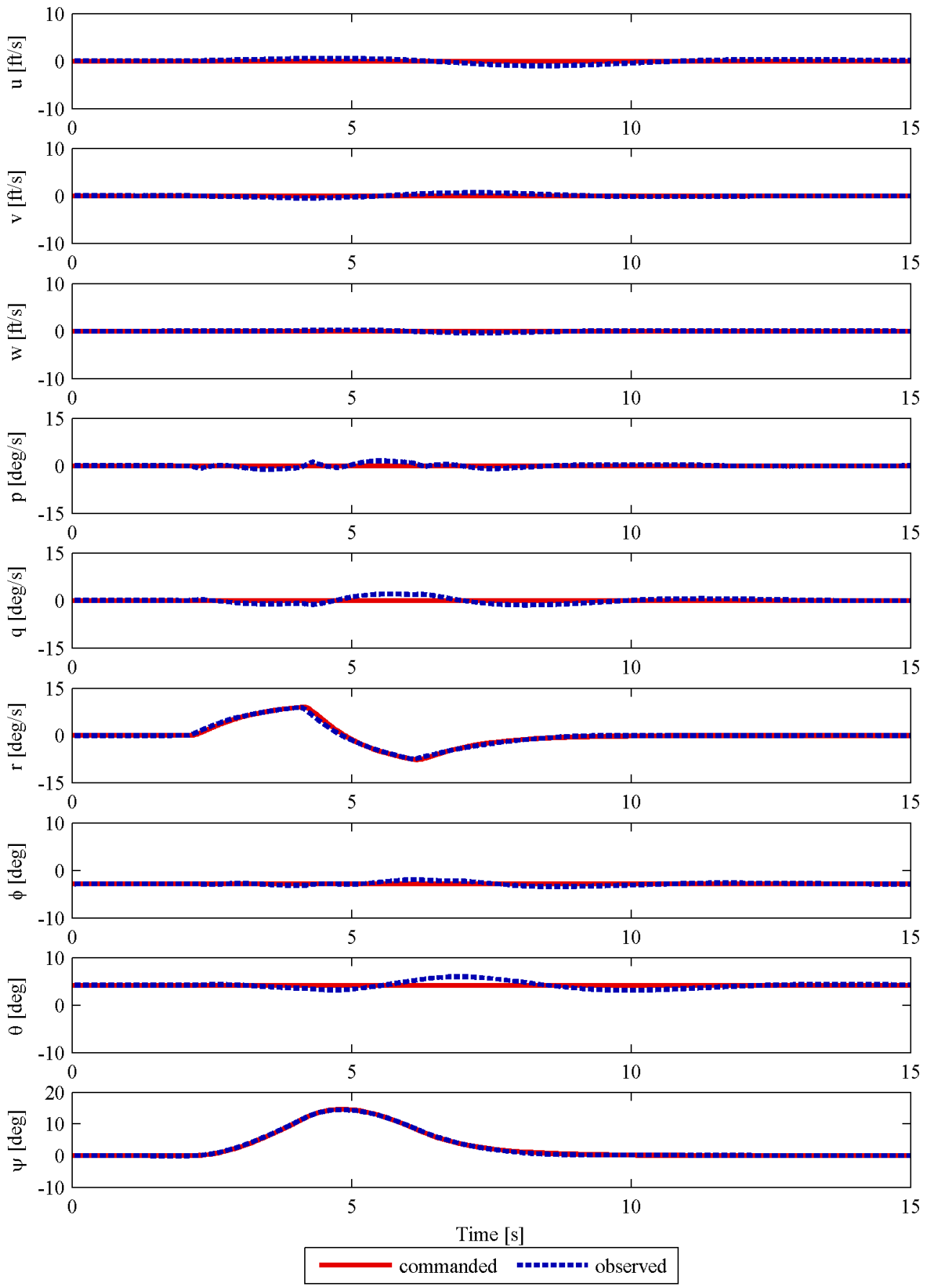

Figure 6.12: Pedal axis doublet response 


\section{Chapter 7}

\section{Hardware-in-the-Loop Simulation}

\subsection{RASCAL Development Facility}

The RASCAL Development Facility (DF) is a hardware-in-the-loop simulator used for a final check of the control system before flight testing. The DF has the same flight control computer, cockpit display unit, research flight control system cockpit panel, and evaluation pilot inceptors found on the RASCAL aircraft. The DF is used both to ensure the control system is properly implemented and to familiarize the pilots with the control system. For this research it will also stand in for RASCAL as the flight test vehicle for piloted evaluations.

\subsection{Control System Modifications}

The following sections describe the modifications necessary to make to control laws compatible with the DF.

\subsubsection{Discrete Time}

First, the control laws were be converted from a continuous-time system to a discrete-time system. To accomplish this conversion, the bilinear transform (Tustin's method) was used. 
The bilinear transform approximates $s$ as:

$$
s \approx \frac{2}{T} \frac{z-1}{z+1}
$$

where $T$ is the sample time and $z$ is the discrete variable. This transformation was used for integrators and derivatives as well as the canonical transfer functions in the command model, the transfer functions used to approximate the commanded velocity, and the lead compensators used as derivatives for the attitude commands from velocity.

While this transformation worked well for integrators and differentiators, it did not work well for filters. Applying Equation 7.1 to a filter caused frequency distortion or warping to occur such that the observed cutoff frequency was not the desired cutoff frequency [31]. To account for this, the desired cutoff frequency $\omega_{c}$ was replaced with a pre-warped cutoff frequency $a$ given by:

$$
a=\frac{2}{T} \tan \left(\frac{\omega_{c} T}{2}\right)
$$

and along with Equation 7.1, substituted into the filter equation. For example, a prewarped, second order Butterworth filter would be given by:

$$
H_{p}(z)=\frac{a^{2}}{s^{2}+\sqrt{2} a s+a^{2}}
$$

where $H_{p}$ is the pre-warped filter with a cutoff frequency at the desired $\omega_{c}$.

Once the appropriate continuous elements were converted to discrete, the system was evaluated with CONDUIT ${ }^{\circledR}$ and RIPTIDE using the optimized design parameters from the continuous system. This test ensured that there were no problems due to the conversion to a discrete system.

\subsubsection{GenHel Interface}

The DF uses GenHel as the math model but it is set up so that the model includes actuators, control mixers, and the sensors and filters. The inputs to GenHel are the servo commands 
while the outputs are the measured and filtered body states; the rotor flapping angles are not currently measured on RASCAL so the model in the DF does not output them. Additionally, the new model uses different units than the control laws were designed with as shown in Table 7.1. Rather than converting the control laws to work with the math model units, the signals are converted as they enter or leave the control laws.

Table 7.1: Control Law and Math Model Units

\begin{tabular}{lcc}
\hline signals & CLAWS & Model \\
\hline stick inputs & in & $\%, \mathrm{in}^{\mathrm{a}}$ \\
servo commands & in & in \\
attitudes & $\mathrm{rad}$ & $\mathrm{deg}$ \\
attitude rates & $\mathrm{rad} / \mathrm{s}$ & $\mathrm{deg} / \mathrm{s}$ \\
velocities & $\mathrm{ft} / \mathrm{s}$ & $\mathrm{knot}$ \\
\hline
\end{tabular}

${ }^{a}$ the collective is in inches while the cyclic and pedals are in \%

\subsubsection{Frequency Sweeps}

The automated sweeps used to determine the end-to-end, broken loop, and disturbance responses are not included as a separate block as was the case in RIPTIDE. Instead, the sweep is generated by the flight control computer and fed into the block diagram via all in ports associated with sweeps. Gains after the in ports are used to control which axis is being swept and to scale the sweep to the appropriate magnitude. Figure 7.1 shows the architecture used to sweep an axis. The sweep parameters and scaling gains used are the same as those used in RIPTIDE (Table 6.1 and Table 6.2).

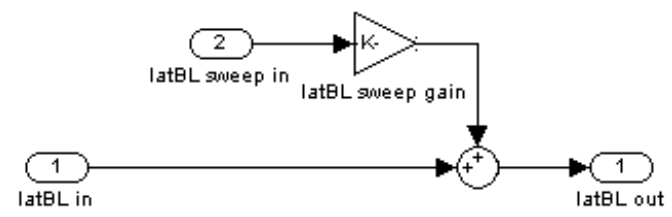

Figure 7.1: Frequency sweep input architecture 


\subsubsection{Control Stick Deadbands}

Since the cyclic, collective and pedals are all real hardware, there is error in the positions they report. This is problematic as even small errors (on the order of $0.1 \%$ ) can cause a velocity command to build up. This commanded velocity will not match the actual velocity preventing the system from properly engaging. To prevent this error, deadbands are placed on the cyclic and pedal signals with a bandwidth of $\pm 2.5 \%$. Values that fall within the deadband are output as zero while values outside the band are offset by the bandwidth to prevent discontinuities. The collective does not have a deadband since there is no centered position.

\subsubsection{Trim, Initial Heading, and Servo Commands at System Engage}

In RIPTIDE, the trim attitudes and initial heading were known beforehand which allowed these values to be hard coded into the control system. In flight, that will not always be the case. Wind could change the trim attitude slightly and the initial heading could be different every time the system is to be used. To accommodate the lack of a priori knowledge of trim attitudes and heading angle, the values at the moment the system is activated are used.

\subsubsection{Inverse Plant Model}

As in the desktop simulation, the bare airframe response of the DF simulation did not match the bare airframe of the linearized model leading to high model following costs. New inverse plant models and equivalent time delays were calculated from bare airframe data of the simulation and implemented which improved the model following costs.

\subsection{Simulation Results}

\subsubsection{Frequency Domain Results}

Table 7.2 compares the model following costs from the development facility with those from CONDUIT $^{\circledR}$. All costs are acceptable however, the $p$ cost just barely acceptable. This 
high $p$ model following cost is due to mismatch between the second order inverse plant fit shown in Figure 7.2. Notice below $6 \mathrm{rad} / \mathrm{s}$ that second order fit does not capture the bare airframe dynamics. A higher order inverse might better capture the dynamics, however higher derivatives of $p$ would be needed from the command model which is not practical.

Table 7.2: Model following costs

\begin{tabular}{ccr}
\hline State & CONDUIT $^{\circledR}$ & \multicolumn{1}{c}{ DF } \\
\hline$p$ & 15.1 & 97.0 \\
$q$ & 24.6 & 31.5 \\
$r$ & 19.9 & 80.8 \\
$u$ & 10.4 & 9.2 \\
$v$ & 25.0 & 6.3 \\
$w$ & 7.5 & 6.8 \\
\hline
\end{tabular}
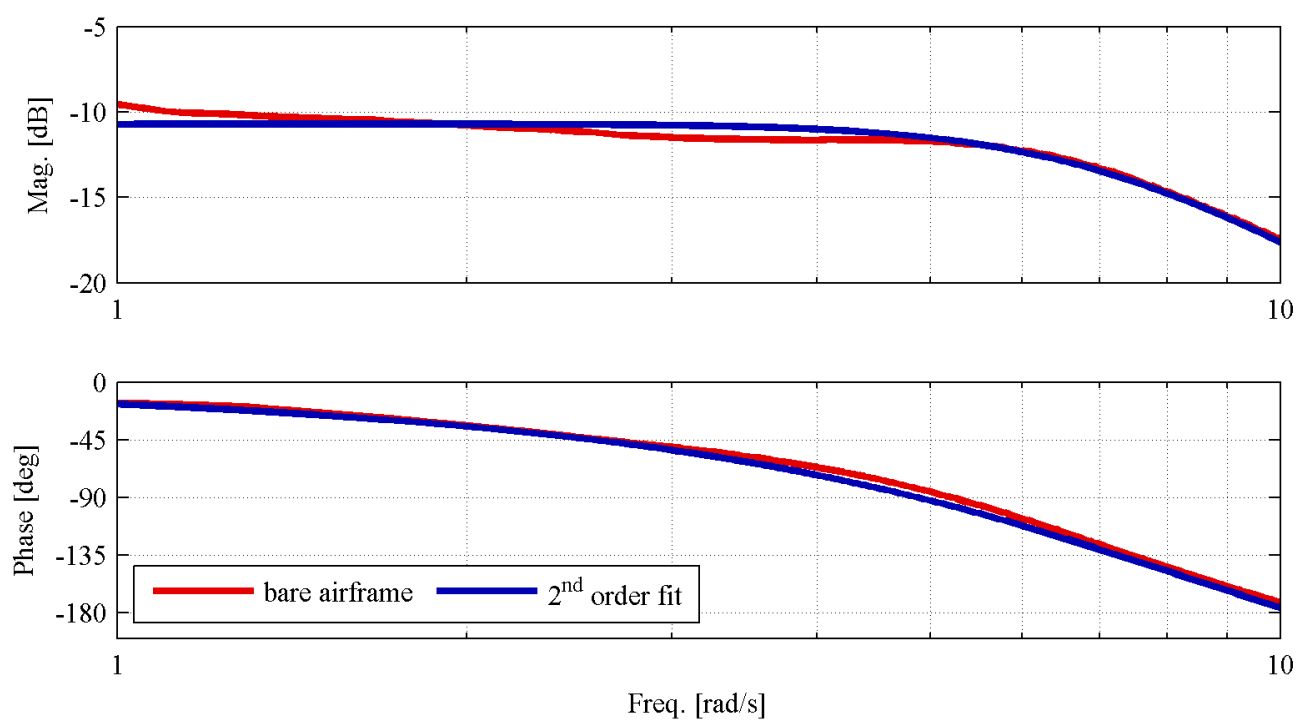

Figure 7.2: $p$ inverse plant transfer function fit

Due to the mismatch in bare airframe response between the FORECAST model and GenHel used in the DF, the crossover frequencies and stability margins did not match the CONDUIT $^{\circledR}$ predictions. To improve the predictions from CONDUIT $^{\circledR}$, the optimization was repeated using the frequency response versions of the crossover frequency, minimum crossover frequency, and stability margins specifications which use the identified bare air- 
frame response instead of the state space model to calculate the parameters. Re-optimizing the system with these specifications maintained the model following and disturbance rejection performance while improving the broken loop performance. Table 7.3 compares the stability margins from the DF with those from CONDUIT ${ }^{\circledR}$. These values show good agreement with the predictions using the frequency response specifications.

Table 7.3: Broken loop stability margins and crossover frequencies

\begin{tabular}{|c|c|c|c|}
\hline \multirow{3}{*}{ Roll } & \multirow{3}{*}{$\begin{array}{l}\text { GM } \\
\mathrm{PM}\end{array}$} & CONDUIT $^{\circledR}$ & $\mathrm{DF}$ \\
\hline & & $9.7 \mathrm{~dB}$ at $9.14 \mathrm{rad} / \mathrm{s}$ & $7.0 \mathrm{~dB}$ at 9.14 \\
\hline & & $46.2^{\circ}$ at $3.00 \mathrm{rad} / \mathrm{s}$ & at $2.93 \mathrm{rad} / \mathrm{s}$ \\
\hline \multirow{2}{*}{ Pitch } & GM & $8.4 \mathrm{~dB}$ at $6.97 \mathrm{rad} / \mathrm{s}$ & $6.4 \mathrm{~dB}$ at $7.68 \mathrm{rad} / \mathrm{s}$ \\
\hline & $\mathrm{PM}$ & $49.0^{\circ}$ at $3.00 \mathrm{rad} / \mathrm{s}$ & at $3.42 \mathrm{rad} / \mathrm{s}$ \\
\hline \multirow{2}{*}{ Yaw } & GM & $10.6 \mathrm{~dB}$ at $13.12 \mathrm{rad} / \mathrm{s}$ & $12.3 \mathrm{~dB}$ at $15.47 \mathrm{rad} / \mathrm{s}$ \\
\hline & $\mathrm{PM}$ & $54.6^{\circ}$ at $4.09 \mathrm{rad} / \mathrm{s}$ & at $3.68 \mathrm{rad} / \mathrm{s}$ \\
\hline \multirow{2}{*}{ Lon. Vel. } & GM & 3 at 1.8 & $12.4 \mathrm{~dB}$ at 1.77 \\
\hline & PM & at $0.49^{\mathrm{r}}$ & $50.35^{\circ}$ at $0.84 \mathrm{rad} / \mathrm{s}$ \\
\hline \multirow{2}{*}{ Lat. Vel. } & GM & $13.0 \mathrm{~dB}$ at $4.08 \mathrm{rad} / \mathrm{s}$ & $13.7 \mathrm{~dB}$ at $3.87 \mathrm{rad} / \mathrm{s}$ \\
\hline & PM & $87.7^{\circ}$ at $1.08 \mathrm{rad} / \mathrm{s}$ & at $1.01 \mathrm{rad} / \mathrm{s}$ \\
\hline \multirow{2}{*}{ Heave } & GM & $16.8 \mathrm{~dB}$ at $13.31 \mathrm{rad} / \mathrm{s}$ & $15.5 \mathrm{~dB}$ at $11.34 \mathrm{rad} / \mathrm{s}$ \\
\hline & $\mathrm{PM}$ & at $1.00 \mathrm{rad} / \mathrm{s}$ & at $0.98 \mathrm{rad} / \mathrm{s}$ \\
\hline
\end{tabular}

Table 7.4 compares the disturbance rejection bandwidths from the DF with those of CONDUIT ${ }^{\circledR}$. The DF bandwidths are all close to the CONDUIT ${ }^{\circledR}$ values and the $p, q$, and $r$ bandwidths meet the ADS-33 requirements.

Table 7.4: Disturbance rejection bandwidth $[\mathrm{rad} / \mathrm{s}]$

\begin{tabular}{ccc}
\hline State & CONDUIT $^{\circledR}$ & DF \\
\hline$\phi$ & 2.14 & 1.92 \\
$\theta$ & 0.95 & 0.91 \\
$\psi$ & 0.85 & 0.81 \\
$u$ & 0.41 & 0.43 \\
$v$ & 1.05 & 1.01 \\
$w$ & 1.01 & 1.12 \\
\hline
\end{tabular}


The following figures show the model following error of the DF results. Like the results of the previous section, these results slightly exceed the mismatch boundaries. Notice that near $2 \mathrm{rad} / \mathrm{s}$ and $4 \mathrm{rad} / \mathrm{s}$, the error in $p$ (Figure 7.3 leaves the bounds. This corresponds to the poor inverse fit at lower frequencies shown in Figure 7.2 and the model following cost greater than 50. The $r$ response (Figure 7.8) also leaves the boundaries near $4 \mathrm{rad} / \mathrm{s}$
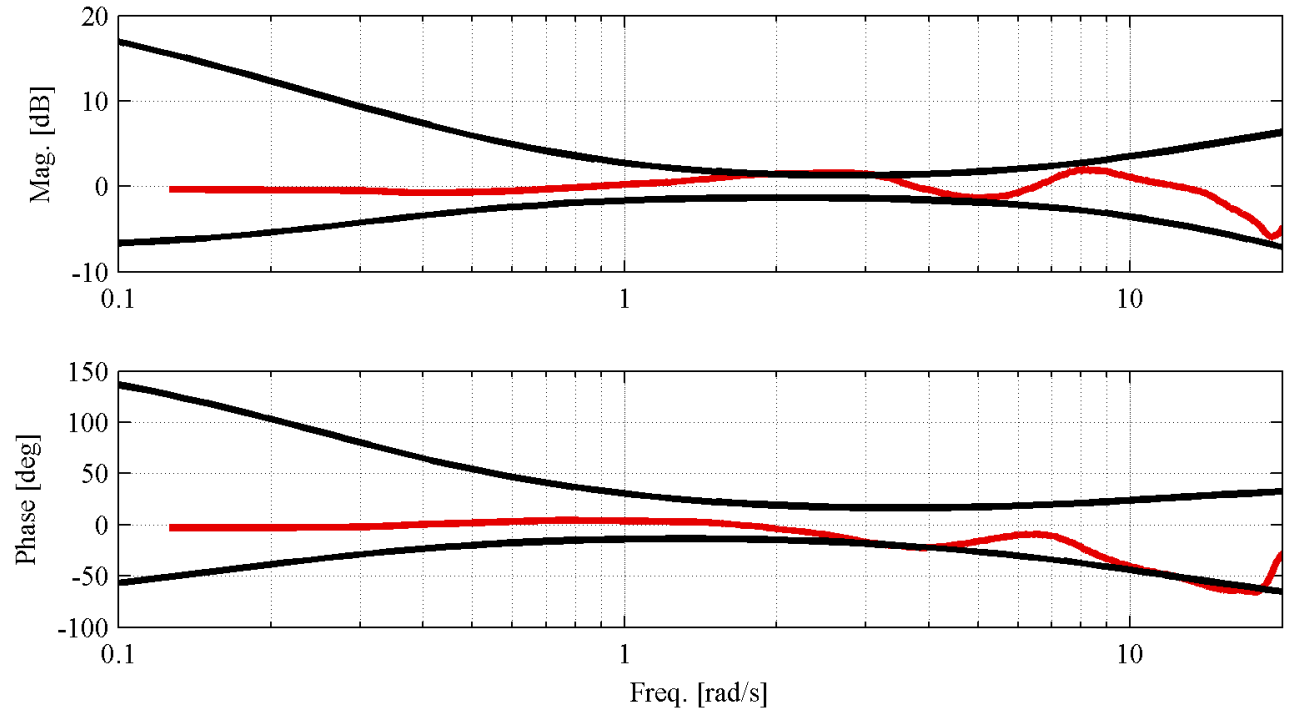

Figure 7.3: $p$ model following error 

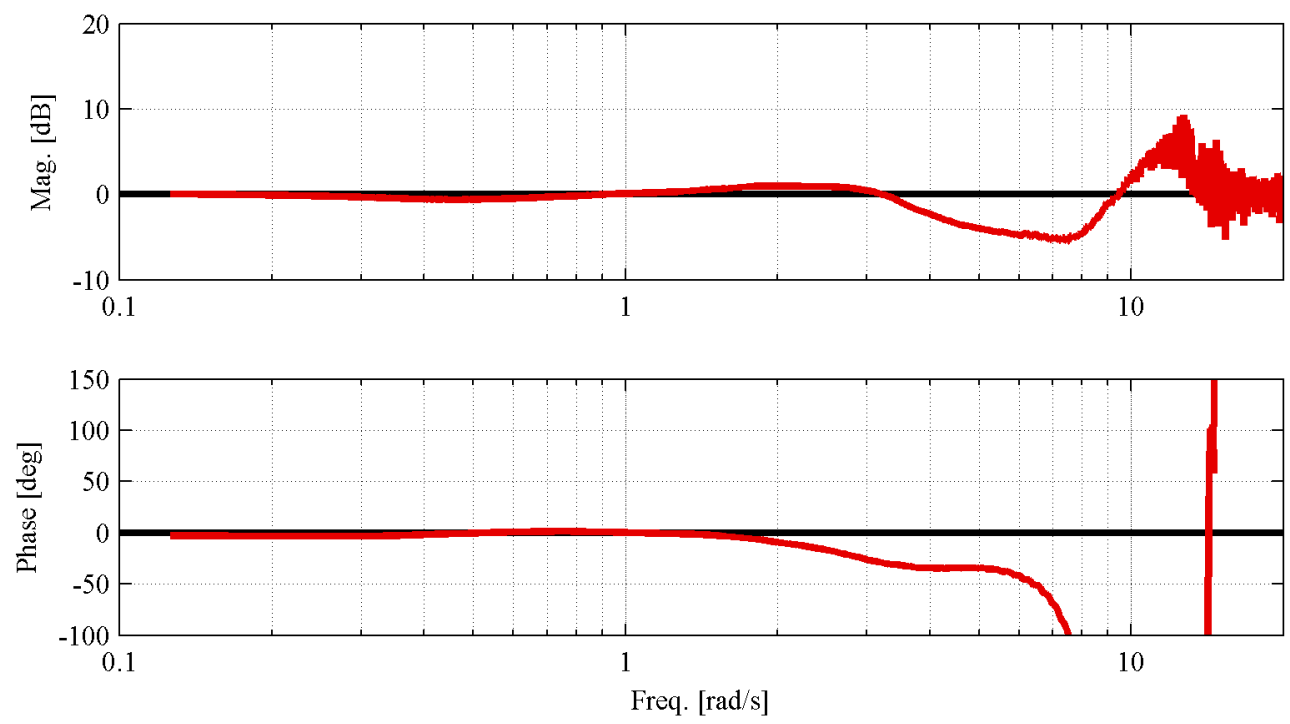

Figure 7.4: $v$ model following error
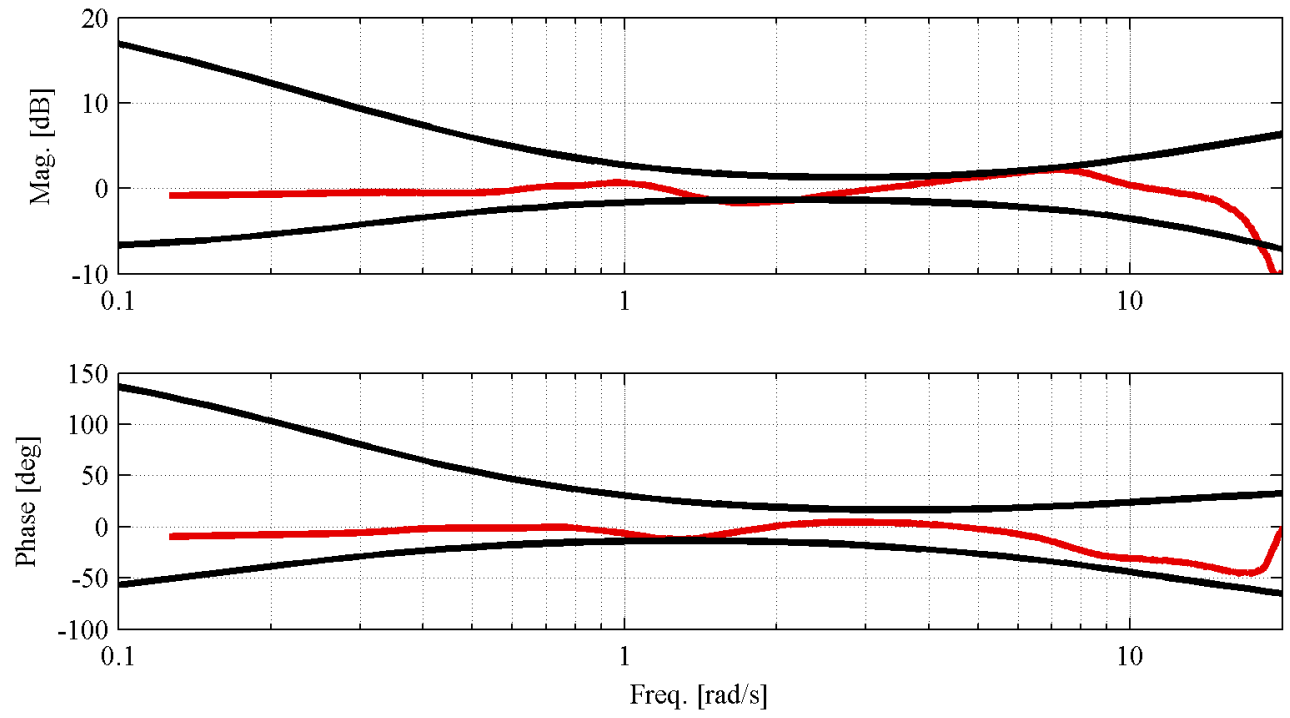

Figure 7.5: $q$ model following error 

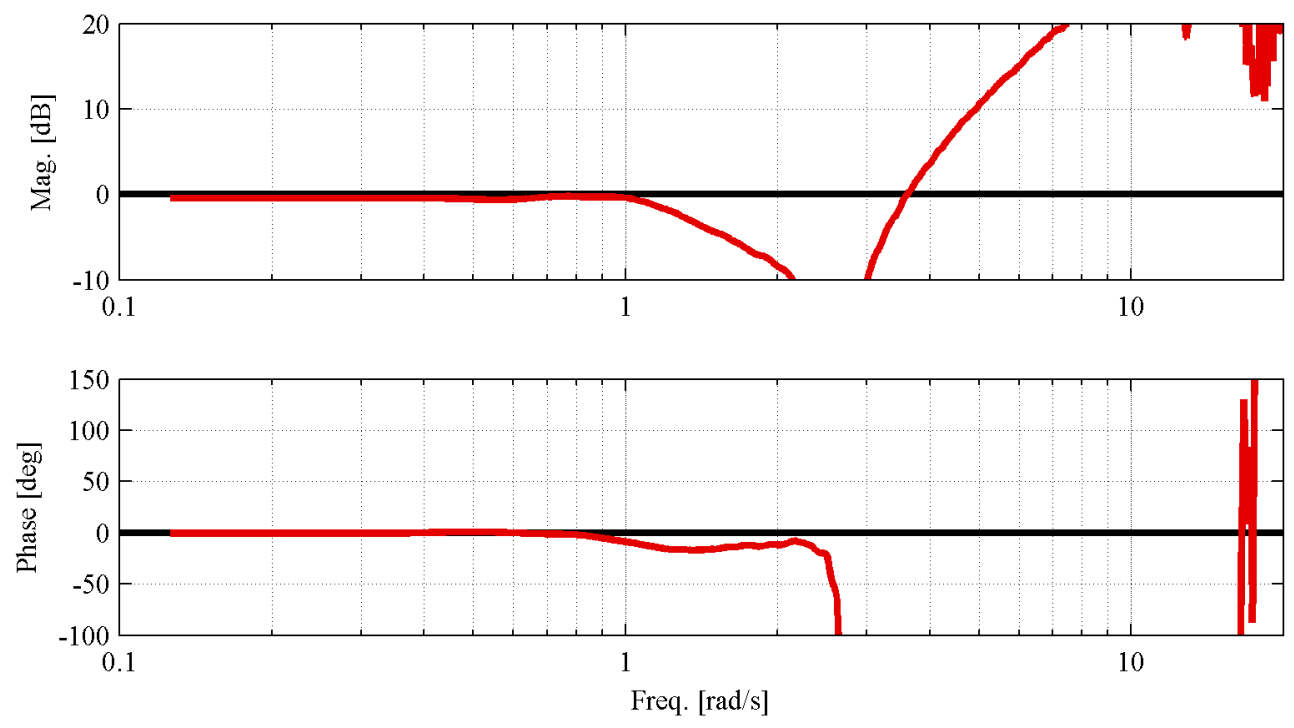

Figure 7.6: $u$ model following error
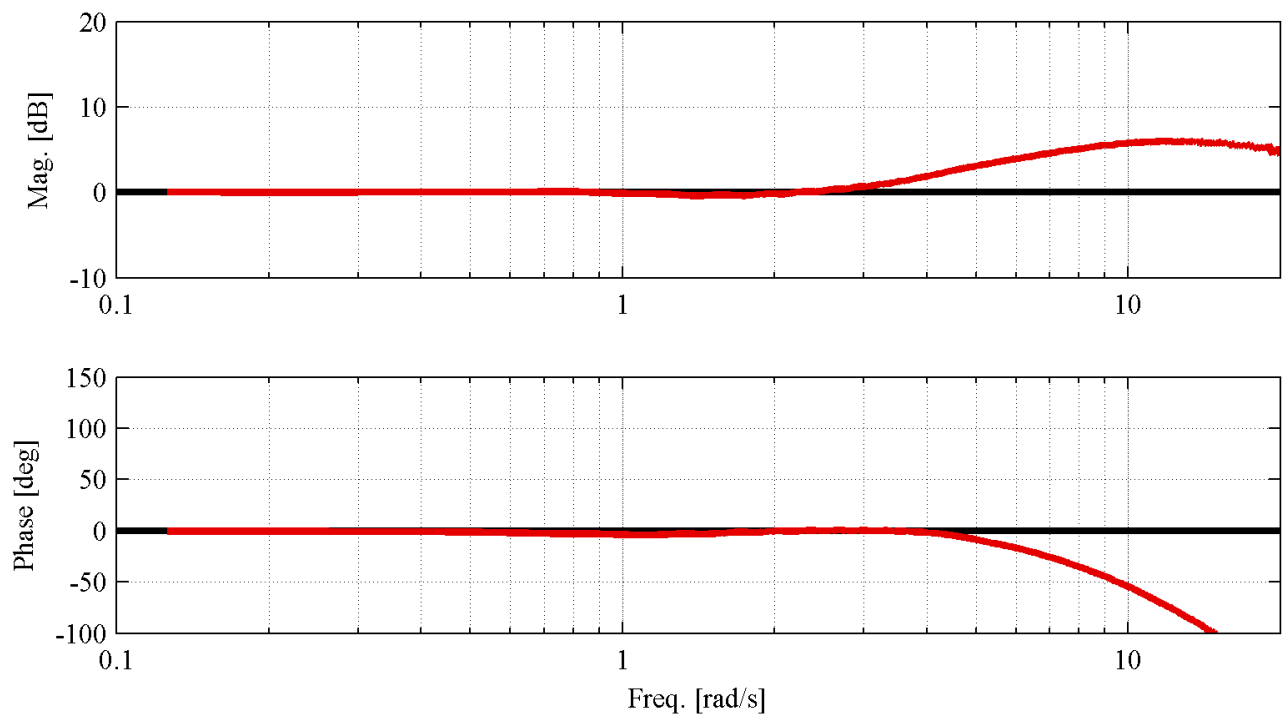

Figure 7.7: $w$ model following error 

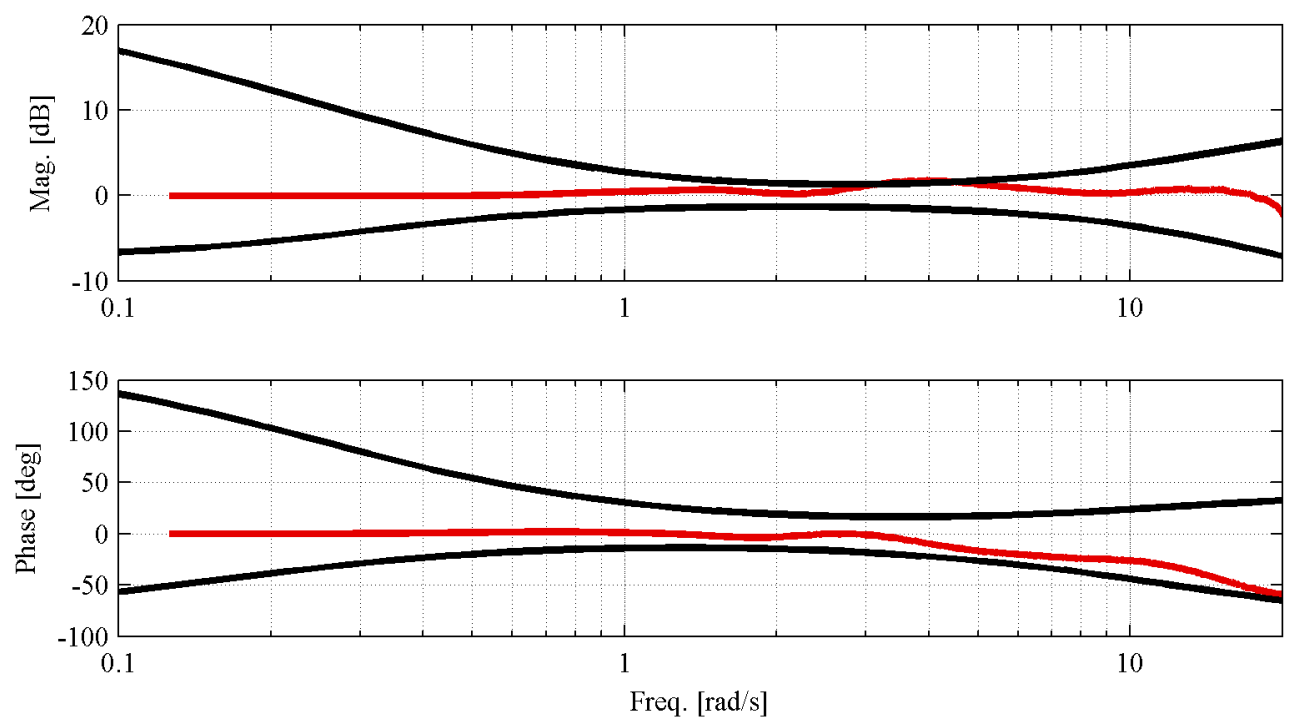

Figure 7.8: $r$ model following error

\subsubsection{Piloted Evaluation}

After the system was validated, the control system was flown in the DF by three pilots: Munroe Dearing, Terry Turpin, and Lieutenant Colonel Steve Braddom. Mr. Dearing and Mr. Turpin simply flew the control laws around exciting all the control axes. Both pilots commented that the roll axis was very sensitive but the pitch axis was nice. Mr. Dearing mentioned that he experienced overshoot in the yaw axis while Mr. Turpin felt that the yaw axis was good, specifically mentioning that he noticed little overshoot. Overall, both felt that the system was stable and behaved generally as they expected.

In addition to flying the control system around as Mr. Dearing and Mr. Turpin did, LTC. Braddom also performed mission task elements (MTEs) from ADS-33 [14]. While exciting the control axes, LTC. Braddom agreed with Mr. Dearing and Mr. Turpin in that the system was stable and behaved as expected. Additionally, LTC. Braddom flew the hover, hovering turn, and lateral reposition MTEs. For specific information on these mission task elements, see the appendix. Time histories of each of these MTEs is shown in Figures 7.9- 
7.11 and the RMS costs are shown given in Table 7.5. Overall, the performance is seen to be very good with all RMS costs below 2 .

\section{Hover MTE}

The hover MTE consists of approaching a target hover point at a $45^{\circ}$ angle and at speeds below 10 knots. The pilot decelerates to a hover over the indicated point and aligns a sight with a target board and holds hover for 30 seconds. Table 7.5 shows that the RMS cost for the hover MTE was less than 1 indicating excellent time domain model following. This can also be seen in Figure 7.9. Overall, the model following for this maneuver is good however, there is noticeable error in $\theta$ and $u$, and there is off-axis activity in $r$, though it is relatively small.

\section{Hovering Turn MTE}

For the hovering turn MTE, the pilot starts in a hover with a sight and target board (same as hover) lined up. The pilot turns $180^{\circ}$ to line up with another sight and target board. Figure 7.10 shows a time history record for the hovering turn. This figure also shows good model following overall with some error in the longitudinal response.

\section{Lateral Reposition}

The lateral reposition maneuver is performed starting from a hover, and transiting laterally $400 \mathrm{ft}$ and ending in a hover in a specific amount of time. Additionally, longitudinal position must be maintained within a set tolerance. Table 7.5 shows an RMS cost of 1.19 for this mission task element which is acceptable and is due to the increased error seen in Figure 7.11, especially the the off-axis responses. However, the lateral velocity is nearly $50 \mathrm{ft} / \mathrm{s}$ (30 knots) and recall that the gains were optimized around the hover/low speed condition. Recall from chap.linear analysis that at higher speeds, the hover gains no longer provide acceptable model following performance. 
Table 7.5: DF piloted simulation RMS costs

\begin{tabular}{ll}
\hline \multicolumn{1}{c}{ MTE } & RMS cost \\
\hline Hover & 0.74 \\
Hovering turn & 0.58 \\
Lateral reposition & 1.19 \\
\hline
\end{tabular}



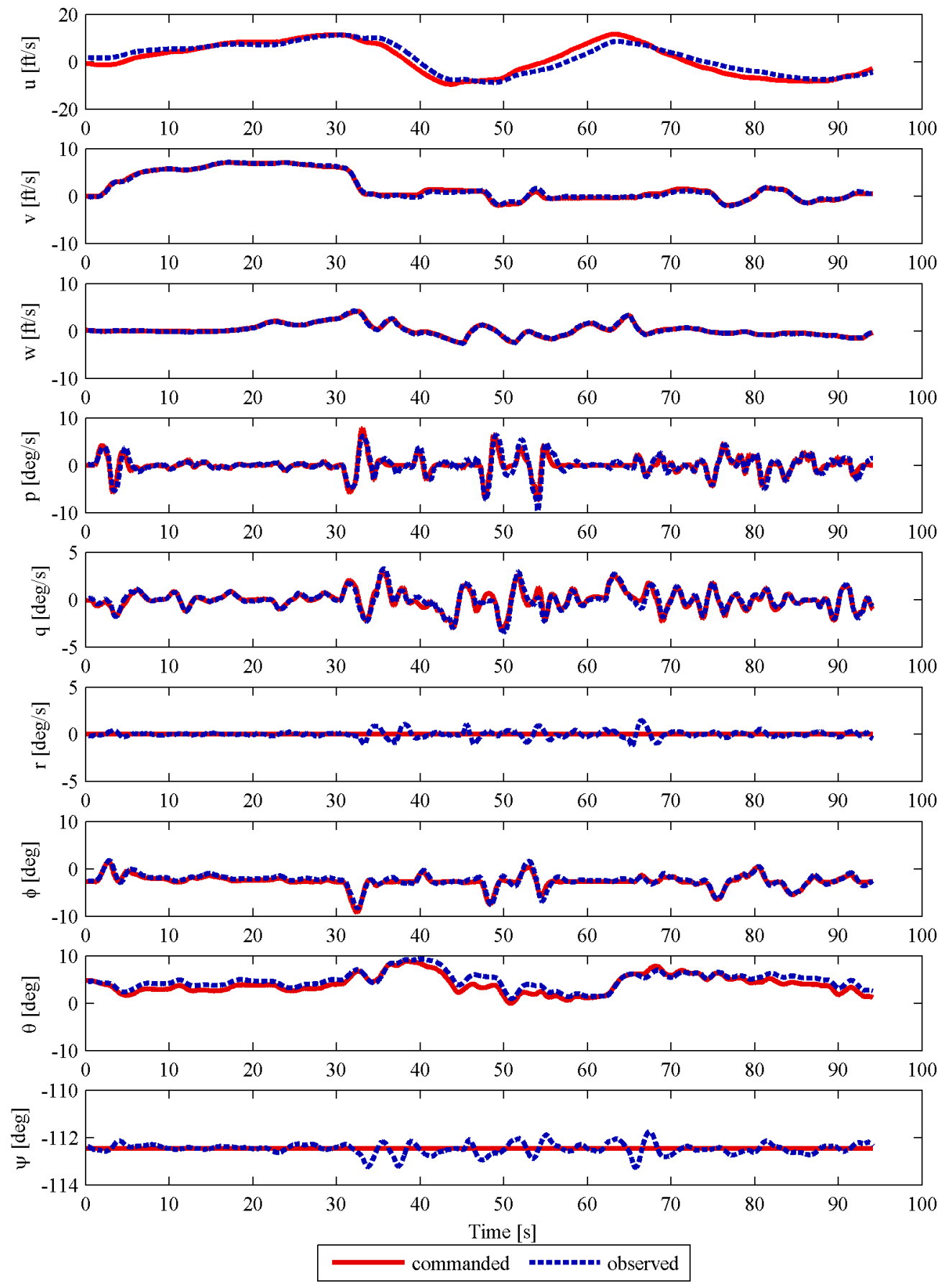

Figure 7.9: Hover MTE data 

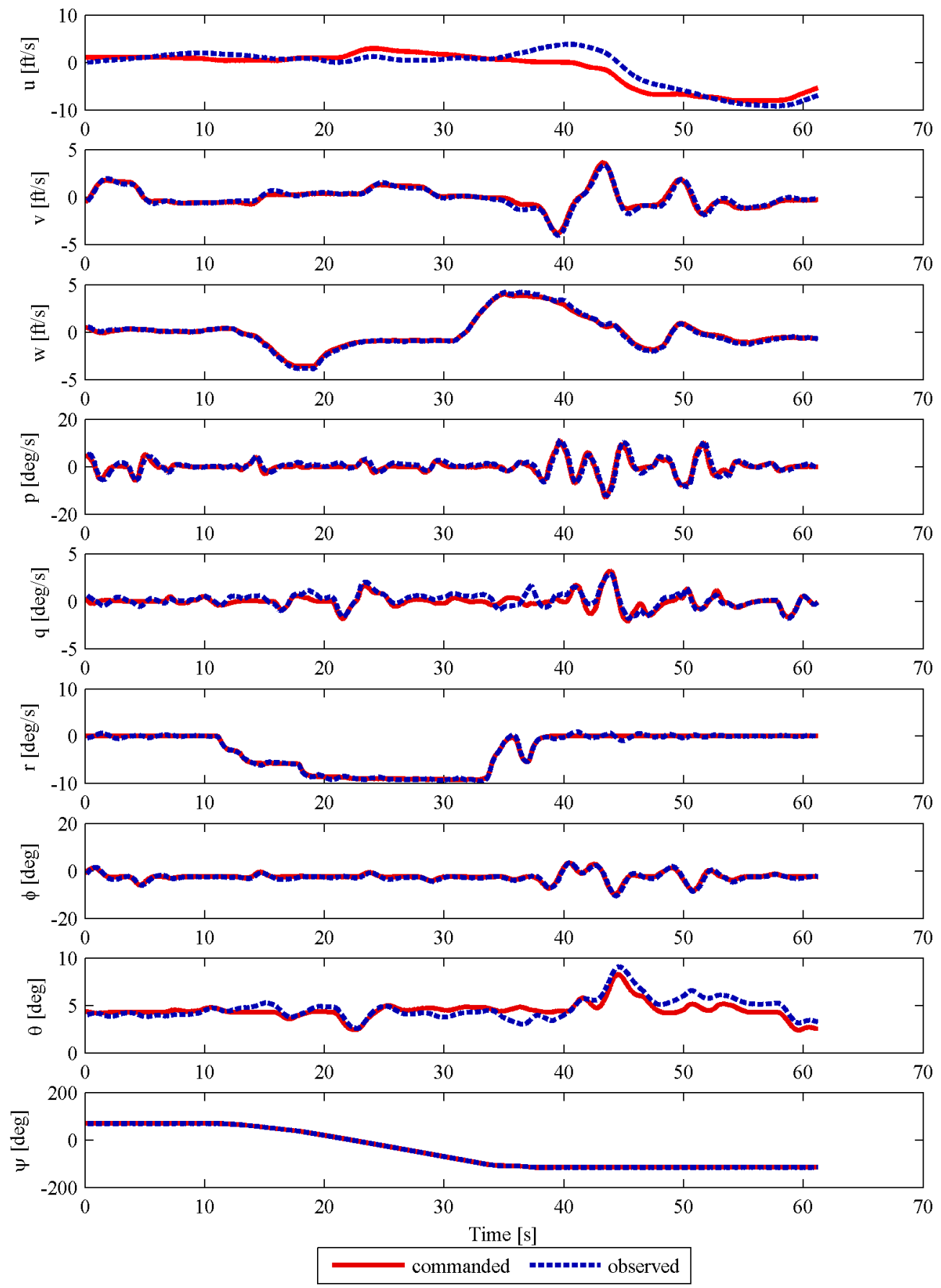

Figure 7.10: Hovering turn MTE data 

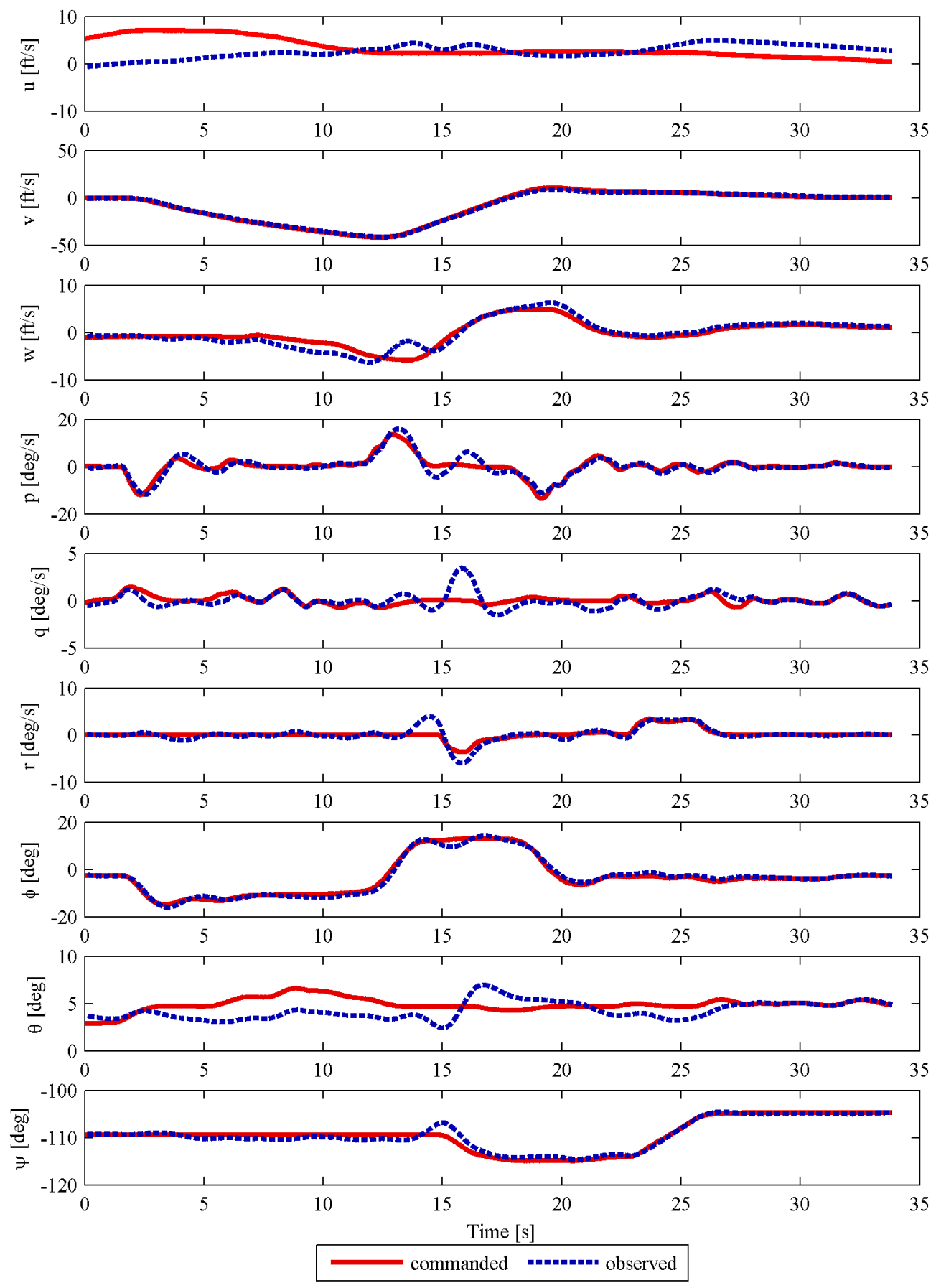

Figure 7.11: Lateral reposition MTE data 


\section{Chapter 8}

\section{Conclusions}

\subsection{Summary of Findings}

An in-flight simulation control system for RASCAL in the hover/low speed flight condition has been designed and analyzed in CONDUIT $^{\circledR}$ and validated using the non-linear helicopter model GenHel in desktop simulations and hardware-in-the-loop simulations. The classical explicit model following control system architecture was used which consisted of a simple, decoupled, transfer function command model; a diagonalized inverse plant model; a decoupling matrix; a high-order linearized model of a UH-60 helicopter with actuator, sensor, and filter models; and a frequency dependent feedback controller with cross-feed gains. The frequency dependent feedback controller provided the ability to follow commanded attitude rates in the short term and commanded velocities in the long term.

As demonstrated when using GenHel for the non-linear simulations, it is important to have an accurate inverse plant model to ensure good model following performance. Additionally, the inverse plant affects the stability margins and crossover frequencies. By using the frequency response specifications with the identified bare airframe responses, the overall performance of the non-linear simulations, both the desktop and hardware-in-the-loop simulations, track well with the CONDUIT ${ }^{\circledR}$ predicted performance as demonstrated by the frequency and time domain results.

Finally, the current control system does have limitations as presented in Chapter 5. The controller gains were tuned using a model linearized around the hover condition. These 
gains are acceptable up to airspeeds of about 25 knots. Additionally, RASCAL being a UH60, will have difficulty simulating aircraft with natural frequencies greater than $7.2 \mathrm{rad} / \mathrm{s}$ in the roll axis and greater than $3.2 \mathrm{rad} / \mathrm{s}$ in the pitch axis.

\subsection{Future Work}

Several possibilities for future work have been identified during this research, the most logical being flight test on RASCAL. The control system as implemented in the development facility is identical to what is loaded on the aircraft flight control computers for test flights. However, before flight tests could be performed, a test plan and safety of flight review would be necessary. Additionally, as demonstrated in the simulations performed during this research, it would be necessary to identify a new inverse plant model of RASCAL to ensure adequate model following performance.

Once flight testing is possible, it would useful to verify the predicted limitations in-flight. This would consist of performing frequency sweeps at different airspeeds without changing the gains and calculating the model following cost to determine the airspeed limit. To determine the command model natural frequencies, a similar test as that performed in the DF would be used: increase the natural frequency until a step input causes the safety monitors to trigger.

Also, it would be useful to test the control laws using a command model which represents the dynamics of a current production aircraft. Pilots familiar with the simulated aircraft would provide useful qualitative data on whether the simulation is accurate or not. Additionally, MTEs could be used to assign handling qualities ratings and compared with the ratings of the aircraft being simulated to see if the simulator is accurate.

Another logical extension of the current in-flight simulation control laws would be to expand the flight envelope from 25 knots to the full flight envelope of a UH-60. This would require scheduling the gains for airspeed and by replacing the hover model in CONDUIT $^{\circledR}$ 
with models at different airspeeds. The gains would then be tested in simulation and in flight in a manner similar to that used for this research. 


\section{References}

[1] Tischler, M. B., editor, Advances in Aircraft Flight Control, Taylor \& Francis Ltd., London, 1996.

[2] Fletcher, J. W., Mansur, M. H., Moralez, E., LTC Robinson, D. E., Arterburn, D. R., Cherepinsky, I., Driscol, J., Morse, C. S., and Kalinowski, K. F., "UH-60M Upgrade Fly-By-Wire Flight Control Risk Reduction Using the RASCAL JUH-60A In-Flight Simulator," American Helicopter Society 64th Annual Forum, Montréal, Canada, 29 April-1 May, 2009.

[3] Justiz, C. R. and Patel, S. M., "NASA Shuttle Training Aircraft Flight Simulation Overview," AIAA Paper No. 88-4608, 1988.

[4] Carignan, S. J. R. P., Gubbels, A. W., and Ellis, K., "Assessment of Handling Qualities for the Shipborne Recovery Task - ADS-33(maritime)," American Helicopter Society Annual Forum, Virginia Beach, VA, 2-4 May 2000.

[5] Weingarten, N. C., "History of In-Flight Simulation at General Dynamics," Journal of Aircraft, Vol. 42, No. 2, 2005, pp. 290-298.

[6] Shafer, M. F., "In-Flight Simulation Studies at the NASA Dryden Flight Research Facility," Technical Memorandum TM-4396, NASA, 1992.

[7] Erdos, R. T., Gubbels, A. W., and Ellis, D. K., "Variable Stability Airborne Simulation: Applications in Flight Testing," American Helicopter Society 58th Annual Forum, Montréal, Canada, 11-13 June, 2002. 
[8] Knotts, L. and Parrag, M., "In-Flight Simulation at the US Air Force and Naval Test Pilot School," Flight Simulation Technologies Conference Technical Papers, AIAA, 1983, pp. 23-31.

[9] Pausder, H. J., Bouwer, G., and von Grünhagen, W., "A Highly Maneuverable Helicopter In-Flight Simulator - Aspects of Realization," .

[10] Hilbert, K. B., Lebacqz, J. V., and Hindson, W. S., "Flight Investigation of a Multivariable Model-Following Control System for Rotorcraft," AIAA Paper No. 86-9779, 1986.

[11] Moralez III, E., Hindson, W. S., Frost, C. R., Tucker, G. E., Arterburn, D. R., Kalinowski, K. F., and Dones, F., "Flight Research Qualification of the Army/NASA RASCAL Variable Stability Helicopter," American Helicopter Society 58th Annual Forum, Montréal, Canada, 11-13 June, 2002.

[12] Krieger, J. P., Preliminary Control Law Design for a Helicopter In-Flight Simulator, Master's thesis, University of California, Davis, 2007.

[13] Tischler, M. B., Colbourne, J. D., Morel, M. M., Biezad, D. J., Levine, W. S., and Moldoveanu, V., "CONDUIT - A New Multidisiplinary Integration Environment for Flight Control Development," AIAA Guidance, Navigation and Control Conference, New Orleans, LA, Technical Papers, Vol. 3, AIAA, August 1997.

[14] Anon., Aeronautical Design Standard, Handling Quality Requirements for Military Rotorcraft, ADS-33E-PRF, U.S. Army Aviation and Missile Command (USAAMCOM), 2000.

[15] Anon., Flying Qualities of Piloted Aircraft, MIL-STD-1797B, U.S. Air Force, 2006.

[16] Anon., Flight Control Systems-Design, Installation and Test of Piloted Aircraft, General Specifications For, MIL-DTL-9490E, Department of Defense, 2008. 
[17] Tischler, M. B. and Remple, R. K., Aircraft and Rotorcraft System Identification, AIAA, Reston, VA, 2006.

[18] Mansur, M. H. and Dai, W., RIPTIDE Installation and User's Guide, University Affiliated Research Center.

[19] Howlett, J. J., "UH-60 Black Hawk Engineering Simulation Program: Volume 1 Mathematical Model," Technical Report CR-166309, NASA, 1981.

[20] Kim, F. D., Formulation and Validation of High-Order Mathematical Models of Helicopter Flight Dynamics, Ph.D. thesis, University of Maryland, 1991.

[21] Leissling, D., Getswa, M., and Bauschat, J., "In-Flight Simulation in Support of an Aircraft Certification Process," AIAA Modeling and Simulation Technologies Conference and Exhibit, Austin, Texas 11-14 August 2003, Paper No. AIAA 2003-5532.

[22] Kaletka, J., Kurschied, H., and Butter, U., "FHS, the New Research Helicopter: Ready for Service," Journal of Aerospace Science and Technology, Vol. 9, No. 5, 2005, pp. 456467.

[23] Cooper, G. E. and Harper, R. P., "The Use of Pilot Rating in the Evaluation of Aircraft Handling Qualites," Technical Note D-5153, NASA, 1969.

[24] Duda, H., "Prediction of Pilot-in-the-Loop Oscillations Due to Rate Saturation," Journal of Guidance, Control, and Dynamics, Vol. 20, No. 3, 1997, pp. 581-587.

[25] Blanken, C. L., Hoh, R. H., Mitchell, D. G., and Key, D. L., Test Guide for ADS-33EPRF, U.S. Army Research, Development, and Engineering Command, July, 2008.

[26] Lusardi, J. A., Tischler, M. B., and Blanken, C. L., "Empirically Derived Helicopter Response Model and Control System Requirements for Flight in Turbulence," Journal of the American Helicopter Society, Vol. 49, No. 3, 2004, pp. 340-349.

[27] Hodgkinson, J., Aircraft Handling Qualites, AIAA, Reston, VA, 1999. 
[28] Mitchell, D. G., Hoh, R. H., He, C., and Strope, K., "Determination of Maximum Unnoticed Added Dynamics," AIAA Paper No. 2006-6492, 2006.

[29] Heffely, R. K., Jewell, W. F., Lehman, J. M., and Van Winkle, R. A., “A Compilation and Analysis of Helicopter Handling Qualities Data, Volume One: Data Compilation," NASA CR 3144, 1979.

[30] Heffely, R. K., Bourne, S. M., Curtiss, H. C., Hindson, W. S., and Hess, R. A., "Study of Helicopter Roll Control Effectiveness," NASA CR 177404, 1986.

[31] Franklin, G. F. and Powell, J. D., Digital Control of Dynamic Systems, Addison-Wesley Publishing Company, 1981. 


\section{Appendix A}

\section{ADS-33 Mission Task Elements}

The following are pages from ADS-33E-PRF, the military rotorcraft handling qualities standard. For hover and lateral reposition, the task description and a suggested course layout are shown. For the hovering turn, only the task description is included. 
ADS-33E-PRF

\subsubsection{Hover}

a. Objectives.

- Check ability to transition from translating flight to a stabilized hover with precision and a reasonable amount of aggressiveness.

- Check ability to maintain precise position, heading, and altitude in the presence of a moderate wind from the most critical direction in the GVE; and with calm winds allowed in the DVE.

b. Description of maneuver. Initiate the maneuver at a ground speed of between 6 and 10 knots, at an altitude less than $20 \mathrm{ft}$. For rotorcraft carrying external loads, the altitude will have to be adjusted to provide a $10 \mathrm{ft}$ load clearance. The target hover point shall be oriented approximately 45 degrees relative to the heading of the rotorcraft. The target hover point is a repeatable, ground-referenced point from which rotorcraft deviations are measured. The ground track should be such that the rotorcraft will arrive over the target hover point (see illustration in Figure 24). In the GVE, the maneuver shall be accomplished in calm winds and in moderate winds from the most critical direction. If a critical direction has not been defined, the hover shall be accomplished with the wind blowing directly from the rear of the rotorcraft.

c. Description of test course. The suggested test course for this maneuver is shown in Figure 24. Note that the hover altitude depends on the height of the hover sight and the distance between the sight, the hover target, and the rotorcraft. These dimensions may be adjusted to achieve a desired hover altitude.

d. Performance standards. Accomplish the transition to hover in one smooth maneuver. It is not acceptable to accomplish most of the deceleration well before the hover point and then to creep up to the final position.

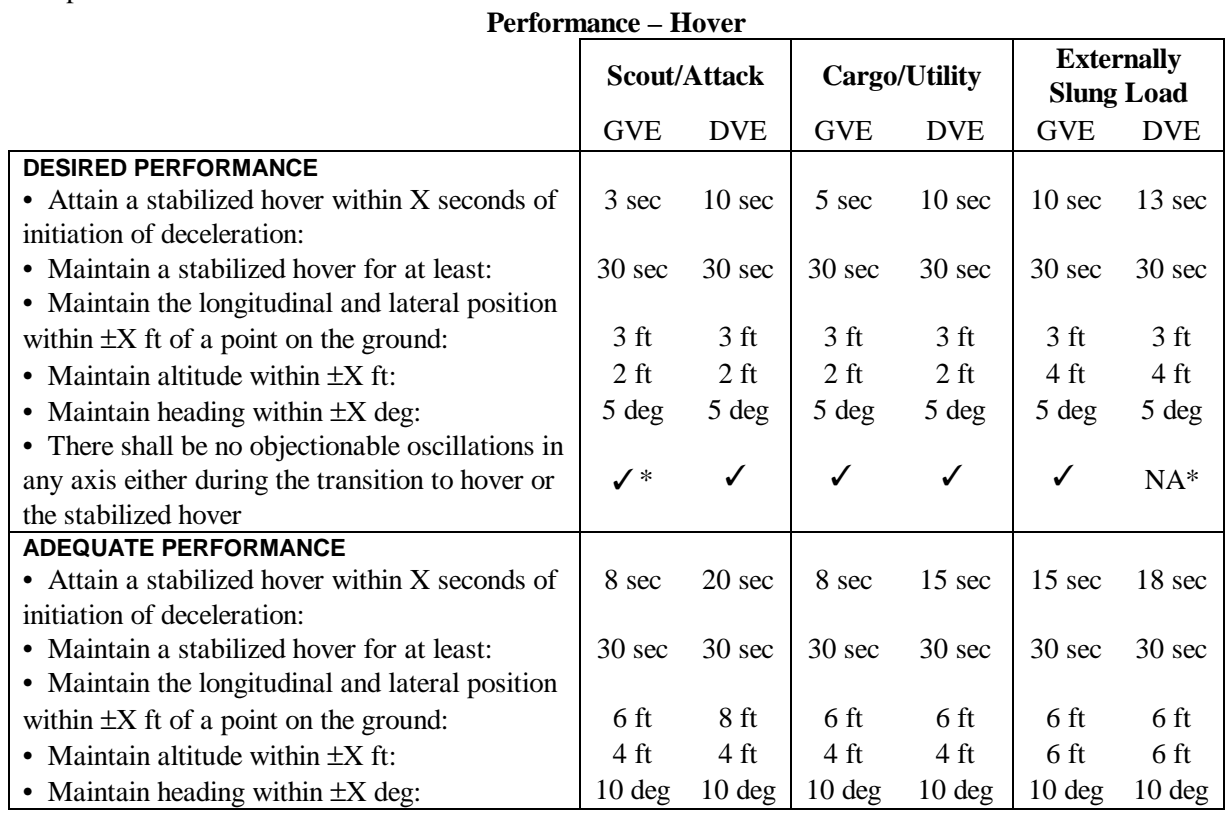

*Note: For all tables, $\boldsymbol{V}=$ performance standard applies; NA = performance standard not applicable 


\subsubsection{Hovering Turn}

\section{a. Objectives.}

- Check for undesirable handling qualities in a moderately aggressive hovering turn.

- Check ability to recover from a moderate rate hovering turn with reasonable precision.

- Check for undesirable interaxis coupling.

- In the DVE, check for undesirable display symbology and dynamics for hover.

b. Description of maneuver. From a stabilized hover at an altitude of less than $20 \mathrm{ft}$, complete a 180 degree turn. Perform the maneuver in both directions. In the GVE, the maneuver shall be accomplished in calm winds and in moderate winds from the most critical direction. If a critical direction has not been defined, the turn shall be terminated with the wind blowing directly from the rear of the rotorcraft.

c. Description of test course. It is suggested that this maneuver use the test course described for the pirouette (Figure 25) with the rotorcraft located at the center of the pirouette circle. An alternate suggestion is to use the hover course with two extra markers placed in the 6 o'clock position relative to the rotorcraft. The maneuver begins with the rotorcraft lined up on these extra markers and the hover target and board located at the rotorcraft's 6 o'clock position.

\section{d. Performance standards.}

\section{Performance - Hovering Turn}

\begin{tabular}{|c|c|c|c|c|}
\hline & \multicolumn{2}{|c|}{ Scout/Attack } & \multicolumn{2}{|c|}{ Cargo/Utility } \\
\hline & GVE & DVE & GVE & DVE \\
\hline \multicolumn{5}{|l|}{ DESIRED PERFORMANCE } \\
\hline $\begin{array}{l}\text { - Maintain the longitudinal and lateral position } \\
\text { within } \pm X \mathrm{ft} \text { of a point on the ground }\end{array}$ & $3 \mathrm{ft}$ & $6 \mathrm{ft}$ & $3 \mathrm{ft}$ & $6 \mathrm{ft}$ \\
\hline - Maintain altitude within $\pm X \mathrm{ft}:$ & $3 \mathrm{ft}$ & $3 \mathrm{ft}$ & $3 \mathrm{ft}$ & $3 \mathrm{ft}$ \\
\hline $\begin{array}{l}\text { Stabilize the final rotorcraft heading at } 180 \\
\text { deg from the initial heading within } \pm X \text { deg: }\end{array}$ & $3 \mathrm{deg}$ & $5 \mathrm{deg}$ & $5 \mathrm{deg}$ & $5 \mathrm{deg}$ \\
\hline $\begin{array}{l}\text { - Complete turn to a stabilized hover (within the } \\
\text { desired window) within X seconds from } \\
\text { initiation of the maneuver }\end{array}$ & $10 \mathrm{sec}$ & $15 \mathrm{sec}$ & $15 \mathrm{sec}$ & $15 \mathrm{sec}$ \\
\hline \multicolumn{5}{|l|}{ ADEQUATE PERFORMANCE } \\
\hline $\begin{array}{l}\text { - Maintain the longitudinal and lateral position } \\
\text { within } \pm X \mathrm{ft} \text { of a point on the ground }\end{array}$ & $6 \mathrm{ft}$ & $12 \mathrm{ft}$ & $6 \mathrm{ft}$ & $12 \mathrm{ft}$ \\
\hline - Maintain altitude within $\pm \mathrm{X} \mathrm{ft:}$ & $6 \mathrm{ft}$ & $6 \mathrm{ft}$ & $6 \mathrm{ft}$ & $6 \mathrm{ft}$ \\
\hline $\begin{array}{l}\text { - Stabilize the final rotorcraft heading at } 180 \\
\text { deg from the initial heading within } \pm X \text { deg: }\end{array}$ & $6 \mathrm{deg}$ & $10 \mathrm{deg}$ & $10 \mathrm{deg}$ & $10 \mathrm{deg}$ \\
\hline $\begin{array}{l}\text { - Complete turn to a stabilized hover (within the } \\
\text { desired window) within X seconds from } \\
\text { initiation of the maneuver }\end{array}$ & $15 \mathrm{sec}$ & $15 \mathrm{sec}$ & $20 \mathrm{sec}$ & $20 \mathrm{sec}$ \\
\hline
\end{tabular}


ADS-33E-PRF

\subsubsection{Lateral Reposition}

\section{a. Objectives.}

- Check roll axis and heave axis handling qualities during moderately aggressive maneuvering.

- Check for undesirable coupling between the roll controller and the other axes.

- With an external load, check for dynamic problem resulting from the external load configuration.

b. Description of maneuver. Start in a stabilized hover at $35 \mathrm{ft}$ wheel height (or no greater than $35 \mathrm{ft}$ external load height) with the longitudinal axis of the rotorcraft oriented 90 degrees to a reference line marked on the ground. Initiate a lateral acceleration to approximately 35 knots groundspeed followed by a deceleration to laterally reposition the rotorcraft in a stabilized hover $400 \mathrm{ft}$ down the course within a specified time. The acceleration and deceleration phases shall be accomplished as single smooth maneuvers. The rotorcraft must be brought to within $\pm 10 \mathrm{ft}$ of the endpoint during the deceleration, terminating in a stable hover within this band. Overshooting is permitted during the deceleration, but will show up as a time penalty when the pilot moves back within $\pm 10 \mathrm{ft}$ of the endpoint. The maneuver is complete when a stabilized hover is achieved.

c. Description of test course. The test course shall consist of any reference lines or markers on the ground indicating the desired track and tolerances for the acceleration and deceleration, and markers to denote the starting and endpoint of the maneuver. The course should also include reference lines or markers parallel to the course reference line to allow the pilot and observers to perceive the desired and adequate longitudinal tracking performance, such as the example shown in Figure 26.

\section{d. Performance standards.}

Performance - Lateral Reposition

\begin{tabular}{|l|cc|cc|}
\cline { 2 - 5 } \multicolumn{1}{c|}{} & \multicolumn{2}{c|}{ Cargo/Utility } & \multicolumn{2}{c|}{$\begin{array}{c}\text { Externally Slung } \\
\text { Load }\end{array}$} \\
\cline { 2 - 6 } \multicolumn{1}{l|}{} & GVE & DVE & GVE & DVE \\
\hline - Maintain longitudinal track within $\pm X \mathrm{ft}:$ & $10 \mathrm{ft}$ & $10 \mathrm{ft}$ & $10 \mathrm{ft}$ & $10 \mathrm{ft}$ \\
- Maintain altitude within $\pm X \mathrm{ft}:$ & $10 \mathrm{ft}$ & $10 \mathrm{ft}$ & $10 \mathrm{ft}$ & $10 \mathrm{ft}$ \\
- Maintain heading within $\pm X$ deg: & $10 \mathrm{deg}$ & $10 \mathrm{deg}$ & $10 \mathrm{deg}$ & $10 \mathrm{deg}$ \\
- Time to complete maneuver: & $18 \mathrm{sec}$ & $20 \mathrm{sec}$ & $25 \mathrm{sec}$ & $25 \mathrm{sec}$ \\
\hline ADEQUATE PERFORMANCE & & & & \\
- Maintain longitudinal track within $\pm X \mathrm{ft}:$ & $20 \mathrm{ft}$ & $20 \mathrm{ft}$ & $20 \mathrm{ft}$ & $20 \mathrm{ft}$ \\
- Maintain altitude within $\pm X \mathrm{ft}:$ & $15 \mathrm{ft}$ & $15 \mathrm{ft}$ & $15 \mathrm{ft}$ & $15 \mathrm{ft}$ \\
- Maintain heading within $\pm X$ deg: & $15 \mathrm{deg}$ & $15 \mathrm{deg}$ & $15 \mathrm{deg}$ & $15 \mathrm{deg}$ \\
- Time to complete maneuver: & $22 \mathrm{sec}$ & $25 \mathrm{sec}$ & $30 \mathrm{sec}$ & $30 \mathrm{sec}$ \\
\hline
\end{tabular}




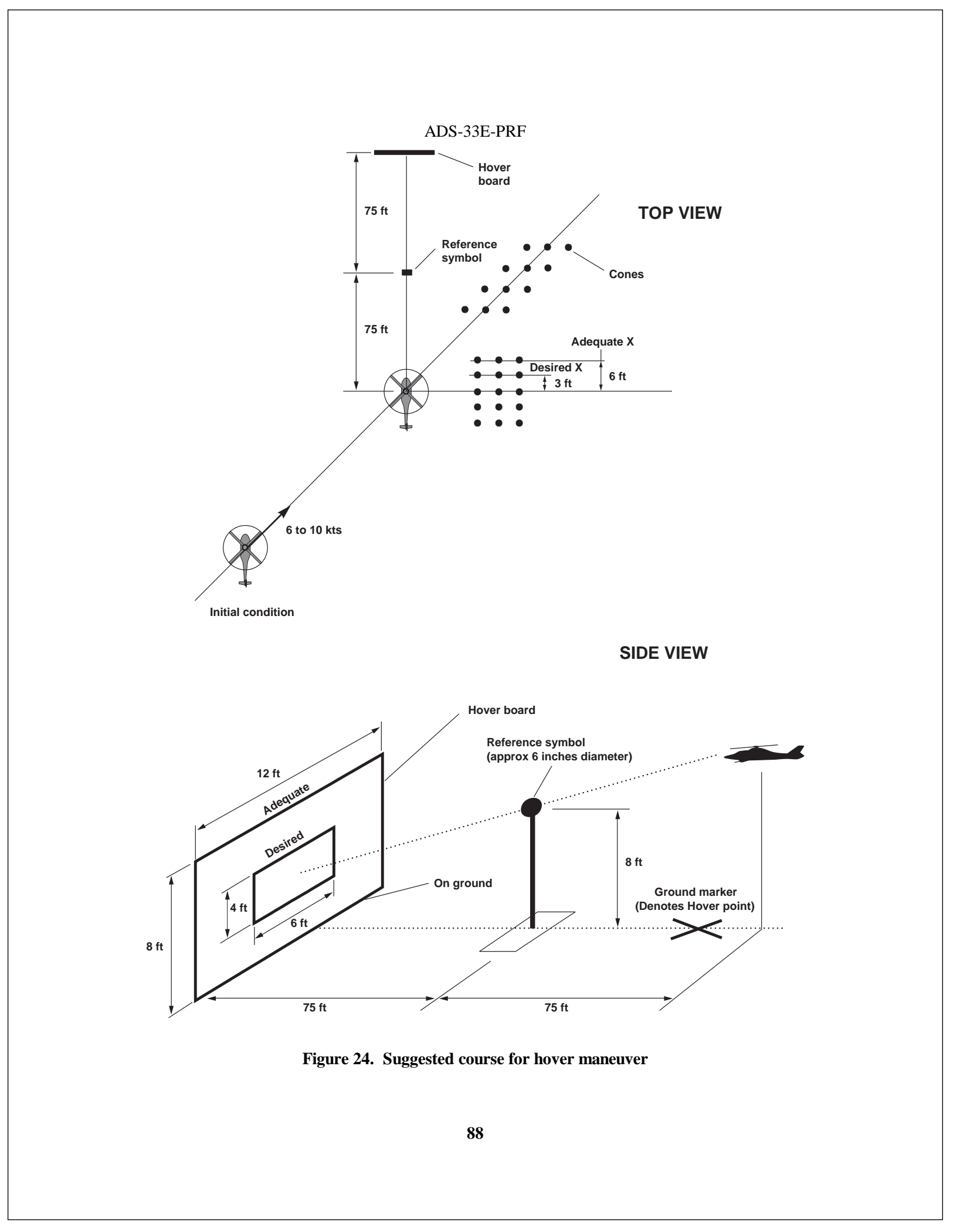


ADS-33E-PRF

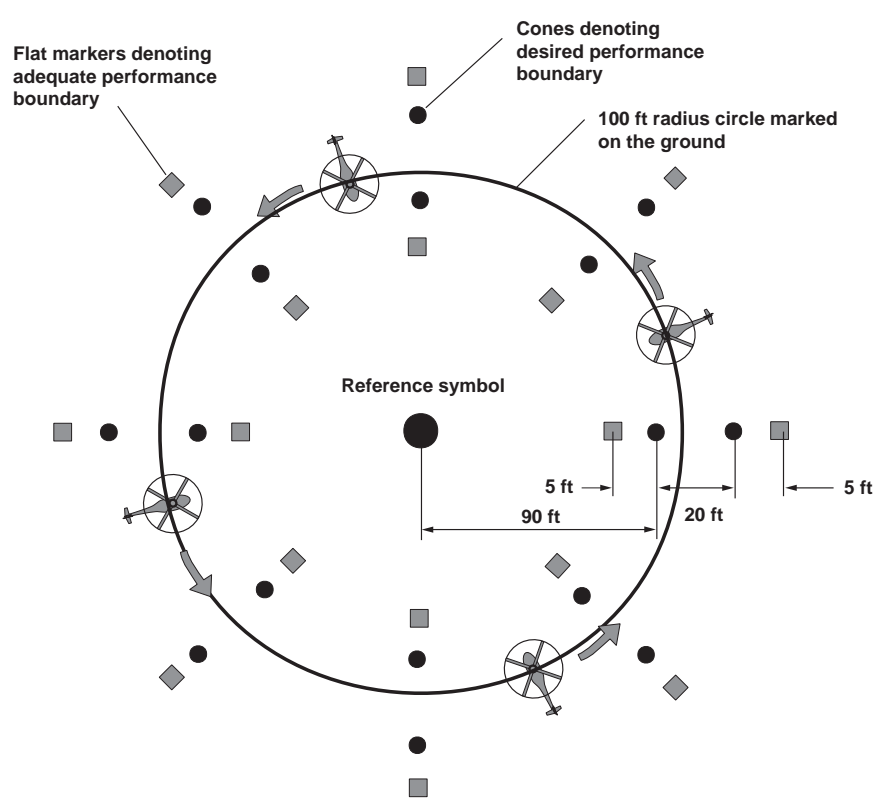

Figure 25. Suggested course for pirouette maneuver

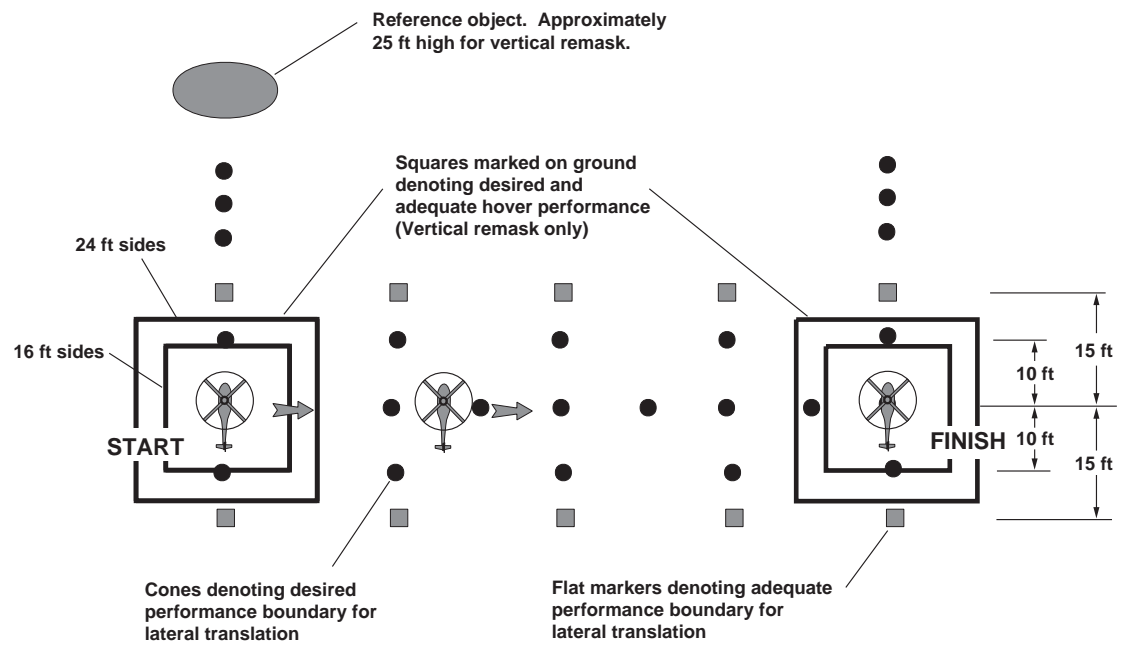

Figure 26. Suggested course for sidestep and vertical remask maneuvers 


\section{Appendix B}

\section{Optimized Controller Gains}

The following table provides the final optimized gains used in this research. The units used within the control system are rad/s, rad, and ft/s.

Table B.1: Optimized Controller Gains

\begin{tabular}{lll}
\hline Gain & \multicolumn{1}{c}{ Description } & Value \\
\hline$K_{p_{p}}$ & Roll derivative gain & 1.7076 \\
$K_{\phi_{p}}$ & Roll proportional gain gain & 7.0059 \\
$K_{\phi_{i}}$ & Roll integral gain & 2.6272 \\
$K_{q_{p}}$ & Pitch derivative gain & 7.5542 \\
$K_{\theta_{p}}$ & Pitch proportional gain gain & 7.9036 \\
$K_{\theta_{i}}$ & Pitch integral gain & 2.9639 \\
$K_{r_{p}}$ & Yaw derivative gain & 8.3396 \\
$K_{\psi_{p}}$ & Yaw proportional gain gain & 12.8399 \\
$K_{\psi_{i}}$ & Yaw integral gain & 6.4200 \\
$K_{u_{p}}$ & Long. velocity proportional gain gain & $1.2747 \times 10^{-2}$ \\
$K_{u_{i}}$ & Long. velocity integral gain & $7.9375 \times 10^{-4}$ \\
$K_{v_{p}}$ & Lat. velocity proportional gain gain & $2.5523 \times 10^{-2}$ \\
$K_{v_{i}}$ & Lat.velocity integral gain & $3.1904 \times 10^{-4}$ \\
$K_{w_{p}}$ & Heave proportional gain gain & $1.6777 \times 10^{-1}$ \\
$K_{w_{i}}$ & Heave integral gain & $2.0962 \times 10^{-3}$ \\
$K_{p 2 p e d}$ & Roll rate to lateral cross-feed & $6.7158 \times 10^{-1}$ \\
$K_{r 2 l a t}$ & Yaw rate to lateral cross-feed & 1.8356 \\
$K_{r 2 l o n}$ & Yaw rate to longitudinal cross-feed & 1.7773 \\
\hline
\end{tabular}

